\title{
DOES VISUAL EXPOSURE TO ONE'S PET REGULATE STRESS LEVELS DURING THE
} MENTAL ARITHMETIC TASK?

\author{
by \\ Natalie Ein, Bachelor of Arts, \\ Ryerson University, 2012 \\ A thesis \\ presented to Ryerson University \\ in partial fulfillment of the \\ requirements for the degree of \\ Master of Arts \\ in the Program of \\ Psychology
}

Toronto, Ontario, Canada 2015

(C) (Natalie Ein) 2015 


\section{AUTHOR'S DECLARATION FOR ELECTRONIC SUBMISSION OF A THESIS}

I hereby declare that I am the sole author of this thesis. This is a true copy of the thesis, including any required final revisions, as accepted by my examiners.

I authorize Ryerson University to lend this thesis to other institutions or individuals for the purpose of scholarly research

I further authorize Ryerson University to reproduce this thesis by photocopying or by other means, in total or in part, at the request of other institutions or individuals for the purpose of scholarly research.

I understand that my thesis may be made electronically available to the public. 


\begin{abstract}
Does Visual Exposure to One's Pet Regulate Stress Levels during the Mental Arithmetic Task?
\end{abstract}

\author{
Master of Arts, 2015 \\ Natalie Ein \\ Psychology \\ Ryerson University
}

This thesis examined the role of viewing a picture of one's pet as a mechanism for alleviating the symptoms of stress. The mental arithmetic task (MAT), a psychosocial stressor was used to induce stress. Participants were randomly assigned into one of six visual conditions: either a picture of their personal pet $(n=9)$, an unfamiliar animal $(n=9)$, a person who is supportive and important to the participant $(n=9)$, an unfamiliar person to the participant $(n=$ 8), a pleasant image (control 1) $(n=8)$ or no image (control 2) $(n=8)$. Stress reactivity, both physical (e.g., blood pressure) and subjective (self-reported anxiety), were measured. Findings indicated that contrary to the hypothesis, viewing a picture of one's personal pet did not reduce stress reactivity, measured either subjectively (self-report) or objectively (physiological assessment). However, the study suggests that various images can influence stress reactivity. 


\section{Acknowledgements}

I would like to thank my supervisor, Dr. Kristin Vickers for all her patience and guidance through this process. She has been available at any hour and has been understanding about the constant questions. She has provided a wonderful learning experience. Also, thank you to Dr. Marilyn Hadad for her insightful feedback with this project. Even though she has retired, she has been willing to help with this thesis. Thank you to Dr. Maureen Reed for being part of my thesis committee. Her time and comments have been greatly appreciated. Thank you to the participants who came to the lab and provided their responses to this project. I want to thank my family and friends for their encouragement and support. Finally, thank you to my animals for their calming presence. 


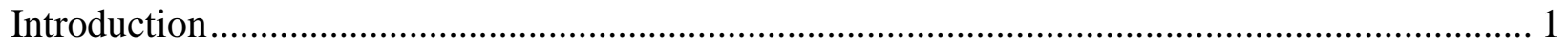

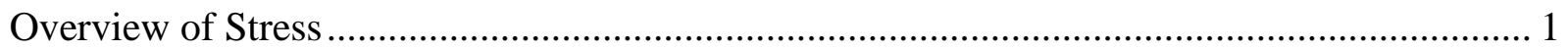

Mental Arithmetic Task Research .................................................................................... 3

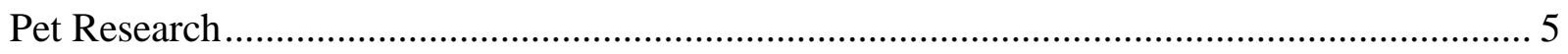

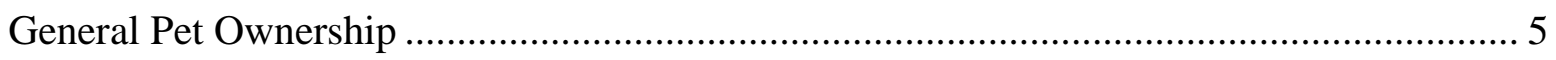

Pets' Effect on the Physiological Responses to Stress............................................................. 6

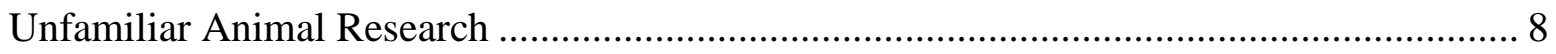

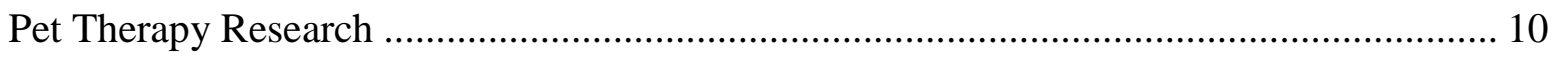

Pets as a Non-Judgmental Social Support .................................................................... 11

Cognitive and Visual Representations of Pets ................................................................... 12

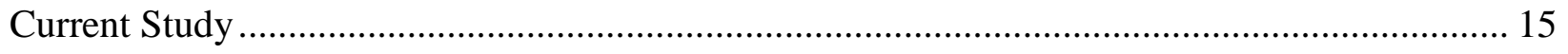

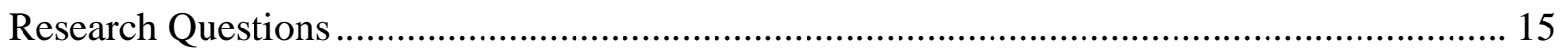

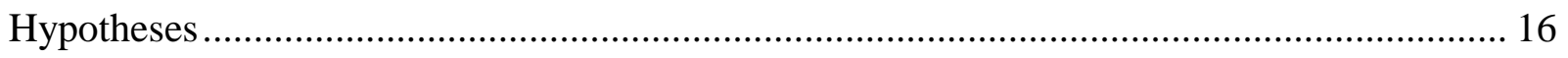

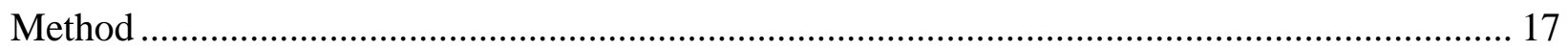

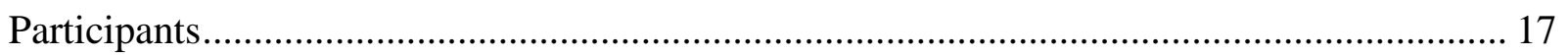

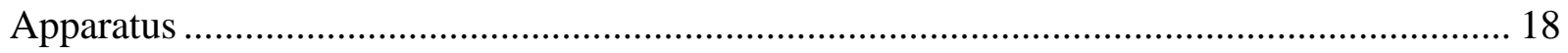

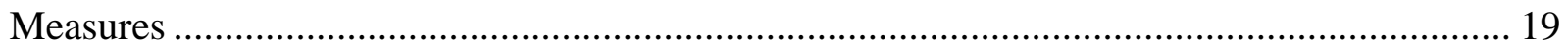

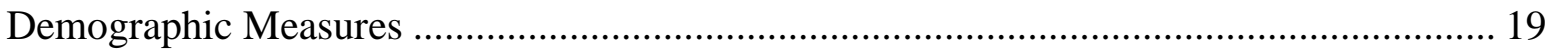

Pet and Social Support Measures......................................................................................... 19

Social Phobia and Stress Measures ...................................................................................... 22

Pre- and Post-Challenge Symptom Measures .................................................................... 23

Visual Representation Measure .................................................................................... 24

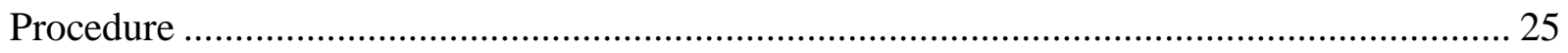

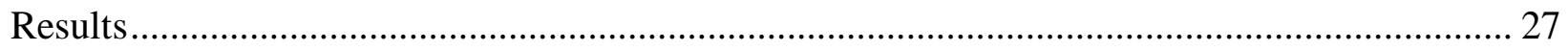




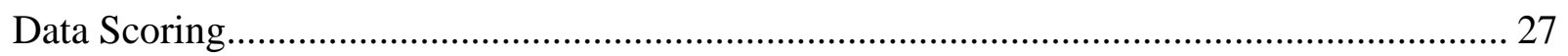

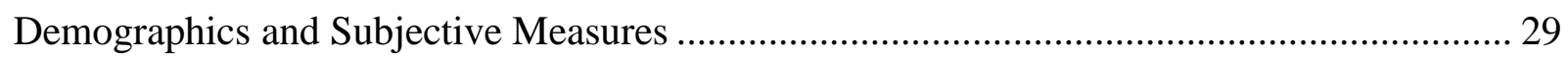

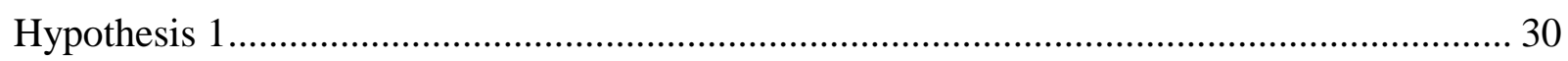

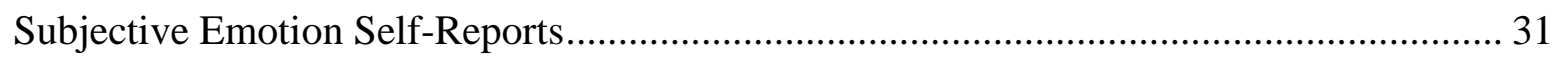

Subjective Physiology Self-Reports …………………………....................................... 31

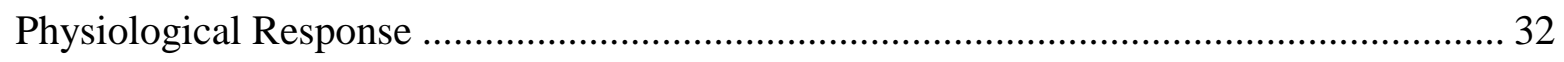

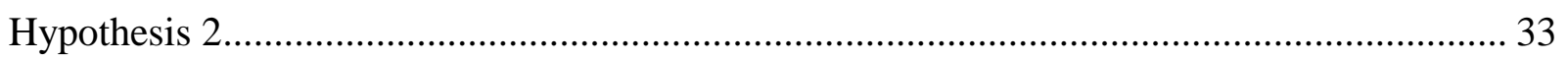

Subjective Emotion Self-Report .................................................................................... 33

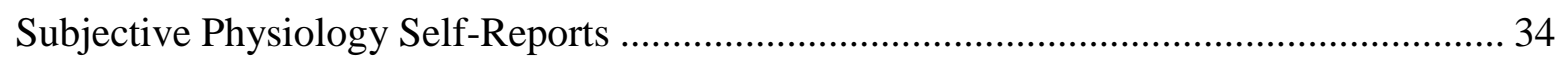

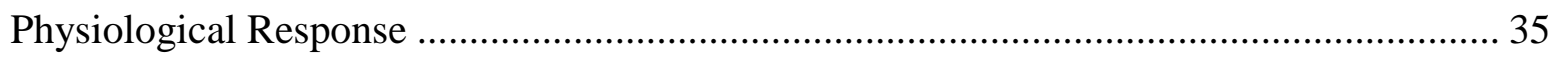

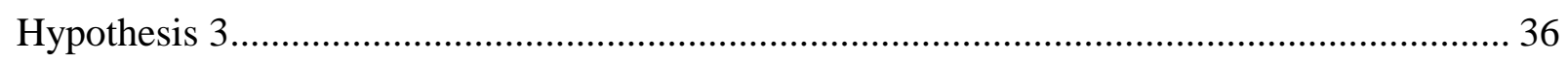

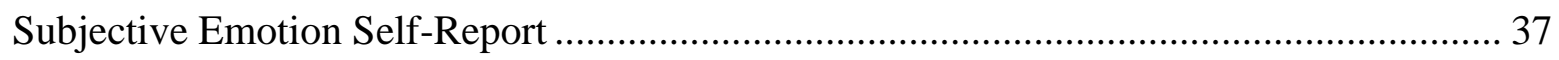

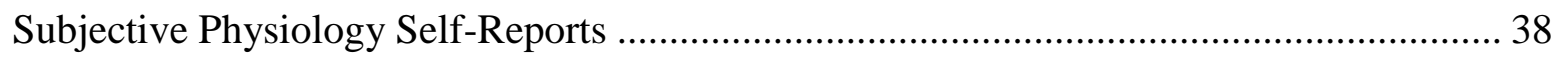

Physiological Response ………………………………............................................. 39

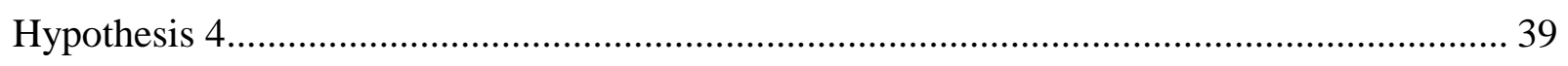

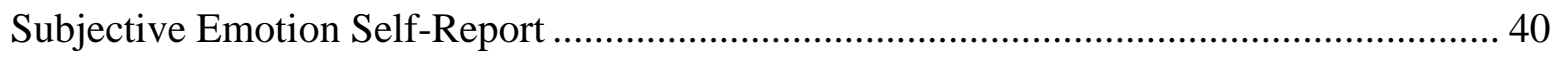

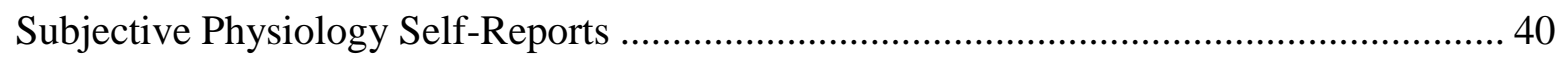

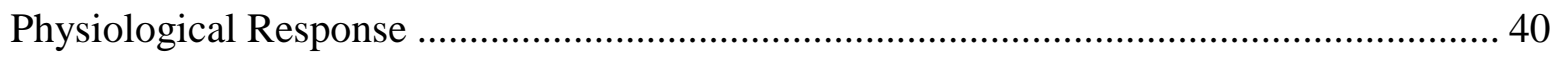

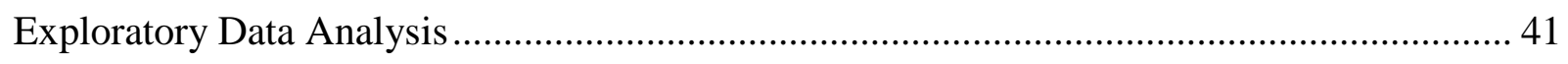

Comparison of Groups in How the Image Made Participants Feel at the End of the Study. 41

Comparison between Cat and Dog Owners.................................................................... 42

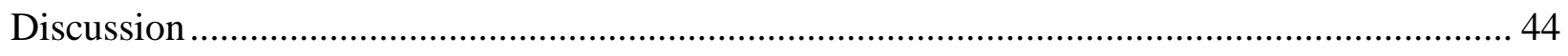

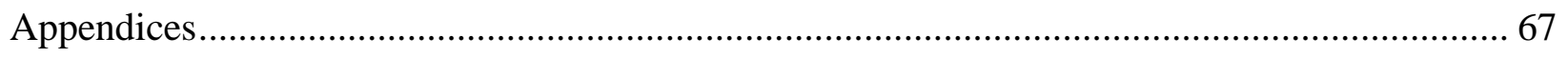

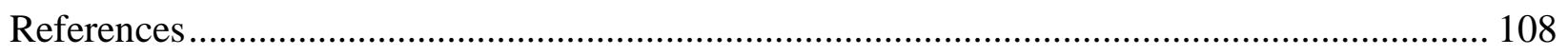




\section{List of Tables}

Table 1 Psychological and Emotional Measures and Subjective Physiological Symptoms

Table 2 Sample Demographic, Characteristics and Psychological Measures Separated by Condition

Table 3 Comparison between Experimental Conditions and Control Conditions on Subjective and Objective Measure 56

Table 4 Conditions on Subjective Emotion Self-Reports and Physiological Measures 57

Table 5 Planned Comparison in Subjective Measures between Personal Pet Condition and other

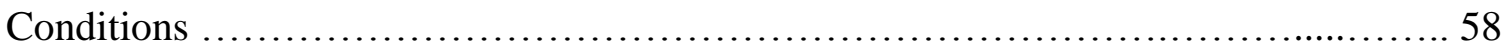

Table 6 Conditions on Physiological Measures ............................................. 59

Table 7 Planned Comparison in Physiological Measures between Personal Pet Condition and other Condition

Table 8 Planned Comparison in Subjective Measures between Supportive Important Person Condition and other Conditions

Table 9 Planned Comparison in Physiological Measures between Supportive Important Person Condition and other Conditions

Table 10 Planned Comparison in Subjective Measures between Unfamiliar Person Condition and Control Conditions

Table 11 Planned Comparison in Physiological Measures between Unfamiliar Person Condition and Control Conditions 


\section{List of Figures}

Figure 1 Mean Differences between the Pre- and Post-Stressor on Anxiety Scores across

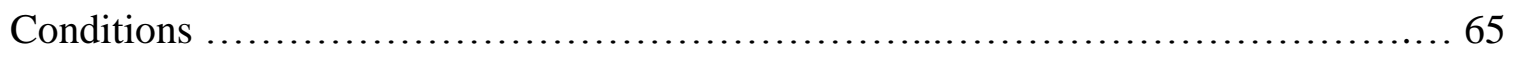

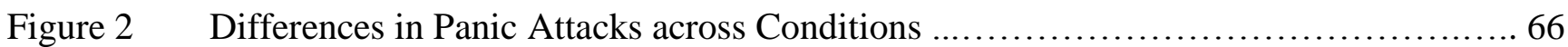




\section{List of Appendices}

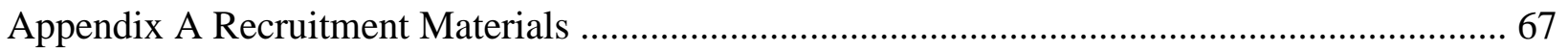

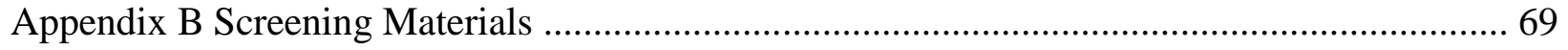

Appendix C Informed Consent Forms …............................................................... 71

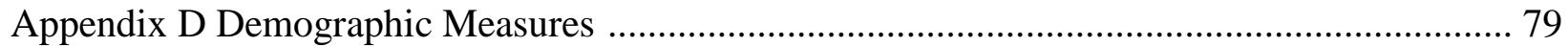

Appendix E Pet and Social Support Measure …............................................................. 80

Appendix F Social Phobia and Stress Measures ........................................................... 88

Appendix G Pre- and Post-Challenge Symptom Measures ............................................... 90

Appendix H Visual Representation Measure ............................................................. 96

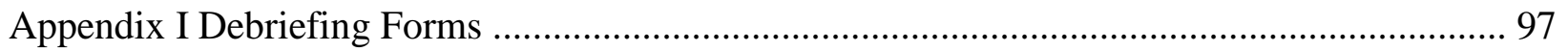

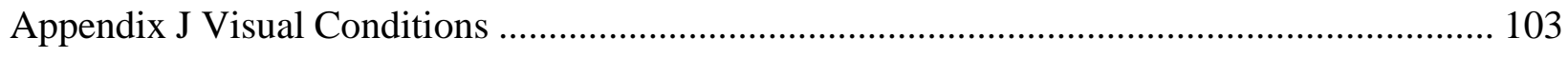


Does Visual Exposure to One's Pet Regulate Stress Levels during the Mental Arithmetic Task?

Many Canadians experience stress on a daily basis (Statistics Canada, 2013). Some researchers consider stress to be a negative experience as it can cause biochemical, physiological and behavioural changes (Baum, 1990), whereas other researchers have found stress to be a positive experience that can facilitate personal growth (Tedeschi \& Kilmer, 2005). In stress research, the following terms are commonly used: "stress," defined as the cognitive, emotional, physiological and behavioural reactions an individual experiences when exposed to a stimulus that is perceived as challenging (Harrington, 2013), "stressor," defined as the stimulus or demand that causes stress for the individual, and "stress reactivity," defined as the emotional and physical response to the specific stressor (Blonna, 2007). These terms will be used throughout this thesis.

\section{Overview of Stress}

A common challenge that individuals face is the inability to manage stress in an effective manner. Indeed, job stress has cost the United States' industries more than $\$ 300$ billion a year in productivity loss and insurance costs on physical and mental health issues (Rosch, 2001). In 2013, 6.6 million Canadians reported that they experienced moderate to high stress on most days (Statistics Canada, 2013). Stress can have a detrimental effect on the physiological, psychological and behavioural aspects of the human body. More specifically, stress can strain the cardiovascular system, which can increase the risk of strokes and myocardial infarctions (McEwen, 2007). In addition, it is well-established that high levels of glucocorticoids (a stress hormone) can suppress immune function. Without a functional immune system, the body becomes susceptible to various illnesses (for a review, see Glaser \& Glaser, 2005). 
Stress can also affect cognitive abilities such as memory function and emotion regulation, increasing the risk of psychological illnesses including depression, anxiety and cognitive impairment (Marin et al., 2011). Lastly, stress can generate behavioural variation such as disruptive sleeping patterns. The sympathetic nervous system (SNS) is responsible for the body's fight or flight response and is activated when an individual experiences a perceived threat. Activation of the SNS elevates cortisol levels and increases blood pressure, which are the two main causes of sleep restriction. Over-activity of the SNS due to stress will prevent the body from entering a relaxed state, ultimately leading to sleep deprivation and insomnia (McEwen, 2007). Lack of sleep that results from stress can have serious consequences, ranging from loss of productivity in the workplace to life threatening car accidents (Rosch, 1996).

It is important to note that stress reactivity varies across individuals, as people respond differently to the same stressor and indeed differ in what events or stimuli are considered to be stressful (Vollrath, 2001). Individual stress reactivity can depend on various factors such as demographics, personality traits and genetic factors, the combination of which in some creates a predisposition for stress-related outcomes such as depressive symptoms (Hagger, 2009; Nestler \& Carlezon, 2006; Vollrath, 2001). Indeed, these individual differences can influence how one emotionally responds to stress. In addition, environmental factors, such as pressure at work, daily hassles and negative social relationships, can create anxiety, anger and sorrow for the individual, thereby exacerbating stress (Peter \& Siegrist, 1999; Rook, Sorkin, \& Zettel, 2004). Further complicating matters, the different components of the stress response (e.g., physiological and emotional) can vary within an individual (Ein \& Vickers, 2015). Consequently, it is imperative to study stress with diverse measures to capture the various physiological and emotional aspects of stress within an individual. 
To summarize, stress comes from various sources and can have negative consequences on psychological and physical health. In addition, stress can affect all individuals, regardless of cultural background, gender and age. The consequences of stress can create strain on society including decreased productivity and increased medical costs. In addition, stress can diminish learning, judgment and adaptive functions which can lead to physical and mental health issues. Society's ability to manage its stress response is thus important to reduce these negative effects (Stixrud, 2012). While stress cannot be eliminated, research that investigates the underlying cognitive and physiological processes of stress and how it occurs may highlight ways to reduce stress intensity and frequency. Therefore, it is important to study stress as this research provides more insight into how and why stress occurs and has the potential to improve the well-being of society by further understanding ways of alleviating stress reactivity.

\section{Mental Arithmetic Task Research}

When studying stress, there are two main approaches: examining stress from a natural stressor (such as stress from exams, natural disasters and prisoner of war experiences) or from a lab based stressor (such as carbon dioxide inhalation, cold pressor test and mental arithmetic task). Some researchers have used naturalistic stressors to investigate the influence of stress on health and its negative consequences (Lewis, Weekes, \& Wang, 2007). Natural stressors provide real world generalizability (Lindsay, Paulhus, \& Nairne, 2008). However, natural stressors cannot be controlled as the participants' exposure to stress may vary. In contrast, lab based stressors provide a controlled dose of stress (Dimsdale, 1984). In addition, a lab based stressor can provide a "snapshot" of an individual's experience to stress (Wetherell et al., 2006, p. 737). Understanding the mechanisms of the stress system is critical for the development of treatment. 
Lab based stressors can provide the ability to reproduce the activation of stress in order to understand and evaluate functioning of the stress system (Kaye, Buchanan, Kendrick, Johnson, \& Lowry, 2004). The ability to create stress in controlled conditions is an essential advantage of a lab based stressor.

The mental arithmetic task (MAT) is one specific lab based stressor that has been of particular interest in stress research. It is well-established that this cognitive challenge significantly affects several aspects of the stress response, including sympathetic (heart rate), parasympathetic (blood pressure) and emotional (subjective stress) components (France \& Ditto, 1992; Kirschbaum, Pirke, \& Hellhammer, 1993). The MAT is a psychological and social stressor that requires participants to complete a subtraction task within a specific amount of time, namely 5 minutes. Participants are instructed to count backwards rapidly out loud from a four-digit number. This mental stressor has been extensively used in psychological studies to provoke a stress response (Allen, Blascovitch, \& Mendes, 2002; DeMello, 1999; Polheber \& Matchock, 2014). For example, Allen, Blascovich and Mendes (2002) examined the effects that various forms of social support have on stress reactivity to the MAT. The results showed that the presence of a pet while performing the MAT buffered the stress response compared to other types of social support (a friend or spouse). The results suggested that exposure to the MAT with a pet present lessened emotional, cognitive and physiological stress responses, which enhanced participants' ability to handle the stressor.

To summarize, the MAT has been established as a valuable tool to study acute stress reactivity, which has created the opportunity to investigate factors that could affect stress reactivity. However, the MAT has only recently become a popular method for studying the 
impact a pet has on stress reactivity, leaving many unanswered questions. One approach that has not been examined using the MAT is the effect of a visual representation of one's pet on stress reactivity.

\section{Pet Research}

General Pet Ownership. It has been reported that $56 \%$ of Canadian households have at least one dog or cat (Perrin, 2009), demonstrating the popularity of pet ownership in Canadian households. Findings from several studies indicate that the presence of one's pet during a stressor can significantly reduce stress reactivity. For example, research done by Friedmann and Thomas (1998) found that post myocardial infarction patients who owned pets had a significantly better 1-year survival rate after a heart attack. Another study found that pet owners living with AIDS reported fewer depressive symptoms than those who did not own a pet (Siegel, Angulo, Detels, Wesch, \& Mullen, 1999). Siegel (1990) also found that elderly individuals with pets had fewer physician contacts over a 1-year period. McConnell, Brown, Shoda, Stayton and Martin (2011) found that pet owners fared better on well-being (greater self-esteem), positive individual differences (greater conscientiousness, less fearful attachment) and were more effective at minimizing negative thoughts, compared to people with other (non-pet) sources of social support, such as best friends. This study also examined the mental health, personality and fulfillment of social needs of pet owners, compared to non-owners. In this correlational study, the researchers found that pets fulfilled social needs for their owners and that pet owners had enhanced well-being in several ways; pet owners engaged in more exercise and reported having increased self-esteem and less loneliness compared to non-owners. 
Research has also investigated differences between types of pets. Studies have shown that there is no difference in blood pressure and pulse rate between dog and cat owners (Allen et al., 2002). Somervill, Kruglikova, Robertson, Hanson and MacLin (2008) researched the difference between unfamiliar dogs compared to unfamiliar cats for pet therapy purposes. They found that there was a reduction in blood pressure associated with animal contact, regardless of the type of animal. Taken together, these results suggest that there is no difference between dogs and cats (as pet therapy animals). Additionally, no gender differences have been observed in how participants respond physiologically to either a dog or a cat (Somervill et al., 2008).

Pets' Effect on the Physiological Responses to Stress. Research has shown that humandog interactions such as talking to and petting a dog are accompanied by lower blood pressure (Vormbrock \& Grossberg, 1988). For example, Allen, Blascovich, Tomaka and Kelsey (1991) found that the presence of pets reduced physiological responses to a mental stressor, while the presence of a friend increased stress responses. The participants' heart rate, systolic blood pressure, and diastolic blood pressure were measured throughout the experiment. Once baseline physiology was established, the participants completed the MAT. Allen and colleagues (1991) found that the presence of participants' pets caused a decrease in physiological responses, while the presence of participants' friends resulted in greater physiological reactivity. In another study, Allen, Blascovich and Mendes (2002) compared stress reactivity when either a friend, a spouse or a pet was present for social support. The researchers found that with a pet present, participants showed significantly lower heart rate, systolic blood pressure and diastolic blood pressure levels during a resting baseline, significantly smaller increases from baseline levels during the stressor and faster recovery time post stressor. In addition, the pet condition performed the MAT more quickly and also had fewer errors on the MAT compared to all other conditions. In light of these 
findings, the researchers suggested that the social support of a pet allowed the participant to cope more effectively with the stressor presented as pets may provide a non-judgmental atmosphere. The human social support might not have been effective because of the potential for negative judgment from humans that is not present in pets.

Other findings also indicate the beneficial effect of pets on physical health. For example, Anderson, Reid and Jennings (1992) used a large sample (784 pet owners, 4957 non-pet owners) and found a reduction in systolic blood pressure levels in pet owners. More specifically, the pet owners' triglyceride levels (important in cardiovascular disease) were significantly lower than those of the non-pet owners, suggesting that pet ownership may reduce the risk for cardiovascular disease. In another study, Allen, Shykoff and Izzo (2001) examined the effects of pets on blood pressure response to mental stress. The participants were stockbrokers suffering from hypertension (high blood pressure) and were randomly assigned into two conditions: pet present or no pet condition. The pet present condition consisted of participants who adopted a pet and were given lisinopril, a medication for lowering blood pressure, while the control group (no pet condition) only received lisinopril. The researchers used the MAT to induce stress and recorded heart rate and blood pressure every minute. The researchers found that if a pet was present, participants showed lower levels of blood pressure under the induction of stress and also improved cognitive performance. More specifically, only resting blood pressure was reduced in the control group, whereas the pet present condition showed not only a decrease in blood pressure but also a decrease in heart rate during the stressful tasks. It is also significant to note that at the beginning of the study, all participants performed the stress inducing tasks; both conditions received $74 \%$ correct answers. Six months later, at the end of the study, the control 
group increased very slightly to $75 \%$ correct, while the pet present condition increased to $92 \%$ correct.

These findings, taken together, indicate that having one's pet present during stress can reduce both psychological and physiological post-stressor responses. In contrast, findings suggest that the presence of an important person in the participants' life, such as a best friend or spouse, actually increases participants' physiological arousal when they are presented with a mental stressor (Allen et al., 1991, 2002; McConnell et al., 2011). However, other research has shown that the presence of a supportive person can reduce stress. For example, Carter, Hollon, Carson and Shelton (1995) found that the presence of a safe person decreased arousal when participants experienced the carbon dioxide physiological stressor. Brown, Sheffield, Leary and Robinson (2003) examined the effects of social support when performing the cold pressor task, a physiological stressor in which participants put their hand in ice water to induce pain. The researchers found that participants who had a friend or stranger present during the pain task reported less pain than the participants in the alone condition. McClelland and McCubbin (2008) also examined the effects of social influence on response to the cold pressor task. However, they found that women reported more pain in the presence of a friend than when alone, while men reported less pain when a friend was present. These contradictory findings demonstrate that more research is needed. In particular, it is unclear which type of social support (a pet or an important person) can best help participants' stress reactivity.

Unfamiliar Animal Research. Not only has research investigated personal pets and the influence they have on reducing stress for owners, but the literature has also delved into the effect of unfamiliar animals on stress. Along these lines, DeMello (1999) examined whether the 
presence of an unfamiliar friendly animal affected blood pressure and heart rate after a cognitive stressor. The study used three different animals that included two small dogs and a kid goat that were presented independently. These animals were owned by the researcher and her colleagues and deemed friendly based on their sociable nature and small size. Results indicated that the presence of an unfamiliar friendly animal reduced physiological arousal, a finding that suggests that animals can buffer cardiovascular reactivity. Furthermore, Wilson (1991) investigated the effects of friendly but unfamiliar animals on the physiological and psychological responses to stress. She found that animals decreased both anxiety and the response of the SNS after a stressor, which was reading aloud. In light of these results, Wilson (1991) suggested that animals can promote a safe and comforting environment which can reduce stress and moderate the development of stress-related diseases such as heart disease. Another study examined the stress reactivity of participants who interacted with their own dog or an unfamiliar dog following a stress induction task (Barker, Knisely, McCain, Schubert \& Pandurangi, 2010). Bio-behavioural stress responses, including blood pressure, heart rate, salivary cortisol, and salivary alphaamylase, were measured. The researchers found that physiological arousal decreased from baseline following the stress task for both groups. However, the group interacting with their own dog had less perceived stress and anxiety when compared to those interacting with an unfamiliar dog. Lastly, Polheber and Matchock (2014) investigated various types of social support and its influence on stress reactivity among university students. Participants were randomly assigned into one of three conditions: human friend, novel dog or no social support. All participants completed the Trier Social Stress Test (TSST) which contains an arithmetic and speech task. During these tasks, participants' cortisol levels and heart rates were measured throughout the study. The study found that the novel dog condition had reduced cortisol levels throughout the 
procedure and heart rate during the TSST when compared to the other conditions. These studies, taken together, suggest that personal pets can buffer stress and even unfamiliar dogs can help reduce stress reactivity.

Pet Therapy Research. The findings discussed above have helped develop pet therapy programs for people with various psychological and medical disorders. Pet therapy is a form of therapy that includes a certified animal, trained for a therapy environment, as a central part of the individuals' treatment to help improve their social, emotional and cognitive functioning (Coren, 2010). Along these lines, researchers have found that the presence of a pet therapy dog increased socialization, specifically, both verbal and nonverbal (e.g., smiling) communication, in individuals with Alzheimer's disease. This finding suggests that pet therapy could be a beneficial intervention for people diagnosed with Alzheimer's disease, perhaps due to pets' ability to provide a basic need for communication (Batson, McCabe, Baun, \& Wilson, 1998). The literature also suggests that pet therapy can be used as a complementary and alternative medical technique, in combination with conventional treatment, for cancer patients. For example, researchers found that cancer patients viewed pet therapy as part of their therapy treatment and were more likely to tell another person about their visit (Johnson, Meadows, Haubner \& Sevedge, 2003). Pet therapy may also benefit physically healthy participants. For example, Adamle, Riley and Carlson (2009) examined healthy freshman college students and found that incorporating a pet therapy program effectively helped students lower stress levels. The students indicated that the pet therapy program helped provide a form of social support and also served a catalyst for creating new relationships. More recently, Stewart, Dispensa, Parker, Chang and Cunnien (2014) examined an animal-assisted therapy outreach program and its usefulness for 
reducing anxiety levels and loneliness for college students. The results showed that students reported less anxiety and loneliness after taking part in the animal-assisted therapy program.

Pets as a Non-Judgmental Social Support. The mechanism enabling pets to alleviate stress and buffer cardiovascular reactivity is likely the social support that pet ownership provides (for a review, see Virués-Ortega \& Buela-Casal, 2006). Indeed, substantial evidence indicates that human social support helps decrease stress responses and enables the ability to cope with stress more effectively, although contradictory findings have emerged (e.g., Allen et al., 1991) as previously mentioned. Heinrichs, Baumgartner, Kirschbaum, and Ehlert (2003) examined the effect of best friends as a social support and oxytocin, a bonding hormone, on cortisol levels. The participants were randomly assigned to receive intranasal oxytocin (24 IU) or placebo, and either social support from their best friend or no social support. They found that the participants who received both (social support and oxytocin) showed the lowest anxiety scores and cortisol concentration during the stressful period. Likewise, a study by Odendaal and Meintjes (2003) found that the hormones $\beta$-endorphin (associated with memory and learning), oxytocin and prolactin (associated with bonding), phenyl acetic acid (associated with attraction), and dopamine (associated with pleasurable sensation) all increased while cortisol (associated with stress) decreased after a 30-minute period of talking softly to and gently stroking a dog. Since interacting with a dog increases oxytocin and prolactin and decreases cortisol, these results suggest that dogs have the ability to act as an effective social support system for humans.

The ability of pets to create a non-judgmental atmosphere may be essential to their effectiveness as sources of social support (Allen, et al., 1991). In fact, Lepore (1998) found that when friends are perceived as completely non-judgmental, they too can indeed buffer stress 
responses. Kors, Linden and Gerin (1997) investigated whether a non-evaluative social support was better at reducing stress reactivity than evaluative social support. The results showed that the low-evaluative friend group had lower blood pressure during the stressor than the highevaluative friend group. These findings suggest that a non-judgmental atmosphere may be the mechanism for reducing stress. It has been suggested that pets excel in creating a non-judgmental atmosphere due to their not being able to engage in conversation and also having much simpler basic needs. The results, as summarized above, indicating reduced physiological reactivity to a stressful task in the pet condition, are consistent with the interpretation of pets buffering stress and ultimately being deemed as a non-judgmental social support. As mentioned in a previous section, there are contradictory findings regarding the best type of social support for reducing stress reactivity. However, these findings that a personal pet creates a unique non-judgmental atmosphere suggest that pets could be the most effective social support at reducing stress reactivity.

Cognitive and Visual Representations of Pets. Feasibility concerns of course limit the extent to which participants' personal pets are allowed in public laboratories. Thus, it is noteworthy that participants' cognitive representations of their pets (writing about their pet) is as effective as the physical presence of their pet, as shown by research by Zilcha-Mano, Mikulincer and Shaver (2012). This study had three conditions, a cognitive representation condition which consisted of asking participants to write about their pet before the experiment, a physical presence of their pet condition, and a control condition. All participants performed a difficult cognitive task while having their blood pressure measured before and during the experiment. The researchers found that both pet conditions enabled the participants to feel secure and perform better than the control group. Likewise, the cognitive representation condition and 
physical presence of a pet condition had reduced blood pressure during the distressing cognitive task, while the control group's blood pressure increased. Similar findings occurred in a study by McConnell et al. (2011). To create a cognitive representation of the pet, these researchers had the participant write a passage about their closest pet following a social rejection task. The researchers found that the participants who wrote about their pets were more effective at preventing negative thoughts compared to the control condition. It seemed that the cognitive representation of a pet was better able to minimize the negativity brought about by social rejection, relative to the control condition.

As mentioned, the use of real animals in an experimental setting is not always practical. Visual (pictorial) representation of animals may be a potential alternative for reducing stress. Indeed, research done by DeSchriver and Riddick (1990) found decreases in physiological stress responses in the elderly when watching a videotape of fish swimming in an aquarium. Likewise, researcher Wells (2005) investigated the effect of videotapes of animals on the cardiovascular responses to stress. Participants were randomly assigned to one of five videotape conditions: fish swimming in an aquarium, birds sitting on a perch, zoo monkeys sitting in a tree, a soap opera or a blank TV screen. After the participants watched one of the videos for 10 minutes, they were asked to read aloud. The task of reading aloud acted as a cognitive stressor. Participants' heart rate and blood pressure were measured throughout the experiment. Results showed that heart rate and blood pressure were significantly lower when participants watched the videotapes of animals compared to the control conditions. These findings may suggest that videotapes of animals can reduce the cardiovascular responses to psychological stress. In addition, research has shown that pictures of animals can influence mood and perception; more specifically, people in a photo accompanied by animals are rated as more friendly, less threatening, happier and comfortable 
(Lockwood, 1983). These findings taken together suggest that a visual representation of a pet may alleviate stress reactivity. 


\section{Current Study}

This thesis is similar to studies done by Allen and colleagues $(1991,2002)$ who examined the effects of pets on physiological responses to the mental arithmetic task (MAT). Though, the use of visual representations of one's pet could be used. Wells (2005) found that videotapes of animals reduced stress reactivity to a cognitive stressor. Thus, this study will add to these findings by using a photo of one's pet to further understand whether the cognitive presence of a pet buffers stress. A mental arithmetic task (MAT) was used as a stress induction to investigate the impact pets have on stress reactivity. All participants underwent this stress induction after being randomly assigned into one of six visual stimulation conditions: a picture of their personal pet, an unfamiliar animal (i.e., picture of an unknown dog or cat), a supportive important person (i.e., a picture of the participant's family member, significant other or friend), an unfamiliar person (i.e., picture of a stranger), a pleasant image (lake) or no image.

\section{Research Questions:}

1. Will the cognitive presence of a social support in the experimental conditions (i.e., personal pet, unfamiliar animal, supportive important person and unfamiliar person) be more effective at reducing stress reactivity compared to the control groups (pleasant image and no image)?

2. Will participants who are exposed to their own pet show the most reduction in stress reactivity relative to all other conditions?

3. Will human support reduce stress reactivity more than unfamiliar animal support? 
4. Will the unfamiliar person condition reduce stress reactivity more than the pleasant image condition?

5. Exploratory analysis will also be conducted to investigate potential differences across conditions in how the photo made participants feel at the end of the study (on the Visual Representation Perceptive) and potential differences between cat and dog owners on the pet anthropomorphism measure.

\section{Hypotheses:}

1. The experimental conditions (personal pet, unfamiliar animal, supportive important person, and unfamiliar person) will have less physiological (e.g., blood pressure) and emotional (self-reported anxiety) stress reactivity to MAT, compared to the control conditions (pleasant image and no image).

2. If a person is exposed to a picture of their personal pet, they will have less physiological (e.g., blood pressure) and emotional (self-reported anxiety) stress reactivity to MAT, compared to all other conditions. I predict a ranking order, from the least stress reactivity to the most stress reactivity, of (1) personal pet, (2) supportive important person, (3) unfamiliar animal, (4) unfamiliar person, (5) pleasant image, and (6) no visual.

3. If a person is exposed to a picture of a supportive important person in their lives, they will have less physiological (e.g., blood pressure) and emotional (self-reported anxiety) stress reactivity to MAT, compared to the unfamiliar animal condition, unfamiliar person condition and control groups. 
4. If a person is exposed to a picture of an unfamiliar person, they will have less physiological (e.g., blood pressure) and emotional (self-reported anxiety) stress reactivity to MAT, compared to the control groups.

\section{Method}

\section{Participants}

A total of 75 individuals indicated an interest in the study. The inclusion criteria for the study was the following: (1) they had to have a pet (either at least one dog or at least one cat or both); and (2) be of an age between 18 to 64 years old. There were 16 individuals that either cancelled or did not show up for their appointment. Of the remaining 58 individuals, 8 were unable to provide data. The inability to provide data was due to the following reasons: equipment failure $(n=6)$, they brought their dog to the lab appointment $(n=1)$ or above 65 years old $(n=$ 1), leaving 51 participants. Participants were recruited from two sources (see Appendix for all recruitment materials). The first source of recruitment was undergraduate students from an introductory psychology course at Ryerson University through the research participant pool called SONA. Each undergraduate student received partial course credit for their participation. The second source of recruitment was the Greater Toronto Area community. These participants were recruited through various revenues: (1) flyers placed in pet related facilities (e.g., veterinary offices and grooming places), (2) flyers placed in universities buildings; and (3) online advertisements (e.g., kijiji.ca and craigslist.com). Each community individual was compensated $\$ 10$ cash for their participation. All participants were tested individually. 


\section{Apparatus}

Biopac CNAP® blood pressure system. The Biopac CNAP® system was used to measure the participants' blood pressure and heart rate throughout the study. This system is a noninvasive blood pressure system used to record continuous blood pressure and heart rate signals. Blood pressure was obtained through an inflatable cuff placed on the participants' non-dominant arm. In addition, heart rate was acquired through a double finger cuff placed on two of the participants' fingers. This system displayed the participants' blood pressure and heart rate on a monitor throughout the study. A laptop was connected to the Biopac system which recorded the participants' blood pressure and heart rate through an AcqKnowledge software.

ASUS K750JB Laptop. A laptop which had a 17.3" screen was used to present the image to the participant. The image was displayed through a Powerpoint slide show setting which enabled the photo to become full screen. This full screened image was presented during the stressor.

Visual Images. There were eight images used in this study. Each participant brought with them to the lab (via email or USB) a picture of their personal pet and a picture of their supportive important person, which were the images used in the personal pet condition and the supportive important person condition, respectively. The unfamiliar animal condition had images of an unfamiliar dog or cat. Dog owners viewed the photograph of an unfamiliar dog while cat owners viewed the unfamiliar cat image. The researcher selected these photos from the internet based on breed (common breed) and friendliness. The unfamiliar person condition had pictures of a person the participants did not know (a stranger). Female participants viewed a photograph of an unfamiliar female while male participants viewed an unfamiliar male image, as research has 
shown that strangers of the opposite sex create higher stress reactivity (Duchesne, Tessera, Dedovic, Engert \& Pruessner, 2012). The individuals in these photos were friends of the experimenter. The pleasant image condition was an image of a lake collected from the internet. Lastly, the no image condition was an image of a black screen (see Appendix $\mathbf{J}$ for images).

\section{Measures}

\section{Demographic Measures (see Appendix D)}

Demographic and Pet Ownership Questionnaire. The Demographic and Pet Ownership Questionnaire was used to gather general information about the participants' background such as age, gender and ethnicity. In addition, the questionnaire included questions about the choice of the photo of a supportive person (e.g., "Why did you pick this person?"). This information was used for additional analysis to assess the type of human social support participants viewed as supportive. Lastly, the questionnaire contained questions about the participants' pets (e.g., "What type of pet(s) do you have?"). This questionnaire was used to assess the characteristics of the pets, used for additional analyses. The Demographic and Pet Ownership Questionnaire is shown in Appendix D.

\section{Pet and Social Support Measures (see Appendices E)}

Pet Attitude Questionnaire (PAQ; Templer, Salter, Dickey, Baldwin, \& Veleber, 1981). This measure was used for exploratory analyses. The PAQ is an 18-item questionnaire used to measure the participants' thoughts and feelings towards their pets. The PAQ consists of positively directed questions (e.g., "I would like a pet in my home") and negatively focused questions (e.g., "Having pets is a waste of money"). The scale is formatted with a 7-point Likert 
scale, ranging from 1 (strongly disagree) to 7 (strongly agree). The PAQ had a Cronbach's alpha of .93 and two week test re-test reliability of .92 , and the questionnaire yielded three factors: love and interaction, pets in home and joy of pet ownership (Templer, Salter, Dickey, Baldwin, \& Veleber, 1981). This measure was beneficial for evaluating the participant's attitude towards their pet in order to gain insight regarding their attachment and commitment to their pet as a social support. In the current study, Cronbach's alpha for this measure was .78. The PAQ is shown in Appendix E.

Pet Anthropomorphism (PA; Epley, Waytz, \& Cacioppo, 2007, as adapted by McConnell et al., 2011). This measure was used in exploratory analyses. The PA was used to measure how pet owners' anthropomorphize their pets to attribute more humanlike emotions associated with social connection to their pets. The measure has 3 statements that use a 9-point Likert scale ranging from 1 (not at all true) to 9 (completely true) and assess supportive anthropomorphic traits (thoughtful, considerate, and sympathetic). Previous research found a statistically reliable $(r=-.18, p=.02)$ negative relationship between loneliness and the average rank of the supportive anthropomorphic traits (Epley et al., 2007). The Cronbach's alpha for the three anthropomorphism traits on social connection was .73 in previous research (Epley, Waytz, Akalis, \& Cacioppo, 2008). The scale was relevant to understand how participants' project certain traits onto their pets. In the current study, Cronbach's alpha for this measure was .88 . The PA is shown in Appendix E.

Interpersonal Support Evaluation List (ISEL; Cohen, \& Hoberman, 1983). This measure was used in exploratory analyses. The ISEL assesses the perceived availability of social support. The questionnaire contains 48 statements regarding the sense of available social support. The 
statements are counterbalanced by having half of the items positively stated about social support (e.g., "I know someone who would lend me their notes if I missed class") while the other half are negatively stated (e.g., "There isn't anyone at school or in town with whom I feel perfectly comfortable talking about my career goals"). The participants were asked to rate the statements as "probably true" or "probably false" regarding themselves. The internal reliability (Cronbach's alpha) for the ISEL was .77 in previous research. In the current study, Cronbach's alpha for this measure was .87. In addition, the ISEL measures four separate functions of social support with 12-item subscales for each function. All subscales measured the participant's perceived availability of social support. The "tangible" subscale, which measures accessibility of material aid, had a Cronbach's alpha of .71. In the current study, Cronbach's alpha for this subscale was .81. The "appraisal" subscale measures the availability of someone to talk to about one's problems. This subscale had a Cronbach's alpha of .77. In the current study, Cronbach's alpha for this subscale was .78. The "self-esteem" subscale evaluates how one would compare themselves to others and had a Cronbach's alpha of .60. In the current study, Cronbach's alpha for this subscale was .66. Lastly, the "belonging" subscale, measures the availability of people one can do things with and had a Cronbach's alpha of .75. In the current study, Cronbach's alpha for this subscale was .77. Psychometric data demonstrate that the ISEL is a reliable measure of social support and that its subscales are independent of one another (Cohen \& Hoberman, 1983). The ISEL has been used in studies regarding pet ownership to gather information about participants' views towards social support (Allen et al., 2001; Allen et al., 2002). The measure was necessary to assess how the participants view social support in order to demonstrate how effectively social support can buffer stress. The ISEL is shown in Appendix E. 
Animal-Human Continuity Scale (AHCS; Templer, Connelly, Bassman, \& Hart, 2006). This measure was used for exploratory analysis. The AHCS was used to measure how similar participants view humans and animals to be. The scale has 12 -items with a 7-point Likert format ranging from 1 (strongly disagree) to 7 (strongly agree). The questions assessed the participants' view regarding the capability that animals have for humanlike qualities (e.g. "animals can fall in love"). The AHCS demonstrated internal consistency with a Cronbach's alpha of .69 in previous research. The scale yielded three factors: rational capacity, superiority versus equality and evolutionary continuum. In addition, it demonstrated good content and construct validity. This scale was relevant as it asked about the extent to which a participant agrees with various statements assessing their views on pets. In the current study, Cronbach's alpha for this subscale was .56. The AHCS is shown in Appendix E.

\section{Social Phobia and Stress Measures (see Appendix F)}

Social Phobia Inventory (SPIN; Connor, et al., 2000). The SPIN is a 17-item questionnaire used to measure social anxiety (e.g., "I avoid having to give speeches"). The questionnaire asked the participants to rate each question with a 5-point Likert scale ranging from 0 (not at all) to 4 (extremely). The SPIN demonstrated good test-retest reliability, internal consistency with a Cronbach's alpha of .94, and convergent and divergent validity in previous research (Connor et al., 2000). This questionnaire assessed whether participants experienced symptoms of social anxiety since the MAT is a psychosocial stressor, which may have impacted how effective the visual aids are for an individual participant. In the current study, Cronbach's alpha for this measure was .93. The SPIN is shown in Appendix F. 
Perceived Stress Scale (PSS; Cohen, Kamarck, \& Mermelstein, 1983). The PSS is a 10item instrument used to measure the participants' stress levels in regards to their personal life events by assessing their background stress. This scale was used to evaluate participants' amount of stress prior to the study. The PSS showed adequate reliability and internal validity for experienced levels of stress. For two studies involving college students, the PSS demonstrated coefficient alpha reliability of .84 and .85 . In addition, it demonstrated a two day test-retest reliability of .85 (Cohen et al., 1983). The scale asked the participant's feelings and thoughts within the last month regarding stress such as "In the last month, how often have you felt nervous and stressed?" Responses are rated on a 5-point Likert scale, ranging from 0 (Never) to 4 (Very Often). The PSS was administrated at the beginning of the study in order to measure the potential stress levels that are associated with personal life events as opposed to the MAT. In the current study, Cronbach's alpha for this measure was .85. The PSS is shown in Appendix F.

\section{Pre- and Post-Challenge Symptom Measures (see Appendices G)}

Standard 100-mm Visual Analogue Scales (VAS; Kaye et al., 2004). The VAS is a symptom questionnaire containing three visual analogue scales (used in Kaye et al., 2004) which are used to rate the participants' feelings at the moment regarding anxiety, relaxation, and happiness. In addition, a VAS was used to measure the feeling of stress at the present moment for a total of four visual analogue scales. The VAS scales assess these feelings by asking participants to indicate how they are currently feeling on a scale from 0 (not at all) to 100 (worst ever or best ever). The VAS was administrated 10 minutes prior to the stressor and immediately after the stressor, and change in scores was examined. The VAS was used to gather the participants' reaction on how they feel during the MAT. The VAS is shown in Appendix G. 
Acute Panic Inventory (API; Liebowitz, Gorman, Fyer, Dillon, \& Klein, 1984). The API is a 17-item self-report scale that measures the symptoms associated with spontaneous panic attacks (e.g., “do you feel dizzy or light-headed?”) and enables categorization of responses as a panic attack or not a panic attack. Participants rate each question with a 4-point Likert scale ranging from 0 (not at all) to 3 (severe). The scale was completed before and after the MAT. The API has been commonly used as a measure for assessing panic symptoms (Dillion, Liebowitz, Fyer, \& Klein, 1987; Goetz, Klein, Papp, Martinez, \& Gorman, 2001). A total symptom score (TSS) was calculated, and following the research, a panic attack was deemed to have occurred if at least four items increased from the baseline measurement (thus corresponding to the DSM-IV panic attack criterion of increases in four or more symptoms; Goetz et al., 2001). The API is a valid instrument for evaluating whether a panic attack occurred. The API is shown in Appendix G. In the current study, Cronbach's alpha for this measure before the stressor was .72 and after the stressor was .85 .

Panic Symptom Inventory (PSI; Clark, \& Hemsley, (1982), as adapted by Shufflebotham et al., 2009). The PSI is a scale used to assess general panic related symptoms. It consists of 34 panic related statements with a 5-point Likert scale of 0 (not at all) to 4 (very severe). The PSI was administrated before and after the MAT to ensure a stress response and measure bodily stress reactivity. The PSI is shown in Appendix G. In the current study, Cronbach's alpha for this measure before the stressor was .77 and after the stressor was .87 .

\section{Visual Representation Measure (see Appendix H)}

Visual Representation Perceptive. This measure was used in exploratory analyses. The Visual Representation Perceptive was used to gather information regarding how the participant 
felt about the picture they viewed throughout the experiment (e.g., "how did the picture make you feel?"). This information was used for additional analysis. The participants completed this questionnaire after the stress induction. The Visual Representation Perceptive is shown in Appendix H.

\section{Procedure}

This study was available to all introductory psychology students at Ryerson University and individuals in the Greater Toronto Area community. Eligibility was determined by individuals who indicated that they had a pet (either a dog, a cat or both) on the pre-screen questionnaire. This pre-screen questionnaire was completed through SONA for undergraduate students or telephone screen for community individuals. Once they were deemed eligible, participants signed up for a study. To ensure similar arousal levels between the participants, the experiment was only available between $9 \mathrm{am}$ to $5 \mathrm{pm}$. After they signed up, participants were asked to provide two photos, one of their pet and another of a person they believe to be supportive and important to them. Undergraduate participants were asked to bring these photos on a USB to their lab visit while community participants were asked to send these photos (via email) before the experiment.

Upon their visit to the lab, participants first read and sign the informed consent where the general purpose and procedure of the study were outlined along with potential risks. Once they signed the consent form, participants were connected to the Biopac CNAP® blood pressure system to record their blood pressure and heart rate. Their blood pressure and heart rate were measured through a finger clip transducer and inflatable cuff for pulse and blood pressure. Once the Biopac CNAP was calibrated, participants then completed the Demographic and Pet 
Ownership Questionnaire (as outlined within Measures). Participants then completed a series of self-report measures about pet ownership, social support and social phobia: Pet Attitude Questionnaire (PAQ), Pet Anthropomorphism (PA), Interpersonal Support Evaluation List (ISEL), Animal-Human Continuity Scale (AHCS), and Social Phobia Inventory (SPIN) (as outlined within Measures). Next, the participant completed self-report measures regarding emotional reactivity of stress and panic related symptoms: Perceived Stress Scale (PSS), Visual Analogue Scales (VAS), Acute Panic Inventory (API), and Panic Symptom Inventory (PSI) (as outlined within Measures).

Prior to the study, participants were randomly assigned into of six conditions: either a picture of their personal pet $(n=9)$, an unfamiliar animal $(n=9)$, a supportive important person $(n=9)$, an unfamiliar person $(n=8)$, a pleasant image $(n=8)$ or no image $(n=8)$. Once the questionnaires were completed, a laptop containing the photograph was placed in front of the participant. After the photo was properly placed, the participants were briefed about the stress induction, the MAT. Participants were informed that they had reached the math portion of the study. They were instructed to complete a backwards subtraction task out loud in multiples of seven starting from 2538 while focusing their gaze onto the computer screen containing the photograph throughout the task. Following the stress induction, the participants once again completed the post challenge self-report measures: VAS, API, and PSI. In addition, they completed the Visual Representation Perceptive questionnaire (as outlined within Measures). Once the questionnaires were completed, they were debriefed and informed that the experiment was finished. Participants were also informed that their photos were removed from the computer. Participants then received their compensation: university participants received 1 course credit while community participants received $\$ 10$ for completing the study. 


\section{Results}

\section{Data Scoring}

Physiological data were obtained through the Biopac CNAP® blood pressure system. The data had time-period markers for three time points: baseline (questionnaire period), stressor (MAT), and post-stressor (questionnaire period). The data were collected using AcqKnowledge software. Through this software, the physiological data received a transformation function to connect time points when a loss of signal occurred. Then, the mean of each time points was extracted. Items on questionnaires were totaled (after reverse coding select items) for the PSS, SPIN, and PSI. Consistent with standard practice, the API was scored as a binary variable, such that if the participant scored $\geq 4$, it was concluded that a panic attack occurred, while a score less than 4 was coded as no panic occurring.

In preliminary analysis, the data were screened for missing values. A total of 27 responses from individual participants were missing out of 12,444 questions, meaning that only $0.21 \%$ of the entire data matrix was missing. The most missing data from a participant was $2 \%$ and thus no participants were removed. All missing items were replaced with mean substitution such that missing items were replaced with the mean of that item.

Physiological data and questionnaires were carefully examined to determine whether transformation was required and if the data had any outliers. Outliers were determined based on scores that were beyond three standard deviations from the mean. Data transformations were determined based on improving normality with the use of the most common transformations; square root, log and inverse (Osbourne, 2002). The physiological variables (pulse, systolic blood

pressure and diastolic blood pressure) for the three time points (pre, during and post-stressor) did 
not require any data transformation as all had a normal distribution; additionally no outliers occurred in this physiological data. With respect to the questionnaire data, the PSS required a square root transformation as it was positively skewed while the SPIN did not require any data transformation. Once transformed, no outliers were found in these questionnaires. Then the residual change scores were computed for the pre to post challenge self-report measures, specifically, the PSI and the four scales from the VAS; anxiety, stress, happiness, relaxation. In addition, the time points (pre and post-stressor) for physiological variables (pulse, systolic blood pressure and diastolic blood pressure) were computed into residual change scores. According to Steketee and Chambless (1992) a residual change score is useful to assess change on two measures of the same item as the residual change score rescales an individual's score to the typical score made by other individuals at the same point. To compute residual change scores, the raw scores are first converted into $\mathrm{Z}$ scores for Time 1 and Time 2 scores. Then the residual change score is calculated by subtracting the Time 1 score, multiplied by the correlation between scores at Time 1 and 2, from the Time 2 score. This method is preferable to ordinary pre-post change scores because the residual change score approach controls for the initial differences between participants as well as the correlation between time 1 and time 2 measurements. Once computed, the residual change scores were examined for normality. A transformation if needed was selected based on the transformation that best improved an individual variable's normality. The residual anxiety required a square root transformation as it was moderately positively skewed. The residual happiness was negatively skewed; thus, the data were reflected and submitted to a $\log$ transformation. The residual stress and residual relaxation did not require any data transformation. The PSI required an inverse square root transformation due to pronounced skew. The residual pulse and residual diastolic blood pressure had mild skewness (skewness test 
statistic values of 2.6 and 2.5 respectively). Given the sample size and lack of outliers, they were not transformed. However, residual systolic blood pressure was negatively skewed which was reflected and required a log transformation. No outliers occurred in these measures.

\section{Demographics and Subjective Measures}

A total of 51 participants were included in the data analysis. Participants ranged in age from 18 to 64 years $(M=26.98, S D=12.41)$. The participants were mostly females: $n=40$ (78.4\%) compared to males: $n=11(21.6 \%)$. Most participants identified their ethnicity as White/European (52.9\%), followed by Asian (32.3\%), Other (5.9\%), Aboriginal (2\%), Black/Afro-Caribbean/African (2\%), and Biracial/Multiracial (2\%).

Self-reports measures were used to assess emotional and psychological characteristics as well as subjective physiological symptoms. Table 1 shows the descriptive information for the subjective psychological, emotional and physiological measures. Participants' self-reported stress levels over the last 4 weeks were assessed with the PSS. The PSS mean score for all participants was $17.35(S D=6.23)$. Social phobia symptoms were assessed with the SPIN. The SPIN mean score for all participants was $36.70(S D=13.21)$. Subjective emotional states were assessed with scales on the VAS for anxiety, stress, relaxation and happiness. The mean score for the VAS measures before the stressor were; anxiety $20.25(S D=21.63)$; stress $25.80(S D=$ 28.21); relaxation $59.27(S D=28.48)$; and happiness $60.65(S D=25.18)$. The mean score for the VAS measures after the stressor were; anxiety $31.33(S D=26.14)$; stress $37.63(S D=28.89)$; relaxation $35.67(S D=28.82)$; and happiness $45.51(S D=27.33)$. The PSI mean score before the stressor was $3.96(S D=4.43)$ and after the stressor was $6.82(S D=7.01)$. 
Table 2 shows the demographics, characteristics and psychological measures of the six study conditions. No significant differences occurred across conditions for any of these variables. Specifically, a one-way ANOVA was not significant for age, $F(5,43)=.884, p=.500, \eta_{\mathrm{p}}^{2}=$ .093. Chi-squares were not significant for gender across the six conditions, $\chi^{2}(5, N=51)=$ 3.299, $p=.654, V=.254$. Chi-squares were not significant for ethnicity across the six conditions, $\chi^{2}(25, N=51)=20.069, p=.743, V=.281$. Chi-squares were not significant for liking of math across the six conditions, $\chi^{2}(5, N=51)=1.909, p=.862, V=.193$. Chi-squares were not significant for severity on the SPIN across the six conditions, $\chi^{2}(20, N=51)=23.494, p=.265$, $V=.339$. A one-way ANOVA was not significant for the PAQ, $F(5,45)=.516, p=.763, \eta_{\mathrm{p}}{ }^{2}=$ .054. As well, there was no significant differences for the PA, $F(5,45)=1.416, p=.237, \eta_{\mathrm{p}}{ }^{2}=$ .136. A one-way ANOVA found no significant differences for the AHCS, $F(5,45)=.207, p=$ $.958, \eta_{\mathrm{p}}{ }^{2}=.022$. A one-way ANOVA was not significant for the ISEL, $F(5,45)=1.102, p=$ $.373, \eta_{\mathrm{p}}{ }^{2}=.109$. A one-way ANOVA found no significant differences for the $\operatorname{SPIN}, F(5,45)=$ $1.516, p=.204, \eta_{\mathrm{p}}{ }^{2}=.144$. As well, there were no significant differences across the groups for the PSS, $F(5,45)=0.48, p=.79, \eta_{\mathrm{p}}^{2}=.051$. Given the lack of differences among study conditions in these measures, no covariates were include in analyses of the experimental hypotheses.

\section{Hypothesis 1: Comparison between Experimental Conditions to the Control Conditions on Emotional and Physiological Stress Reactivity}

This research question focused on the differences, if any, between the experimental conditions (a personal pet, an unfamiliar animal, a supportive important person, and an unfamiliar person) and control conditions (a pleasant image and no image) on self-reports (i.e., 
subjective emotionality and physiological symptoms) and physiological responses (i.e., heart rate and blood pressure). Table 3 shows the test-statistics, degrees of freedom, $p$-values and effect sizes for the comparison of the experimental conditions and control conditions on all outcome measures.

Subjective Emotion Self-Reports. To examine whether the experimental conditions responded differently from the control conditions for the self-report measures, a one-way between subjects analysis of variance (ANOVA) with a between subjects of condition (experimental, $n=35$; control, $n=16$ ) was used. For the self-report measures regarding emotional state (residual anxiety, residual stress, residual happiness and residual relaxation), the results indicated that there was a trend towards a significant effect of condition on residual anxiety scores, $F(1,49)=3.295, p=.076, \eta_{\mathrm{p}}{ }^{2}=.063$. Contrary to the hypothesis, the mean score for the residual anxiety scores for the experimental conditions $(M=1.56, S D=.28)$ was higher than the control conditions $(M=1.42, S D=.18)$ suggesting that the experimental conditions had higher levels of anxiety compared to the control conditions following the MAT. Also, there was a trend towards a significant effect of condition on residual stress scores, $F(1,49)=3.836, p=$ $.056, \eta_{\mathrm{p}}{ }^{2}=.073$. Contrary to the hypothesis, the mean score for the residual stress scores for the experimental conditions $(M=.15, S D=.84)$ was higher than the control conditions $(M=-.32$, $S D=.66)$ suggesting that the experimental conditions had higher levels of stress compared to the control conditions following the MAT (see Table 3 for all test-statistics).

Subjective Physiology Self-Reports. For the self-reports regarding physiological symptoms (PSI and API), the results indicated that there were no significant differences between the experimental and control conditions (see Table 3 for test-statistics, $p$-values, and effect sizes). 
Physiological Response. To examine whether the conditions affected the physiological measures differently, a mixed ANOVA with a within-subjects factor of time (baseline, stressor, post stressor), and a between subjects factor of conditions (experimental, $n=35$; control, $n=16$ ) was used. There was a significant main effect of time on pulse, $F(2,98)=13.721, p<.001, \eta_{\mathrm{p}}{ }^{2}=$ .219. This effect tells us that the participants' pulse changed throughout the MAT. However, there was no interaction between time and condition for pulse, $F(2,98)=.000, p=1.000, \eta_{\mathrm{p}}{ }^{2}=$ .000. Also, the between subjects factor of condition was not significant for pulse, $F(1,49)=$ $.091, p=.764, \eta_{\mathrm{p}}{ }^{2}=.002$. There was a significant main effect of time on systolic blood pressure, $F(2,98)=5.317, p=.006, \eta_{\mathrm{p}}^{2}=.098$. This effect tells us that the participants' systolic blood pressure changed throughout the MAT. However, there was no interaction between time and condition for systolic blood pressure, $F(2,98)=.139, p=.870, \eta_{\mathrm{p}}{ }^{2}=.003$. Also, the between subjects factor of condition was not significant for systolic blood pressure, $F(1,49)=.086, p=$ $.77, \eta_{\mathrm{p}}{ }^{2}=.002$. There was a significant main effect of time on diastolic blood pressure, $F(2,98)=$ $18.207, p<.001, \eta_{\mathrm{p}}{ }^{2}=.271$. This effect tells us that the participants' diastolic blood pressure changed throughout the MAT. However, there was no interaction between time and condition for diastolic blood pressure, $F(2,98)=.324, p=.724, \eta_{\mathrm{p}}^{2}=.007$. Also, the between subjects factor of condition was not significant for diastolic blood pressure, $F(1,49)=.036, p=.86, \eta_{\mathrm{p}}^{2}=.001$.

For the physiological measures (residual pulse, residual systolic blood pressure and residual diastolic blood pressure, a one-way between subject ANOVA with a between subjects of condition (experimental, $n=35$; control, $n=16$ ) was used. The results indicated that there was no significant effect of condition on the physiological measures (see Table 3). 


\section{Hypothesis 2: Comparison between the Personal Pet Condition and each of the other Conditions on Emotional and Physiological Stress Reactivity}

This research question focused on the differences, if any, between the personal pet condition and each of the other conditions (an unfamiliar animal, a supportive important person, an unfamiliar person, a pleasant image and no image) on self-reports (i.e., subjective emotionality and physiological symptoms) and physiological responses (i.e., heart rate and blood pressure).

Subjective Emotion Self-Report. To examine whether the personal pet condition responded differently from the other conditions for the self-report measures, a one-way between subjects ANOVA with a between subjects of condition (personal pet, $n=9$; unfamiliar animal, $n$ =9; supportive important person, $n=9$; unfamiliar person, $n=8$; pleasant image, $n=8$; no image, $n=8$ ) was used. As well, planned pairwise comparisons for one-way ANOVA were used to compare the personal pet condition to each other condition. The use of planned comparisons after non-significant ANOVAs is recommended by the American Psychological Association's Task Force on Statistical Inference (Wilkinson, 1999).

Table 4 shows the mean and standard deviation at each time point for the subjective emotional and physiological measures in each of the six conditions. Table 5 shows the teststatistics for the planned comparisons comparing the personal pet condition to each of the other conditions for all self-report measures. For the residual anxiety, the omnibus ANOVA results indicated no significant difference across conditions, $F(5,45)=1.770, p=.138, \eta_{\mathrm{p}}^{2}=.164$. The planned comparisons revealed that most findings were not significant. Contrary to the hypothesis, there was a trend towards higher anxiety in the personal pet condition compared to 
the pleasant image condition, $t(45)=1.384, p=.09$, one-tailed, $r=.20, g=.67$. More specifically, the mean score for residual anxiety in the personal pet condition $(M=1.55, S D=$ .26) was higher than in the pleasant image condition $(M=1.38, S D=.14)$ suggesting that the personal pet condition had higher levels of anxiety compared to the pleasant image condition following the MAT. Figure 1 shows the mean differences between the pre- and post-stressor anxiety scores in all six conditions.

For the residual stress, the overall ANOVA results indicated no significant omnibus effect across the conditions, $F(5,45)=1.274, p=.292, \eta_{\mathrm{p}}^{2}=.124$. In terms of the planned comparisons, there were no significant findings between each condition. In addition, the residual happiness for the overall ANOVA was not significant, $F(5,45)=.927, p=.472, \eta_{\mathrm{p}}{ }^{2}=.093$. The planned comparison also showed no significant findings. Lastly, the residual relaxation indicated no significant difference across groups, $F(5,45)=.606, p=.696, \eta_{\mathrm{p}}{ }^{2}=063$ as well no significant findings in the planned comparisons (see Table 5).

Subjective Physiology Self-Reports. For the self-report measures regarding physiological symptoms (PSI and API), the results indicated that there was no significant difference across groups in the overall ANOVA for PSI, $F(5,45)=.392, p=.852, \eta_{\mathrm{p}}{ }^{2}=.042$. The planned comparisons revealed no significant findings (see Table 5). For the API measure, a chi-square test was used, which revealed that the overall chi-square for all conditions was not significant, $\chi^{2}(5, N=51)=5.042, p=.411, V=.314$. Planned comparisons of the proportion having a panic attack in the personal pet condition versus each of the other conditions considered separately showed mostly no significance differences (see Table 5). Table 4 lists the proportion of participants in each condition who had a panic attack (according to the definition of an 
increase in four or more symptoms). Specifically, the proportion of participants that had a panic attack in the personal pet condition ( 4 of $9=44.44 \%$; see Table 4 ) versus the pleasant image condition did differ, $z=2.1, p=.005$. Contrary to the hypothesis, the personal pet condition had a larger proportion of participants that had a panic attack than the pleasant image condition. Figure 2 shows the proportion of participants in each condition who had a panic attack.

Physiological Response. To examine whether the personal pet condition affected the physiological measures on each condition, a mixed ANOVA with a within-subjects of time (baseline, stressor, post stressor), and a between subjects of conditions (personal pet, $n=9$; unfamiliar animal, $n=9$; supportive important person, $n=9$; unfamiliar person, $n=8$; pleasant image, $n=8$; no image, $n=8$ ) was used. Table 6 shows the mean (and standard deviation) of the pre-, during- and post-stressor measures for each condition on the physiological measures.

When comparing all the conditions to the physiological data, the results found a significant main effect of time on pulse, $F(2,90)=14.471, p<.001, \eta_{\mathrm{p}}^{2}=.243$. This effect tells us that the participants' pulse changed throughout the MAT. However, there was no interaction between time and condition for pulse, $F(2,90)=.116, p=1.000, \eta_{\mathrm{p}}^{2}=.013$. Also, the between subjects factor of condition was not significant for pulse, $F(5,45)=.617, p=.687, \eta_{\mathrm{p}}{ }^{2}=.064$. For systolic blood pressure, there was a main effect of time, $F(2,90)=5.407, p=.006, \eta_{\mathrm{p}}{ }^{2}=$ .107. This effect tells us that the participants' diastolic blood pressure changed throughout the MAT. There was no interaction between time and condition for systolic blood pressure, $F(2,90)$ $=.313, p=.976, \eta_{\mathrm{p}}^{2}=.034$. Also, the between subjects factor of condition was not significant for systolic blood pressure, $F(5,45)=.505, p=.771, \eta_{\mathrm{p}}{ }^{2}=.053$. For diastolic blood pressure, there was a significant main effect of time on diastolic blood pressure, $F(2,90)=19.313, p<.001, \eta_{\mathrm{p}}{ }^{2}$ 
$=.300$. This effect tells us that the participants' diastolic blood pressure changed throughout the MAT. However, there was no interaction between time and condition for diastolic blood pressure, $F(2,90)=.253, p=.989, \eta_{\mathrm{p}}^{2}=.027$. Also, the between subjects factor of condition was not significant for diastolic blood pressure, $F(5,45)=.810, p=.549, \eta_{\mathrm{p}}^{2}=.083$.

For the physiological measures (residual pulse, residual systolic blood pressure and residual diastolic blood pressure), a one-way between subject ANOVA with a between subjects of condition (personal pet, $n=9$; unfamiliar animal, $n=9$; supportive important person, $n=9$; unfamiliar person, $n=8$; pleasant image, $n=8$; no image, $n=8$ ) was used. Table 7 shows the test-statistics for all physiological measures comparing the personal pet condition to the other conditions. The assumption of homogeneity of variances was violated for residual pulse, Levene's test, $F(5,45)=2.836, p=.026$. Welch's $F$-test revealed that the total composite score did not differ across groups, Welch's $F(5,20.607)=.669, p=.651$, est. $\omega^{2}=-.03$. Planned comparisons of each condition to the personal pet condition for residual pulse revealed no significant findings (see Table 7). For the residual systolic blood pressure, the overall ANOVA results indicated no significant omnibus effect across the conditions, $F(5,45)=.481, p=.788$, $\eta_{\mathrm{p}}{ }^{2}=.051$. The planned comparisons revealed no significant findings between the personal pet condition and each condition, see Table 7. Likewise, the residual diastolic blood pressure, the overall ANOVA results indicated no significant omnibus effect across the conditions, $F(5,45)=$ $.536, p=.748, \eta_{\mathrm{p}}{ }^{2}=.056$. The planned comparisons found no significant difference in diastolic blood pressure between personal pet condition and each condition (see Table 7).

\section{Hypothesis 3: Comparison between the Supportive Important Person and each of the four other Conditions on Emotional and Physiological Stress Reactivity}


This research question focused on the differences, if any, between the supportive important person condition and each of the other four conditions (an unfamiliar animal, an unfamiliar person, a pleasant image and no image) on self-reports (i.e., subjective emotionality and physiological symptoms) and physiological responses (i.e., heart rate and blood pressure).

Subjective Emotion Self-Report. To examine whether the supportive important person condition responded differently from the other conditions for the self-report measures, first, a one-way between subjects ANOVA with a between subjects of condition was used that revealed no differences overall among the conditions as previously reported (see page 31 for these results listed under Hypothesis 2). To examine the specific comparison of the supportive important person versus each other condition, planned pairwise comparisons were used. As previously mentioned, Table 4 lists the means for each condition. Table 8 shows the test-statistics for the subjective measures for the planned comparisons between the supportive important person condition and other conditions.

For the residual anxiety, the planned comparisons revealed that the supportive important person condition and the unfamiliar animal condition did differ significantly in residual anxiety, $t(45)=2.227, p=.02$, one-tailed, $r=.32, g=1.07$. More specifically, as shown in Table 4 , the mean score for residual anxiety in the supportive important person condition $(M=1.71, S D=$ .28) was higher than in the unfamiliar animal condition $(M=1.44, S D=.24)$, suggesting that the supportive important person condition had higher levels of anxiety compared to the unfamiliar animal condition following the MAT. The supportive important person and pleasant image conditions did differ in residual anxiety, $t(45)=2.647, p=.005$, one-tailed, $\mathrm{r}=.37, g=1.30$; examination of the means (Table 4) shows that the supportive important person condition had 
higher levels of anxiety compared to the pleasant image condition following the MAT. Likewise, the supportive important person and no image conditions differed in residual anxiety, $t(45)=$ 2.052, $p=.023$, one-tailed, $\mathrm{r}=.29, g=1.03$; examination of the means (Table 4 ) indicates that the supportive important person condition had higher levels of anxiety compared to the no image condition following the MAT (see Table 8 for all test-statistics).

For the residual stress, the planned comparisons revealed that the supportive important person and pleasant image conditions did differ in residual stress, $t(45)=1.967, p=.03$, onetailed, $\mathrm{r}=.28, g=.96$; examination of the means (Table 4) indicates that the supportive important person condition had higher levels of stress compared to the pleasant image condition following the MAT. The supportive important person and no image conditions also differed in residual stress, $t(45)=1.826, p=.04$, one-tailed, $\mathrm{r}=.26, g=.89$, such that the supportive important person condition had higher levels of stress compared to the no image condition following the MAT (please see Table 4 and Table 8).

For the residual happiness, the planned comparisons revealed a trend towards significance between the supportive important person and pleasant image conditions in residual happiness, $t(45)=1.815, p=.08, \mathrm{r}=.26, g=.88$; examination of the means (Table 4) indicates that the supportive important person condition had higher levels of happiness compared to the pleasant image condition following the MAT. In addition, for the residual relaxation, the planned comparisons revealed no significant differences between the supportive important person and each of the conditions (see Table 8).

Subjective Physiology Self-Reports. For the self-report measures regarding physiological symptoms (PSI and API), the one-way ANOVA across all condition was not 
significant (as previously mentioned) for PSI. The planned comparisons of each condition to the supportive important person condition revealed no significant differences (see Table 8).

For the API measure, a chi-square test (as previously mentioned) indicated no overall differences in sample proportions (see Table 4). The proportion of participants that had a panic attack in the supportive important person condition did differ from the proportion of participants that had a panic attack in the pleasant image condition, $z=1.8, p=.037$, one-tailed. Contrary to the hypothesis, the supportive important person condition had a larger proportion of participants that had a panic attack than the pleasant image condition (see Table 8).

Physiological Response. As previously noted, a mixed ANOVA for all conditions was not significant for the three time points on the physiological measures. Also, a one-way between subjects ANOVA for all conditions was not significant for the residual physiological data (See Hypothesis 2). Table 6 has the means for the physiological measures. Table 9 shows the teststatistics for the physiological measures between the supportive important person and other conditions. Planned comparisons for the physiological measures (residual pulse, residual systolic blood pressure and diastolic blood pressure) found that the supportive important person condition did not differ from each condition, see Table 9 for all test-statistics.

\section{Hypothesis 4: Comparison between the Unfamiliar Person and each of the Control Conditions on Emotional and Physiological Stress Reactivity}

This research question focused on the differences, if any, between the unfamiliar person condition and each of the control conditions (a pleasant image and no image) on self-reports (i.e., subjective emotionality and physiological symptoms) and physiological responses (i.e., heart rate and blood pressure). 
Subjective Emotion Self-Report. As previously mentioned, a one-way between subjects ANOVA across all conditions was not significant for the self-report measures (see Hypothesis 2). Thus, to examine whether the unfamiliar person condition responded differently from the control conditions for the self-report measures, planned pairwise comparisons for one-way ANOVA were used to compare the unfamiliar person condition to each control condition. There were no significant findings on the subjective emotion measures (residual anxiety, residual stress, residual happiness, and residual relaxation) in the planned comparisons between the unfamiliar person condition and the control conditions. Table 10 shows the test-statistics for all the planned comparisons between each condition on the subjective emotion measures.

Subjective Physiology Self-Reports. For the PSI, the one-way ANOVA across all conditions was not significant (as previously mentioned). The planned comparisons of each control condition to the unfamiliar person condition revealed no significant findings. As previously mentioned, the API measure indicated no overall differences in sample proportions (see Table 4). The proportion of participants that had a panic attack in the unfamiliar person condition versus the control conditions did not differ, see Table 10.

Physiological Response. As previously stated, a mixed ANOVA found no significant omnibus difference in the physiological responses across conditions. As well, a one-way between subjects ANOVA found no significant difference between conditions in their residual physiological change scores (see Table 6 for the means). Lastly, planned comparisons for residual physiological measures (residual pulse, residual systolic blood pressure and diastolic blood pressure) found that the unfamiliar person condition did not differ from the control condition (see Table 11 for test-statistics). 


\section{Exploratory Data Analysis}

In addition to examining the a priori hypotheses, as aforementioned, the thesis also investigated several exploratory questions, as described below. These included potential differences across conditions in how the photo made participants feel at the end of the study (on the Visual Representation Perceptive) and potential differences between cat and dog owners on the pet anthropomorphism measure.

\section{Comparison of Groups in How the Image Made Participants Feel at the End of the}

Study. The Visual Representation Perceptive measure was completed at the end of the study to assess whether the participants found the image relaxing. To examine whether the condition affected how the image made the participants feel, a one-way between subject ANOVA with a between subjects of condition (personal pet, $n=9$; unfamiliar animal, $n=9$; supportive important person, $n=9$; unfamiliar person, $n=8$; pleasant image, $n=8$; no image, $n=8$ ) was used. There was a significant effect of condition on the feeling of being relaxed towards the image, $F(5,47)=2.547, p=.042, \eta_{\mathrm{p}}^{2}=.233$. The post hoc comparisons using the LSD test (to adjust for multiple unplanned comparisons) revealed that individuals who viewed their own pets $(M=5.22, S D=.972)$ showed a greater feeling of being relaxed at the end of the study than those viewing an unfamiliar person $(M=4.13, S D=.641), p=.048, g=.99$. Also, individuals who viewed an unfamiliar animal $(M=5.38, S D=1.188)$ showed a greater feeling of being relaxed at the end of the study than those viewing a supportive important person $(M=4.25, S D=$ $1.165), p=.048, g=1.02$. Individuals who viewed an unfamiliar animal $(M=5.38, S D=1.188)$ showed a greater feeling of being relaxed than those viewing an unfamiliar person $(M=4.13, S D$ $=.641), p=.029, g=1.13$. Individuals who viewed a pleasant image $(M=5.38, S D=1.061)$ showed a greater feeling of being relaxed than those viewing a supportive important person $(M=$ 
$4.25, S D=1.165), p=.048, g=1.02$. Individuals who viewed no image $(M=5.57, S D=1.512)$

showed a greater feeling of being relaxed than those viewing a supportive important person $(M=$ $4.25, S D=1.165), p=.026, g=1.19$. Individual who viewed a pleasant image $(M=5.38, S D=$ 1.061) showed a greater feeling of being relaxed than those viewing an unfamiliar person $(M=$ $4.13, S D=.641), p=.029, g=1.13$. Individual who viewed no image $(M=5.57, S D=1.512)$ showed a greater feeling of being relaxed than those viewing an unfamiliar person $(M=4.13, S D$ $=.641), p=.015, g=1.30$.

Comparison between Cat and Dog Owners. Although as aforementioned, previous research found that cat and dog owners responded similarly to a stressor as both types of pet reduced stress for its owner (Allen et al., 2002; Somervill et al., 2008), possibly, in the current study, dog and cat owners might react differently to seeing a photo of their personal pet. To investigate this issue, first the proportion of participants who were dog owners versus cat owners were compared across conditions. It was found that the proportion of dog versus cat owners did not differ, $\chi^{2}(5, N=51)=2.666, p=.751, V=.229$. Additionally, a series of two-way ANOVAs (with between subject factors of condition and type of pet owned, cat or dog) on the outcome measures (residual anxiety, residual stress, residual relaxation, residual happiness and residual PSI) found no significant effect. For the main effect of condition, the test statistics (F values) ranged from .384 to 1.468 and $p$-values from .222 to .857 . For the main effect of type of pet owned, the test statistics (F values) ranged from .023 to 2.095 and $p$-values from .156 to .881 . The interaction between condition and type of pet owned was also not significant, ranging in test statistics (F values) from .370 to 1.514 and $p$-values from .208 to .866 . Thus cat and dog owners did not differ in how they responded to the different conditions. An independent sample t-test was used to compare dog and cat owners on the pet anthropomorphism measure. There was a 
significant difference in the scores on the pet anthropomorphism measure between dog and cat owners, $t(49)=2.417, p=.019, \mathrm{r}=.33, \mathrm{~g}=.68$. Dog owners $(M=6.60, S D=2.05)$ had higher scores on the pet anthropomorphism measure than cat owners $(M=5.15, S D=2.21)$. In other words, dog owners reflected more anthropomorphic traits onto their pets when compared to cat owners. However, the pet anthropomorphism measure does not include in its official scoring any negative traits; only three positive traits (thoughtful, considerate, and sympathetic) are included. The negative traits (not included in the official scoring) that were agreed upon by two raters (jealous and devious) found that dog and cat owners did not differ, $t(49)=-.157, p=.876, \mathrm{r}=$ $.02, g=-.04$. Taken together, these exploratory findings suggest that dog and cat owners may view their pets differently for positive traits. More research is needed into other traits including judgemental. 


\section{Discussion}

Ample evidence documents that pets reduce reactivity to some kinds of stressors and that pets promote cardiovascular health by reducing physiological responses to stress (Allen et al., 1991; Friedman \& Thomas, 1998). The current study aimed to further this type of research by investigating whether an image of one's pet could reduce the stress response to the mental arithmetic test, relative to other pictures or the no image condition. The current study did not find evidence that an image of one's pet can reduce the stress response to the MAT. Findings are discussed in detail below.

To begin, a trend towards significance was found in the subjective emotional ratings on anxiety and stress between the experimental group (images of a personal pet, unfamiliar animal, supportive important person and unfamiliar person) and control group (images of a pleasant image and no image). The experimental group reported higher anxiety and stress levels than the control group. These results are inconsistent with the hypothesis. Possibly, the "control condition" of a pleasant image (a picture of a lake) was not a true control condition. Indeed, studies have shown that images of nature (e.g., plants) are highly effective at reducing the stress response (Beukeboom, Langeveld, \& Tangja-Dijkstra, 2012). Additionally, the no image condition may not have been a true control condition relative to the social support conditions. More specifically, the no image condition could be viewed as being alone (and thus away from any social evaluative judgement). Along these lines, in Allen and colleagues' (1991) study in which the presence of a friend increased the stress response relative to the presence of a pet or being alone when completing an arithmetic task, the no image group had a lower stress response than the human social support. As shown by the mean residual change scores, the no image 
group had lower anxiety $(M=1.46)$ and stress $(M=-.30)$ scores relative to the supportive important person group on anxiety $(M=1.71)$ and stress $(M=.42)$ scores.

A trend towards significance was found between the personal pet group and the pleasant image group on subjective emotional scores. Also, significant differences were found between the two groups on subjective physiological symptoms. Specifically, the personal pet group had higher anxiety scores and more frequencies of panic attacks than the group seeing the image of a lake. These findings are surprising as it was hypothesized that the personal pet group would have the least stress reactivity. There are a number of possible explanations for this finding. One possibility of course is that a pleasant image does indeed reduce stress reactivity more than an image of one's personal pet, contrary to the hypothesis. Another possibility is that this study used only an image of one's personal pet, a pale proxy for the presence of the actual pet. Perhaps, participants who looked at an image of their pet in some cases started thinking about how much they wished the pet was there with them. Participants could have started to worry about their pet's well-being (i.e., home alone, needs to be fed, etc.). Thus, the image of the personal pet may have increased stress as a result of participants' worry for their pet.

On the other hand, studies have shown that writing about one's pet decreases stress reactivity (McConnell et al., 2011; Zilcha-Mano et al., 2012). The difference in stress levels between viewing a photograph and writing about one's pet could be the timing of the stressor and cognitive stimulation. In the current study, the photos were presented at the same time as the stressor. The participants may have been overwhelmed by being exposed to two stimuli simultaneously. It may be possible that the participants began to worry about the stressor instead of focusing on their pet whereas the other studies had the participants write about their pet before 
the stressor. In addition, the act of writing may activate a cognitive presence of the participants' pets more than does looking at a photo of their pet. A cognitive presence of a pet may be a necessary element for pets to improve their owners' ability to handle the stressor.

Another possible explanation for these results is that despite randomization, post hoc exploration of the data to account for these unexpected findings revealed that the personal pet group had more participants with extremely higher scores on the social phobia scale than the pleasant image group. That is, although the average SPIN scores did not differ across conditions (see Table 2), upon examining the frequencies of severity on the SPIN (i.e., the categorical SPIN measure), the personal pet group had more participants report severe social phobia than the pleasant image condition. Specifically, $44 \%$ of the participants in the personal pet group had severe social anxiety compared to $12 \%$ in the pleasant image group, meaning that the personal pet group had more individuals that become highly anxious in social settings compared to the pleasant image condition. The current study's stressor, the MAT, is a social stressor as it requires the participant to perform a math task out loud in front of an experimenter. Thus, it is possible that the participants in the personal pet group may have been especially anxious because they feared the social component of the stressor, while the pleasant image group felt less anxious about the stressor due to their lower levels of social anxiety. The sample sizes were too small for formal analysis but upon examining the group means in the personal pet group and pleasant image group when the severe social phobia participants were removed, the personal pet group had a decrease in anxiety levels from 1.55 to 1.45 . Importantly, stress levels dropped dramatically, from .14 to -.33 in the personal pet group. For the pleasant image group, there were small decreases in anxiety levels from -1.38 to -1.35 and stress levels from -.35 to -.38 . 
The third possible explanation is that the picture used for the pleasant image group was an image of a lake on a sunny day, which may be a potent stress reducer. Along these lines, as previously stated, research has found that exposure to a real plant or images of plants reduce stress levels when compared to a control group (Beukeboom et al., 2012). Thus, the current findings may demonstrate that an image of nature (in the form of a picture of a lake) may buffer stress reactivity. Possibly, photos of nature do not engender any sense of worry, in contrast to the worry about one's pet's well-being that the participants in the personal pet group may have experienced.

There were no other significant findings between the personal pet group and all other conditions. However, the lack of findings could result from the short amount of time the participant had with the photo. As previously stated, the photos were presented at the same time as the stressor. The participant may have briefly viewed the photo but immediately after exposure to the photo turned their attention to the stressor. This study unfortunately did not formally assess where participants were directing their eye gaze or how much attention participants felt they were giving towards focusing on the picture they had in front of them. Additionally, the photo and stressor were presented at the same time in this thesis; possibly presenting the photo prior to the stressor would have enabled participants to focus better on the image of their pet during the stressor.

There were significant differences between the supportive important person group and three other conditions (unfamiliar animal, pleasant image and no image) on subjective emotional and physiological symptoms. However, the results were contradictory to the current study's hypothesis in that the supportive important person group had higher reports of anxiety, stress and 
panic attacks compared to the other conditions. These results are inconsistent with the hypothesis, but as noted, contradictory findings have emerged in the study of how human support affects stress reactivity. For example, as aforementioned, a study by Allen et al. (2002) found that for participants performing a mental arithmetic task, the presence of a spouse was associated with the highest stress reactivity when compared to other conditions (i.e., pets, alone). However, in another study, the presence of a spouse during the cold pressor task, a physiological stressor, did not affect stress reactivity when compared to other conditions. Likewise, Eisenberger et al. (2011) found that viewing a picture of one's partner while performing a painful task led to lower self-reported pain ratings when compared to the control images of a stranger and object.

The results of these studies taken together suggest that human social support may reduce stress reactivity to a physiological stressor such as pain. However, for a cognitive stressor, such as the MAT, human social support may increase stress reactivity. As previously mentioned, a non-judgmental atmosphere may explain the mechanism behind social support's ability to reduce stress (Allen et al., 1991; Lepore, 1998; Kors et al., 1997). However, the MAT may elicit a judgemental environment as this stressor requires the individual to give a series of correct answers to the mathematical subtraction. Thus, exposure to an image of a supportive important individual may have caused an evaluative environment for the participant, as a human (but not a pet) will understand if the participant correctly completed the math task. This judgmental environment might increase stress reactivity. In line with this idea, relative to the human support condition, the anxiety scores were significantly lower for three conditions that all lacked evaluative capabilities (unfamiliar animal, pleasant image (picture of a lake) and no image (black screen) and also were not the person's own pet (which as mentioned might engender worry). It 
could be suggested that these images, an animal, a lake and a black screen elicit a non-evaluative environment which lowered the anxiety scores.

In addition, the finding that the unfamiliar animal group had significantly lower anxiety scores compared to the supportive important person group could have pet therapy implications. As previously mentioned, pet therapy programs involve a certified dog or cat that are unfamiliar to the individuals taking part in the program (Coren, 2010). Pet therapy programs have been shown to improve psychological deficits, physical ailments and moods among individuals (Adamle et al., 2009; Batson et al., 1998; Johnson et al., 2003). The findings that an unfamiliar animal reduced anxiety could further demonstrate the effectiveness of pet therapy. This result could suggest that merely images of an unfamiliar animal could be used to lower stress. However, these conclusions are preliminary since the statistical power is low due to a small sample size.

Additionally, a trend towards significance was found between the supportive important person and pleasant image groups on subjective happiness scores. The results indicated that the supportive important person group had higher scores on happiness than the pleasant image group. The reason for these findings is unclear based on the results of the current study. One explanation is exposure to a familiar face may create a sense of comfort and happiness. Since the photos was comprised of someone the participants care for and an image they provided, the exposure may have elicited a familiar feeling thereby increasing happiness. The pleasant image was unfamiliar as it was an image the experimenter provided.

No significant differences were found in the comparison of the unfamiliar person group to the control groups (pleasant image and no image). However, examination of the mean residual 
change scores indicated that with a larger sample size, the comparison between the unfamiliar person and pleasant image group may demonstrate differences. Specifically, the pleasant image group anxiety $(M=1.38)$ and stress $(M=-.35)$ scores were better (but not significant) than the unfamiliar person group on anxiety $(M=1.53)$ and stress $(M=.22)$ scores.

It is important to note that there were significant findings in the subjective emotional measures while no significant differences were found in the physiological measures. These findings can be applied to current research which has found a lack of correlation between acute physiological and subjective emotional measures on the stress response. In other words, physiological reactions and subjective emotional responses do not show similar results across difference measures for acute stressors. Some possible factors that could explain this dissociation between biological and emotional measures could be individual differences in emotional regulation, appraisal processes, psychological traits and baseline HPA features (for review, see Campbell \& Ehlert, 2012). This dissociation may explain the current study's differences in physiological and subjective emotional results.

In the exploratory analysis, there were significant differences between the conditions on a subjective question about how the image made the participant feel at the end of the study. First, the results found that the personal pet group were more relaxed than the unfamiliar animal group. An explanation for this finding could be the emotional connection the participants have with their pet. Participants may have felt more relaxed when exposed to a photo of their own pet because they care about and know the animal which promoted a relaxing feeling. Alternatively, the unfamiliar animal image is unknown to them which may have limited their sense of relaxation when compared to their own pet. However, the results found that the image of an 
unfamiliar animal had higher reports of relaxation than both human images (supportive important person and unfamiliar person group). To further demonstrate the implication of pet therapy, it is possible that an image of an unfamiliar animal increases relaxation, thereby reducing the stress response.

Further, the pleasant image group had significantly higher reports of relaxation than both human images. These findings could have therapeutic implications that images of nature can increase relaxation. On the other hand, an image of a human, either supportive or unfamiliar, may increase stress as both groups reported less relaxation. It seems that a visual representation of a human may be less effective at reducing stress compared to other images. Indeed, consistent with this line of reasoning, the group that saw a blank screen had significantly higher relaxation scores compared to the relaxation scores of both groups viewing human images (supportive important person and unfamiliar person). It is possible that participants would rather be alone than presented with an image of a human, regardless of the person's familiarity to them, when completing a cognitive task.

In sum, this thesis found that the image of one's pet may not be effective at reducing stress, relative to other images or a no image condition. Additionally, a picture of human social support may increase stress reactivity to the MAT, a cognitive stressor. This finding, in conjunction with other literature, suggests that in asking whether a certain approach (e.g., a picture of one's supportive important person) affects stress response, it is imperative to clarify the type of stressor under investigation. Finally, the results of this study provide preliminary evidence that an image of an unfamiliar animal or an image from nature may reduce stress reactivity. 
There are several strengths to the current study. To my knowledge, this is the first study to investigate the effects that various types of images have on stress reactivity in a single investigation. However, a larger sample size would provide more statistical power to fully understand the effect of these images on stress reactivity. In addition, the results of this study suggest that the stress reducing effects of a particular image may be dependent on the type of stressor administrated. Thus, more generally, questions about how to help people respond to stressors may benefit from a reframing that emphasizes the particular type of stressor an individual will experience (e.g., an oral presentation versus exposure to pain). Of course, many stressors in daily life are unexpected, and thus research is also needed to determine the approaches that might benefit stress reactivity across stressors.

The current thesis also had limitations, including the small sample size, resulting in low in statistical power. In addition, the Chi-square analyses had small expected counts, which temper the confidence that can be placed in the results. More specifically, the Chi-square test uses the chi-square distribution to approximate the underlying exact distribution. The approximation becomes less suitable for an analysis with small expected cell frequencies (Cochran, 1954). It should be noted that the current project is continuing to collect data to enable greater statistical power and confidence in the results. Another limitation to this study is that as aforementioned, a photograph is a pale proxy for the physical presence of one's pet. Indeed, in the presence of one's pet, the pet owner is able to interact with, touch, and talk to the animal. Thus, there may have been different results if pets were physically present during the study.

In light of the strengths and limitations, there are future directions to consider. Future research could incorporate a cognitive presence (i.e., writing or talking about one's pet) in 
addition to the exposure of the image prior to the MAT. A cognitive presence may be essential for understanding the mechanism behind pets' ability to reduce their owners' stress response. Additionally, a future study could compare the effects that the physical presence of a pet and an image of various types (nature, a pet, human) have on stress reactivity. Lastly, the current study focused on the short term effects of the images on both physiological and psychological stress reactivity. A future study could examine the long term effects these images have on stress reactivity. In spite of the current study's limitations, these preliminary results suggest that various images can influence how one responds to stress. 
Table 1

Psychological and Emotional Measures and Subjective Physiological Symptoms

Measures $-M(S D) \quad \frac{\text { Pre-Stressor }}{(N=51)} \quad \frac{\text { Post-Stressor }}{(N=51)} \quad \underline{\text { Total }}(N=51)$

Psychological

PSS

$-$

17.35(6.23)

SPIN

$-$

$36.70(13.21)$

Emotional (VAS)

Anxiety

Stress

Happiness

Relaxation

59.27(28.48)
31.33(26.14)

$37.63(28.89)$

45.51(27.33)

$35.67(28.82)$

Physiological
PSI
$3.96(4.43)$
$6.82(7.01)$

Note PSS = Perceived Stress Scale; SPIN = Social Phobia Inventory; VAS = Visual Analogue Scale; PSI = Panic Symptom Inventory 
Table 2

Sample Demographic, Characteristics and Psychological Measures Separated by Condition

\begin{tabular}{|c|c|c|c|c|c|c|c|}
\hline Measures & $\frac{\text { PP group }}{(N=9)}$ & $\frac{\text { UA group }}{(N=9)}$ & $\frac{\text { SIP group }}{(N=9)}$ & $\frac{\text { UP group }}{(N=8)}$ & $\frac{\text { PI group }}{(N=8)}$ & $\frac{\text { NI group }}{(N=8)}$ & $\begin{array}{l}\text { Test } \\
\text { Statistics }\end{array}$ \\
\hline Age - M(S.D.) & $19.7(1.7)$ & $31.0(12.9)$ & $29.3(14.7)$ & $28.6(15.0)$ & $27.9(15.5)$ & $26.3(10.6)$ & 0.9 \\
\hline Gender - \% & & & & & & & 3.3 \\
\hline Female & $88.9 \%$ & $77.8 \%$ & $66.7 \%$ & $87.5 \%$ & $87.5 \%$ & $62.5 \%$ & \\
\hline Male & $11.1 \%$ & $22.2 \%$ & $33.3 \%$ & $12.5 \%$ & $12.5 \%$ & $37.5 \%$ & \\
\hline Ethnicity - \% & & & & & & & 20.1 \\
\hline White/European & $55.6 \%$ & $44.5 \%$ & $55.6 \%$ & $62.5 \%$ & $62.5 \%$ & $37.5 \%$ & \\
\hline Asian & $33.3 \%$ & $44.4 \%$ & $33.3 \%$ & $25.0 \%$ & $37.5 \%$ & $37.5 \%$ & \\
\hline African & $0.0 \%$ & $0.0 \%$ & $0.0 \%$ & $0.0 \%$ & $0.0 \%$ & $12.5 \%$ & \\
\hline Hispanic & $0.0 \%$ & $0.0 \%$ & $0.0 \%$ & $0.0 \%$ & $0.0 \%$ & $0.0 \%$ & \\
\hline Aboriginal & $0.0 \%$ & $0.0 \%$ & $0.0 \%$ & $12.5 \%$ & $0.0 \%$ & $0.0 \%$ & \\
\hline Multiracial & $0.0 \%$ & $0.0 \%$ & $0.0 \%$ & $0.0 \%$ & $0.0 \%$ & $12.5 \%$ & \\
\hline Other & $11.1 \%$ & $11.1 \%$ & $11.1 \%$ & $0.0 \%$ & $0.0 \%$ & $0.0 \%$ & \\
\hline \multicolumn{8}{|c|}{ Characteristics $-M(S . D)}$. \\
\hline Math (Yes) - \% & $55.6 \%$ & $44.4 \%$ & $44.4 \%$ & $25.0 \%$ & $37.5 \%$ & $50.0 \%$ & 1.9 \\
\hline PAQ & $108.1(11.5)$ & $107.3(4.3)$ & $108.4(9.9)$ & $112.5(6.2)$ & $105.6(16.0)$ & $111.4(9.7)$ & 0.5 \\
\hline PA & $5.3(2.1)$ & $6.7(1.7)$ & $5.0(2.9)$ & $5.0(2.5)$ & $6.0(2.3)$ & $7.1(1.4)$ & 1.4 \\
\hline AHCS & $61.9(9.1)$ & $60.4(8.2)$ & $61.0(10.4)$ & $63.1(7.3)$ & $63.9(11.0)$ & $60.8(6.1)$ & 0.2 \\
\hline ISEL & $37.4(5.5)$ & $33.3(8.0)$ & $37.0(7.5)$ & $38.9(4.7)$ & $37.3(5.2)$ & $32.4(10.0)$ & 1.1 \\
\hline \multicolumn{8}{|c|}{ Psychological - M(S.D.) } \\
\hline SPIN & $39.0(13.9)$ & $41.3(16.7)$ & $28.4(6.8)$ & $39.4(13.8)$ & $31.5(11.3)$ & $40.8(12.7)$ & 1.5 \\
\hline SPIN (severe) - \% & $44.4 \%$ & $44.4 \%$ & $0.0 \%$ & $62.5 \%$ & $12.5 \%$ & $37.5 \%$ & 23.5 \\
\hline PSS & $16.9(5.5)$ & $19.9(5.0)$ & $16.1(7.7)$ & $17.6(6.6)$ & $16.5(7.1)$ & $17.0(6.2)$ & 0.5 \\
\hline
\end{tabular}

Note. $\mathrm{PP}=$ Personal Pet; UA = Unfamiliar Animal; SIP = Supportive Important Person; UP = Unfamiliar Person; PI = Pleasant Image; NI = No Image; MATH = "Do you like math?"; PAQ = Pet Attitude Questionnaire; PA = Pet Anthropomorphism; ISEL = Interpersonal Support Evaluative List; AHCS = Animal-Human Continuity Scale; SPIN = Social Phobia Inventory; PSS = Perceived Stress Scale. No significant differences were found between the six conditions and the demographics, characteristics and psychological characteristics measures. No significant test statistics occurred. The test statistic is chi-square for gender, ethnicity, math and SPIN (severe), and F for the age, PAQ, PA, AHCS, ISEL, SPIN and PSS. 
Table 3

Comparison between Experimental Conditions and Control Conditions on Subjective and Objective Measures

\begin{tabular}{llllll}
\hline Variable & $\underline{\text { Test- }}$ & $\underline{\text { Degrees of }}$ & $\underline{\text { P-Value }}$ & $\underline{\text { Partial Eta- }}$ & Cramer's V \\
\hline
\end{tabular}

Subjective Emotion (VAS)

$\begin{array}{lcccc}\text { Anxiety } & 3.30 & 1,49 & 0.08 & 0.06 \\ \text { Stress } & 3.84 & 1,49 & 0.06 & 0.07 \\ \text { Happiness } & 0.89 & 1,49 & 0.35 & 0.02 \\ \text { Relaxation } & 0.17 & 1,49 & 0.68 & 0.00\end{array}$

Subjective Physiological

$\begin{array}{llllll}\text { PSI } & 0.24 & 1,49 & 0.63 & 0.01 & - \\ \text { API } & 0.89^{+} & 1,50 & 0.35 & - & 0.13\end{array}$

Physiological

\begin{tabular}{|c|c|c|c|c|}
\hline Residual Pulse & 0.04 & 1,49 & 0.84 & 0.00 \\
\hline Residual Systolic Blood Pressure & 0.10 & 1,49 & 0.76 & 0.00 \\
\hline Residual Diastolic Blood Pressure & 0.74 & 1,49 & 0.39 & 0.02 \\
\hline
\end{tabular}

Note. VAS = Visual Analogue Scale; PSI = Panic Symptom Inventory; API = Acute Panic Inventory. All test-statistics are F values, except API which is Chi-squared noted by + . 
Table 4

Conditions on Subjective Emotion Self-Reports and Physiological Measures

\begin{tabular}{|c|c|c|c|c|c|c|}
\hline Variab & $\frac{\text { PP group }}{(N=9)}$ & $\frac{\text { UA group }}{(N=9)}$ & $\frac{\text { SIP group }}{(N=9)}$ & $\frac{\text { UP group }}{(N=8)}$ & $\frac{\text { PI group }}{(N=8)}$ & $\frac{\text { NI group }}{(N=8)}$ \\
\hline
\end{tabular}

Emotional VAS - M(S.D.)

\begin{tabular}{|c|c|c|c|c|c|c|}
\hline \multicolumn{7}{|l|}{ Anxiety } \\
\hline Pre-Stressor & $20.44(22.01)$ & $33.44(31.52)$ & $19.44(20.26)$ & $17.25(14.98)$ & $8.88(11.06)$ & $20.50(21.33)$ \\
\hline Post-Stressor & $34.22(28.90)$ & $33.78(25.85)$ & $47.11(22.90)$ & $31.63(28.26)$ & $12.50(13.37)$ & $26.13(28.49)$ \\
\hline \multicolumn{7}{|l|}{ Stress } \\
\hline Pre-Stressor & $29.22(26.92)$ & $25.78(28.75)$ & $30.78(37.57)$ & $25.37(29.25)$ & $12.50(24.20)$ & $30.13(24.25)$ \\
\hline Post-Stressor & $43.67(26.06)$ & $32.33(22.47)$ & $52.67(36.60)$ & $43.75(29.79)$ & $19.63(19.88)$ & $31.75(31.12)$ \\
\hline \multicolumn{7}{|l|}{ Happiness } \\
\hline Pre-Stressor & $60.00(31.08)$ & $54.00(30.03)$ & $68.89(21.97)$ & $68.13(17.27)$ & $57.25(27.67)$ & $55.50(22.99)$ \\
\hline Post-Stressor & $51.22(33.00)$ & $40.11(23.45)$ & $41.33(26.49)$ & $46.13(31.93)$ & $54.63(27.33)$ & $40.13(25.75)$ \\
\hline \multicolumn{7}{|l|}{ Relaxation } \\
\hline Pre-Stressor & $56.00(31.08)$ & $48.78(33.56)$ & $54.44(35.59)$ & $61.75(27.63)$ & 72.63(16.39) & $64.38(22.27)$ \\
\hline Post-Stressor & $36.56(31.97)$ & $32.78(24.68)$ & $23.11(25.24)$ & $46.13(33.60)$ & $38.38(29.05)$ & $38.88(31.75)$ \\
\hline \multicolumn{7}{|l|}{ Physiological $-M(S . D)}$. \\
\hline \multicolumn{7}{|l|}{ PSI } \\
\hline Pre-Stressor & $6.11(6.39)$ & $4.22(3.07)$ & $2.44(3.28)$ & $6.38(5.88)$ & $2.13(2.70)$ & $2.38(2.45)$ \\
\hline Post-Stressor & $7.00(5.87)$ & $6.44(4.67)$ & $6.56(4.56)$ & $10.38(6.61)$ & $4.00(4.81)$ & $6.63(13.13)$ \\
\hline \multicolumn{7}{|l|}{ API } \\
\hline Count (panic) & 4 & 2 & 3 & 2 & 0 & 3 \\
\hline Percentage (panic) & $44.44 \%$ & $22.22 \%$ & $33.33 \%$ & $25.00 \%$ & $0.00 \%$ & $37.50 \%$ \\
\hline
\end{tabular}

Note. PP = Personal Pet; UA = Unfamiliar Animal; SIP = Supportive Important Person; UP = Unfamiliar Person; PI = Pleasant Image; NI = No Image; VAS = Visual Analogue Scale; PSI = Panic Symptom Inventory; API = Acute Panic Inventory. 
Table 5

Planned Comparison in Subjective Measures between Personal Pet Condition and other Conditions

\begin{tabular}{|c|c|c|c|c|c|}
\hline Variable & $\begin{array}{l}\text { PP vs. UA groups } \\
(N=18)\end{array}$ & $\begin{array}{l}\text { PP vs. SIP groups } \\
(N=18)\end{array}$ & $\frac{\text { PP vs. UP groups }}{(N=17)}$ & $\frac{\text { PP vs. PI groups }}{(N=17)}$ & $\frac{\text { PP vs. NI groups }}{(N=17)}$ \\
\hline \multicolumn{6}{|l|}{ Emotional } \\
\hline Anxiety - test statistic & 0.93 & -1.30 & 0.16 & 1.38 & 0.79 \\
\hline $\mathrm{df}$ & 45 & 45 & 45 & 45 & 45 \\
\hline p-value (one-tailed) & 0.18 & 0.10 & 0.44 & 0.09 & 0.22 \\
\hline r-value & 0.14 & 0.19 & 0.02 & 0.20 & 0.12 \\
\hline g-value & 0.43 & -0.63 & 0.08 & 0.67 & 0.36 \\
\hline Stress - test statistic & 0.85 & -0.74 & -0.21 & 1.25 & 1.11 \\
\hline df & 45 & 45 & 45 & 45 & 45 \\
\hline p-value (one tailed) & 0.20 & 0.23 & 0.42 & 0.11 & 0.15 \\
\hline r-value & 0.13 & 0.11 & 0.03 & 0.18 & 0.16 \\
\hline g-value & 0.40 & -0.35 & -0.10 & 0.61 & 0.54 \\
\hline Happiness - test statistic & -0.77 & -1.18 & -0.86 & 0.67 & -0.87 \\
\hline df & 45 & 45 & 45 & 45 & 45 \\
\hline p-value (two-tailed) & 0.45 & 0.25 & 0.39 & 0.51 & 0.39 \\
\hline r-value & 0.11 & 0.17 & 0.13 & 0.10 & 0.13 \\
\hline g-value & -0.36 & -0.56 & -0.42 & 0.33 & -0.42 \\
\hline Relaxation - test statistic & -0.01 & 1.08 & -0.54 & 0.60 & 0.19 \\
\hline df & 45 & 45 & 45 & 45 & 45 \\
\hline p-value (two-tailed) & 0.99 & 0.29 & 0.60 & 0.55 & 0.85 \\
\hline r-value & 0.00 & 0.16 & 0.08 & 0.09 & 0.03 \\
\hline g-value & -0.01 & 0.51 & -0.26 & 0.29 & 0.09 \\
\hline \multicolumn{6}{|l|}{ Physiological } \\
\hline PSI - test statistic & -0.77 & -1.23 & -1.01 & -0.40 & -0.46 \\
\hline df & 45 & 45 & 45 & 45 & 45 \\
\hline p-value (one-tailed) & 0.22 & 0.11 & 0.16 & 0.35 & 0.32 \\
\hline r-value & 0.11 & 0.18 & 0.15 & 0.06 & 0.07 \\
\hline $\mathrm{g}$-value & -0.37 & -0.59 & 0.49 & -0.20 & -0.23 \\
\hline API - test statistic & $1.0^{+}$ & $0.5^{+}$ & $0.8^{+}$ & $2.1^{+* *}$ & $0.3^{+}$ \\
\hline df & 1 & 1 & 1 & 1 & 1 \\
\hline p-value (one-tailed) & 0.16 & 0.32 & 0.21 & 0.01 & 0.40 \\
\hline r-value & 0.24 & 0.12 & 0.19 & 0.51 & 0.07 \\
\hline
\end{tabular}

Note. PP = Personal Pet; UA = Unfamiliar Animal; SIP = Supportive Important Person; UP = Unfamiliar Person; PI = Pleasant Image; NI = No Image; $\mathrm{PSI}=$ Panic Symptom Inventory; API = Acute Panic Inventory. All test statistics are $t$, except API where Z is given as noted by + .

** $p<0.01$ 
Table 6

Conditions on Physiological Measures

\begin{tabular}{lllllll} 
Physiological Measures $-M(S . D)$. & $\frac{\text { PP group }}{(N=9)}$ & $\frac{\text { UA group }}{(N=9)}$ & $\frac{\text { SIP group }}{(N=9)}$ & $\frac{\text { UP group }}{(N=8)}$ & $\frac{\text { PI group }}{(N=8)}$ & $\frac{\text { NI group }}{(N=8)}$ \\
\hline & & & & & & \\
Pulse & $79.94(13.38)$ & $87.93(9.96)$ & $89.59(13.02)$ & $81.82(15.53)$ & $83.40(13.43)$ & $84.32(8.90)$ \\
$\quad$ Pre-Stressor & $83.25(15.15)$ & $91.84(10.45)$ & $93.79(21.34)$ & $84.78(17.71)$ & $86.25(16.19)$ & $88.68(14.89)$ \\
$\quad$ During & $78.37(13.71)$ & $85.97(10.74)$ & $89.03(18.43)$ & $81.19(22.82)$ & $81.22(17.23)$ & $84.37(10.83)$ \\
$\quad$ Post-Stressor & & &
\end{tabular}

Systolic Blood Pressure

$\begin{array}{lllllll}\text { Pre-Stressor } & 112.56(15.56) & 116.40(16.97) & 120.23(15.91) & 111.97(17.56) & 113.89(18.40) & 111.89(9.44) \\ \text { During } & 115.27(16.81) & 120.17(15.98) & 126.58(25.87) & 112.36(21.69) & 118.04(21.29) & 117.56(15.86) \\ \text { Post-Stressor } & 110.77(16.43) & 114.09(14.98) & 123.50(24.63) & 108.60(30.72) & 112.88(21.15) & 113.43(12.57)\end{array}$

Diastolic Blood Pressure

\begin{tabular}{|c|c|c|c|c|c|c|}
\hline Pre-Stressor & $61.95(12.73)$ & $70.27(7.78)$ & 70.76(12.39) & 63.74(12.94) & $65.19(12.44)$ & $68.32(6.88)$ \\
\hline During & $64.21(14.61)$ & $74.10(11.20)$ & $74.24(18.65)$ & $67.37(14.11)$ & $67.09(14.24)$ & $71.20(12.12)$ \\
\hline Post-Stressor & $59.47(13.82)$ & $68.38(11.69)$ & $69.64(15.22)$ & $63.47(17.58)$ & $61.13(15.68)$ & $66.84(9.01)$ \\
\hline
\end{tabular}

Note. $\mathrm{PP}=$ Personal Pet; UA = Unfamiliar Animal; SIP = Supportive Important Person; UP = Unfamiliar Person; PI = Pleasant Image; NI = No Image. 
Table 7

Planned Comparisons in Physiological Measures between Personal Pet Condition and other Conditions

\begin{tabular}{|c|c|c|c|c|c|}
\hline Variable & $\begin{array}{l}\text { PP vs. UA } \\
\begin{array}{l}\text { groups } \\
(N=18)\end{array}\end{array}$ & $\begin{array}{l}\text { PP vs. SIP } \\
\text { groups } \\
(N=18)\end{array}$ & 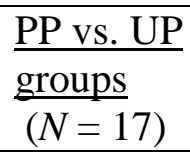 & $\frac{\text { PP vs. PI }}{\frac{\text { groups }}{(N=17)}}$ & $\frac{\text { PP vs. NI }}{\frac{\text { groups }}{(N=17)}}$ \\
\hline \multicolumn{6}{|l|}{ Physiological } \\
\hline $\begin{array}{l}\text { Pulse - test statistic } \\
\text { df } \\
\text { p-value (one-tailed) } \\
\text { r-value } \\
\text { g-value }\end{array}$ & $\begin{array}{l}-1.03 \\
15.21 \\
0.16 \\
0.25 \\
0.34\end{array}$ & $\begin{array}{l}-0.33 \\
14.70 \\
0.37 \\
0.09 \\
0.14\end{array}$ & $\begin{array}{l}0.15 \\
9.22 \\
0.44 \\
0.05 \\
-0.10\end{array}$ & $\begin{array}{l}-0.63 \\
14.97 \\
0.27 \\
0.16 \\
0.23\end{array}$ & $\begin{array}{l}0.46 \\
13.66 \\
0.33 \\
0.12 \\
-0.14\end{array}$ \\
\hline $\begin{array}{l}\text { Systolic Blood Pressure - test statistic } \\
\text { df } \\
\text { p-value (one tailed) } \\
\text { r-value } \\
\text { g-value }\end{array}$ & $\begin{array}{l}0.18 \\
45 \\
0.43 \\
0.03 \\
-0.08\end{array}$ & $\begin{array}{l}-1.08 \\
45 \\
0.14 \\
0.16 \\
0.51\end{array}$ & $\begin{array}{l}-0.11 \\
45 \\
0.46 \\
0.02 \\
0.05\end{array}$ & $\begin{array}{l}-0.11 \\
45 \\
0.46 \\
0.02 \\
0.05\end{array}$ & $\begin{array}{l}-0.77 \\
45 \\
0.22 \\
0.11 \\
0.38\end{array}$ \\
\hline $\begin{array}{l}\text { Diastolic Blood Pressure - test statistic } \\
\text { df } \\
\text { p-value (two-tailed) } \\
\text { r-value } \\
\text { g-value }\end{array}$ & $\begin{array}{l}-0.34 \\
45 \\
0.37 \\
0.05 \\
0.16\end{array}$ & $\begin{array}{l}-0.05 \\
45 \\
0.48 \\
0.01 \\
0.02\end{array}$ & $\begin{array}{l}0.78 \\
45 \\
0.22 \\
0.12 \\
-0.38\end{array}$ & $\begin{array}{l}-0.86 \\
45 \\
0.20 \\
0.13 \\
0.42\end{array}$ & $\begin{array}{l}-0.03 \\
45 \\
0.49 \\
0.00 \\
0.01\end{array}$ \\
\hline
\end{tabular}

Note. $\mathrm{PP}=$ Personal Pet; UA = Unfamiliar Animal; SIP = Supportive Important Person; UP = Unfamiliar Person; PI = Pleasant Image; NI

$=$ No Image. All test statistics are $t$. No significant test statistics occurred. 
Table 8

Planned Comparison in Subjective Measures between Supportive Important Person Condition and other Conditions

\begin{tabular}{|c|c|c|c|c|}
\hline Variable & $\begin{array}{l}\text { SIP vs. UA groups } \\
(N=18)\end{array}$ & $\begin{array}{l}\text { SIP vs. UP groups } \\
(N=17)\end{array}$ & $\begin{array}{l}\text { SIP vs. PI groups } \\
(N=17)\end{array}$ & $\begin{array}{l}\text { SIP vs. NI groups } \\
(N=17)\end{array}$ \\
\hline \multicolumn{5}{|l|}{ Emotional } \\
\hline Anxiety - test statistic & $2.23 *$ & 1.42 & $2.65 * *$ & $2.05 *$ \\
\hline df & 45 & 45 & 45 & 45 \\
\hline p-value (one-tailed) & 0.02 & 0.08 & 0.01 & 0.02 \\
\hline r-value & 0.32 & 0.21 & 0.37 & 0.29 \\
\hline g-value & 1.07 & 0.71 & 1.30 & 1.03 \\
\hline Stress - test statistic & 1.59 & 0.51 & $1.97 *$ & $1.83 *$ \\
\hline df & 56 & 45 & 45 & 45 \\
\hline p-value (one tailed) & 0.06 & 0.30 & 0.03 & 0.04 \\
\hline r-value & 0.23 & 0.08 & 0.28 & 0.26 \\
\hline g-value & 0.75 & 0.25 & 0.96 & 0.89 \\
\hline Happiness - test statistic & 0.41 & 0.28 & 1.82 & 0.27 \\
\hline df & 45 & 45 & 45 & 45 \\
\hline p-value (two-tailed) & 0.68 & 0.78 & 0.08 & 0.78 \\
\hline r-value & 0.06 & 0.04 & 0.26 & 0.04 \\
\hline g-value & 0.19 & 0.14 & 0.88 & 0.13 \\
\hline Relaxation - test statistic & -1.09 & -1.58 & -0.43 & -0.86 \\
\hline df & 45 & 45 & 45 & 45 \\
\hline p-value (two-tailed) & 0.28 & 0.12 & 0.66 & 0.39 \\
\hline r-value & 0.16 & 0.23 & 0.06 & 0.13 \\
\hline g-value & -0.52 & 0.77 & -0.22 & -0.42 \\
\hline \multicolumn{5}{|l|}{ Physiological } \\
\hline PSI - test statistic & 0.46 & 0.19 & 0.79 & 0.73 \\
\hline df & 45 & 45 & 45 & 45 \\
\hline p-value (one-tailed) & 0.65 & 0.85 & 0.43 & 0.47 \\
\hline r-value & 0.07 & 0.03 & 0.12 & 0.11 \\
\hline g-value & 0.22 & 0.09 & 0.39 & 0.36 \\
\hline API - test statistic & $0.5^{+}$ & $0.4^{+}$ & $1.8^{+*}$ & $0.2^{+}$ \\
\hline df & 1 & 1 & 1 & 1 \\
\hline p-value (one-tailed) & 0.30 & 0.35 & 0.04 & 0.42 \\
\hline r-value & 0.12 & 0.10 & 0.44 & 0.05 \\
\hline
\end{tabular}

Note. SIP = Supportive Important Person; UA = Unfamiliar Animal; UP = Unfamiliar Person; PI = Pleasant Image; NI = No Image; PSI = Panic Symptom Inventory; API = Acute Panic Inventory. All test statistics are $t$, except API where Z is given as noted by + .

$* p<0.05 ; * *<0.01$ 
Table 9

Planned Comparison in Physiological Measures between Supportive Important Person Condition and other Conditions

\begin{tabular}{|c|c|c|c|c|}
\hline Variable & 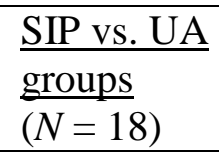 & $\begin{array}{l}\text { SIP vs. UP } \\
\begin{array}{l}\text { groups } \\
(N=18)\end{array}\end{array}$ & $\frac{\text { SIP vs. PI }}{\frac{\text { groups }}{(N=17)}}$ & $\begin{array}{l}\frac{\text { SIP vs. NI }}{\text { groups }} \\
(N=17)\end{array}$ \\
\hline \multicolumn{5}{|l|}{ Physiological } \\
\hline $\begin{array}{l}\text { Pulse - test statistic } \\
\text { df } \\
\text { p-value (one-tailed) } \\
\text { r-value } \\
\text { g-value }\end{array}$ & $\begin{array}{l}-0.48 \\
12.88 \\
0.32 \\
0.13 \\
0.19\end{array}$ & $\begin{array}{l}0.34 \\
10.93 \\
0.37 \\
0.10 \\
-0.25\end{array}$ & $\begin{array}{l}-0.19 \\
14.12 \\
0.43 \\
0.05 \\
0.08\end{array}$ & $\begin{array}{l}0.73 \\
11.59 \\
0.24 \\
0.21 \\
-0.29\end{array}$ \\
\hline $\begin{array}{l}\text { Systolic Blood Pressure - test statistic } \\
\text { df } \\
\text { p-value (one tailed) } \\
\text { r-value } \\
\text { g-value }\end{array}$ & $\begin{array}{l}1.26 \\
45 \\
0.15 \\
0.18 \\
-0.69\end{array}$ & $\begin{array}{l}0.94 \\
45 \\
0.14 \\
0.14 \\
-0.55\end{array}$ & $\begin{array}{l}0.94 \\
45 \\
0.26 \\
0.14 \\
-0.55\end{array}$ & $\begin{array}{l}0.28 \\
45 \\
0.47 \\
0.04 \\
-0.23\end{array}$ \\
\hline $\begin{array}{l}\text { Diastolic Blood Pressure - test statistic } \\
\text { df } \\
\text { p-value (two-tailed) } \\
\text { r-value } \\
\text { g-value }\end{array}$ & $\begin{array}{l}-0.29 \\
45 \\
0.39 \\
0.04 \\
0.14\end{array}$ & $\begin{array}{l}0.82 \\
45 \\
0.21 \\
0.12 \\
-0.40\end{array}$ & $\begin{array}{l}-0.81 \\
45 \\
0.21 \\
0.12 \\
0.40\end{array}$ & $\begin{array}{l}0.02 \\
45 \\
0.49 \\
0.00 \\
-0.01\end{array}$ \\
\hline
\end{tabular}

Note. SIP = Supportive Important Person; UA = Unfamiliar Animal; UP = Unfamiliar Person; PI = Pleasant

Image; NI = No Image. All test statistics are $t$. No significant test statistics occurred. 
Table 10

Planned Comparison in Subjective Measures between Unfamiliar Person Condition and Control Conditions

\begin{tabular}{|c|c|c|c|}
\hline Variable & $\begin{array}{l}\text { UP vs. PI groups } \\
(N=16)\end{array}$ & $\begin{array}{l}\text { UP vs. NI groups } \\
(N=16)\end{array}$ & \\
\hline \multicolumn{4}{|l|}{ Emotional } \\
\hline Anxiety - test statistic & 1.19 & 0.61 & \\
\hline df & 45 & 45 & \\
\hline p-value (one-tailed) & 0.12 & 0.27 & \\
\hline r-value & 0.17 & 0.09 & \\
\hline g-value & 0.60 & 0.31 & \\
\hline Stress - test statistic & 1.42 & 1.28 & \\
\hline $\mathrm{df}$ & 45 & 45 & \\
\hline p-value (one tailed) & 0.08 & 0.10 & \\
\hline r-value & 0.21 & 0.19 & \\
\hline g-value & 0.71 & 0.64 & \\
\hline Happiness - test statistic & 1.49 & -0.01 & \\
\hline df & 45 & 45 & \\
\hline p-value (two-tailed) & 0.14 & 1.00 & \\
\hline r-value & 0.22 & 0.00 & \\
\hline g-value & 0.75 & 0.00 & \\
\hline Relaxation - test statistic & 1.11 & 0.70 & \\
\hline df & 45 & 45 & \\
\hline p-value (two-tailed) & 0.27 & 0.49 & \\
\hline r-value & 0.16 & 0.10 & \\
\hline g-value & 0.55 & 0.35 & \\
\hline \multicolumn{4}{|l|}{ Physiological } \\
\hline PSI - test statistic & 0.59 & 0.53 & \\
\hline df & 45 & 45 & \\
\hline p-value (one-tailed) & 0.56 & 0.60 & \\
\hline r-value & 0.09 & 0.08 & \\
\hline g-value & 0.30 & 0.27 & \\
\hline API - test statistic & $1.5^{+}$ & $0.5^{+}$ & \\
\hline df & 1 & 1 & \\
\hline p-value (one-tailed) & 0.06 & 0.29 & \\
\hline r-value & 0.38 & 0.13 & 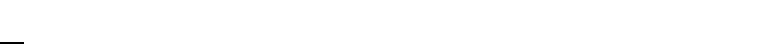 \\
\hline
\end{tabular}


Table 11

Planned Comparison in Physiological Measures between Unfamiliar Person Condition and Control Conditions

\begin{tabular}{|c|c|c|}
\hline Variable & $\begin{array}{l}\text { UP vs. PI groups } \\
(N=16)\end{array}$ & $\frac{\text { UP vs. NI groups }}{(N=16)}$ \\
\hline \multicolumn{3}{|l|}{ Physiological } \\
\hline $\begin{array}{l}\text { Pulse - test statistic } \\
\text { df } \\
\text { p-value (one-tailed) } \\
\text { r-value } \\
\text { g-value }\end{array}$ & $\begin{array}{l}0.49 \\
9.11 \\
0.32 \\
0.16 \\
0.33\end{array}$ & $\begin{array}{l}-0.06 \\
8.01 \\
0.48 \\
0.02 \\
-0.04\end{array}$ \\
\hline $\begin{array}{l}\text { Systolic Blood Pressure - test statistic } \\
\text { df } \\
\text { p-value (one tailed) } \\
\text { r-value } \\
\text { g-value }\end{array}$ & $\begin{array}{l}0.00 \\
45 \\
0.50 \\
0.00 \\
0.00\end{array}$ & $\begin{array}{l}0.65 \\
45 \\
0.26 \\
0.10 \\
0.32\end{array}$ \\
\hline $\begin{array}{l}\text { Diastolic Blood Pressure - test statistic } \\
\text { df } \\
\text { p-value (two-tailed) } \\
\text { r-value } \\
\text { g-value }\end{array}$ & $\begin{array}{l}1.59 \\
45 \\
0.06 \\
0.23 \\
0.79\end{array}$ & $\begin{array}{l}0.78 \\
45 \\
0.22 \\
0.12 \\
0.39\end{array}$ \\
\hline
\end{tabular}

Image; NI = No Image. All test statistics are $t$. No significant test statistics occurred. 


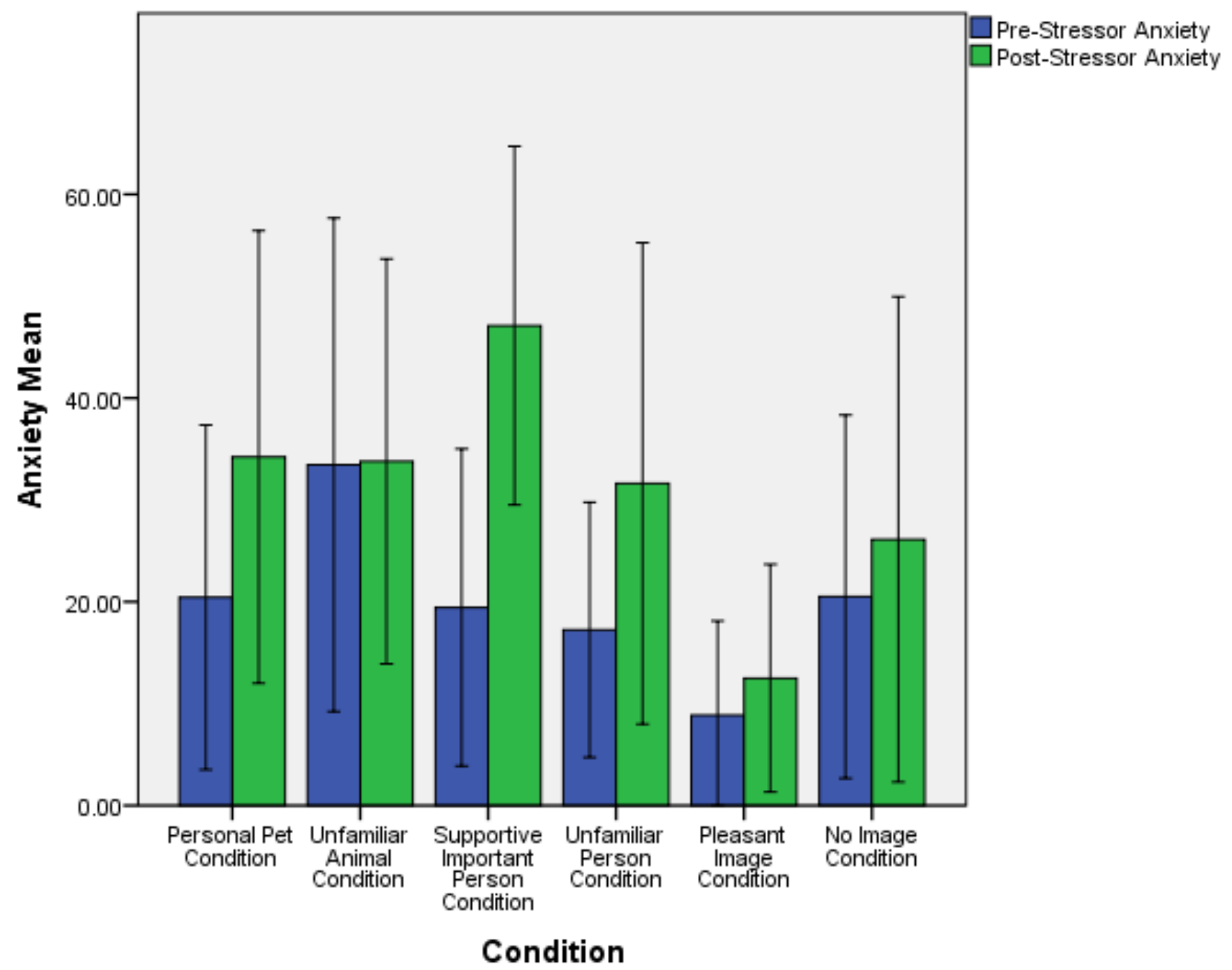

Figure 1. Mean Differences between the Pre- and Post-Stressor on Anxiety Scores across Conditions 


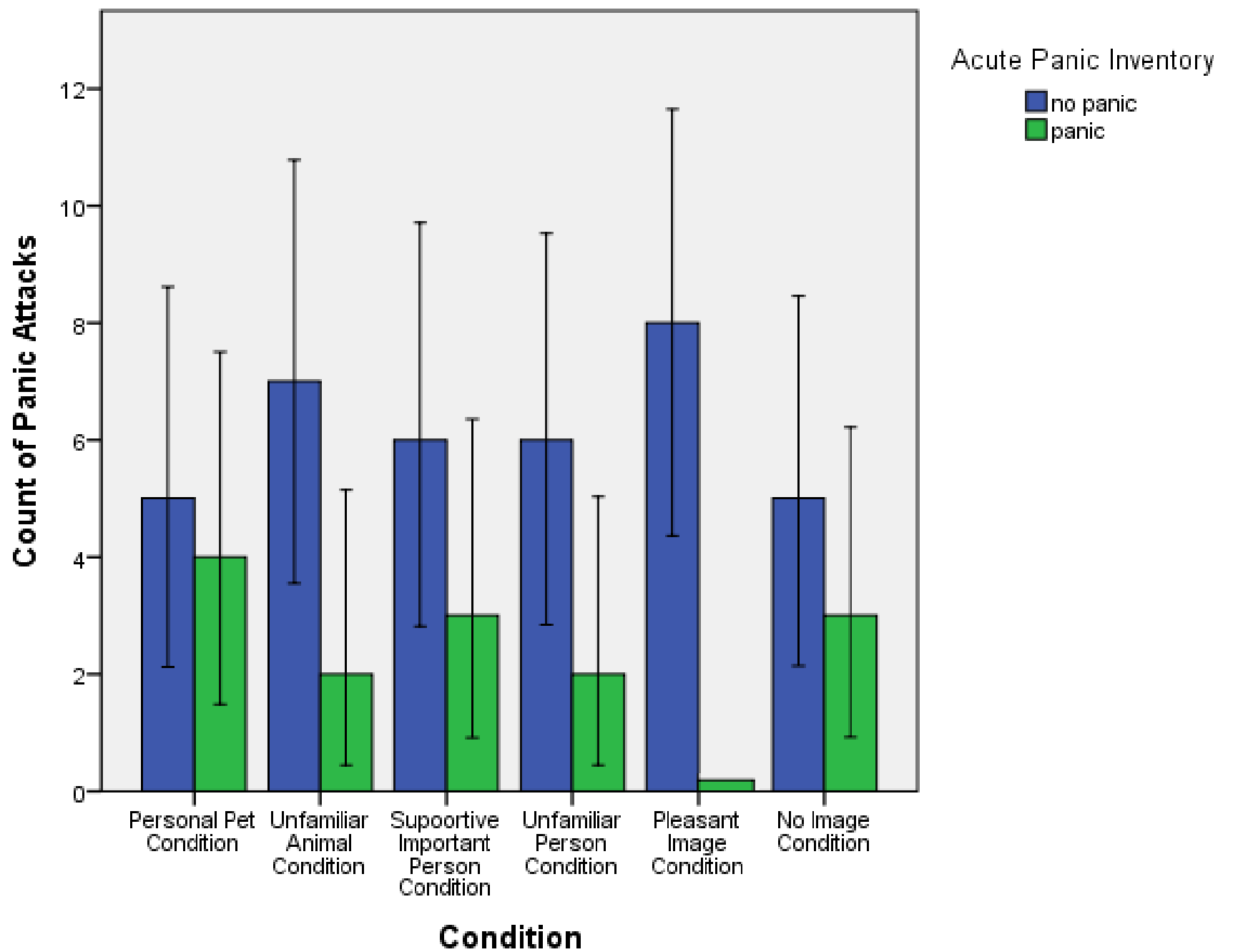

Figure 2. Differences in Panic Attacks across Conditions 
Appendix A - Recruitment Material

$\underline{\text { Advertisements for Kijiji.ca and Craigslist.com (for Community) }}$

Pet Ownership and Stress

Do you currently have a pet (either a cat or a dog)? Are you currently between the ages of 18-64? You may be eligible to participant in a research study about pet ownership and stress. This study investigates current pet owners and the way they respond to stress through a lab based stressor. It involves a 10-minutes telephone screen to determine eligibility; eligible participants will partake in one 1-hour study session at Ryerson University. Participants will have their blood pressure and heart rate recorded, complete questionnaires, view a photograph and engage in an experimental task, involving answering a simple arithmetic problem. You will be compensated for your participation.

All queries are confidential.

For more information please contact:

Email: nein@psych.ryerson.ca 
Flyers - University Buildings \& Pet related Facilities (for Community)

RYERSONUNIVERSITY

\section{RESEARCH PARTICIPANTS NEEDED}

\section{Do you currently have a pet (either a cat, a dog or both)?}

2. Are you between the ages of 18-65?

If you answered yes to these questions, you may be eligible to participate in a research study about pet ownership and stress.

This study involves a 10-minute telephone screen to determine eligibility; eligible participants will partake in one 1-hour study session at Ryerson University. Participants will complete questionnaires and engage in an experimental task, involving answering a simple arithmetic problem.

You will be compensated for your participation This study has been approved by the Ryerson University Research Ethics

For more information please contact

Phone: (416) 573-9047

Email: nein@psych.ryerson.ca

All queries are confidential.
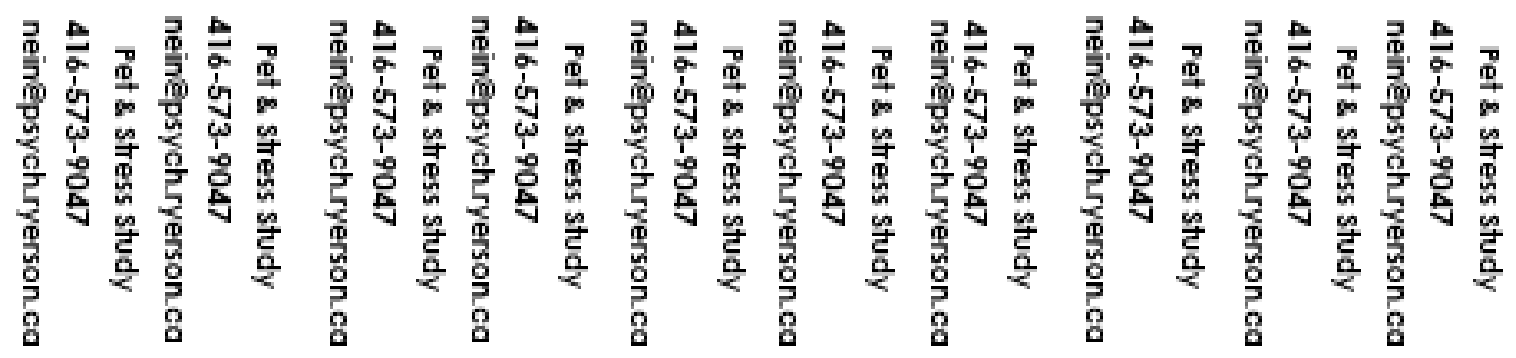
Appendix B - Screening Materials

Telephone Screen (for Community Participants)

\section{SECTION 1: Study Information and Informed Consent Script}

$\mathrm{Hi}$, my name is and I am a researcher in the Psychophysiology Lab at Ryerson

University. I am contacting you because you had expressed interest in participating in our study entitled Pet Ownership and Stress.

"Is this a good time for you?" Yes _

No

IF NO, ask, "When would be a good time to call back?" Date/time to call back

If YES, continue.

In order to see if you would be eligible to participate in the study, I have to ask you some questions over the telephone and tell you about the study. This telephone screen will take between 5 to 10 minutes. You will not be compensated for answering these questions - we are simply trying to find out if you are eligible to participate in this study; if you are eligible, then you would be compensated for your time spent in our lab.

"Would you like to proceed?" YES $\mathrm{NO}$

If NO, stop. If YES, continue.

I'll first tell you briefly what this study is about. The purpose of this study is to learn about current pet owners and the way they respond to stress. The experiment will involve one visit to our laboratory at Ryerson University, located at 105 Bond Street. The total time commitment in the laboratory will be approximately 1 hour, and you'll receive a total of $\$ 10$ for completing the study. During the visit, you will be hooked up to the BioPAC CNAP blood pressure and heart rate monitoring system, complete several questionnaires that ask about your thoughts, emotions and behaviours. You will then engage in one stress-induction method in a laboratory setting, such as a mental arithmetic task. If you meet the requirements to participate, I will email you a document that outlines the study procedures in more detail for you to review. Also, you will be asked to provide TWO separate photos. One photo of your own pet (only one pet if you have multiple pets). Another of one person you believe is supportive and important to you. This study does not required you to bring your pet or supportive person, only photos are needed. You will be asked to provide these photos through email prior to your visit.

"Would you like to proceed?" Yes _

No

If NO, stop. IF YES, proceed to next question.

"Do you have a pet, either a cat, dog or both?"

Yes No

If NO, stop. IF YES, proceed to next question Age: (between 18-64 years old) proceed to SECTION II below 
Eligible to participate? Yes $I$ No - Reason:

\section{If NO:}

That concludes the telephone interview. Thank you for taking the time to answer my questions. Unfortunately, you are not eligible to participate in this study. We are looking for people with a specific set of experiences and your experiences do not match what we're specifically investigating in this study. Do you have any questions?

We offer everyone who completes the telephone screen a list of resources that includes psychological services in the GTA. Is this something that you would be interested in receiving? If so, would you like me to email the list to you?

\section{If YES:}

That concludes the telephone interview. Thank you for taking the time to answer my questions. You are eligible to participate in this study!

As discussed earlier, this study involves one visit to our lab at Ryerson University. The total time commitment is 1 hour. You will be compensated $\$ 10$ if you complete the entire study. If you do not complete the study in its entirety, you will be compensated for the amount of time you participated, which is $\$ 10$ per hour. Please remember to provide the photos through email before your visit to nein@ psych.ryerson.ca

Would you like to set up an appointment to complete the study?

IF NO: Thank you for your time. We offer everyone who completes the telephone screen a list of resources that includes psychological services in the GTA. Is this something that you would be interested in receiving? If so, would you like me to email the list to you?

IF YES: Laboratory appointment day/time:

Would you like to provide your email information so I can send you a consent form and information about the photos you will need to bring to the lab?

IF YES: email address:

If YES or NO: Can we contact you for future studies about pets?

Preferred Contact information (Phone or Email): 
Appendix C - Informed Consent Forms

Informed Consent (for Community participants)

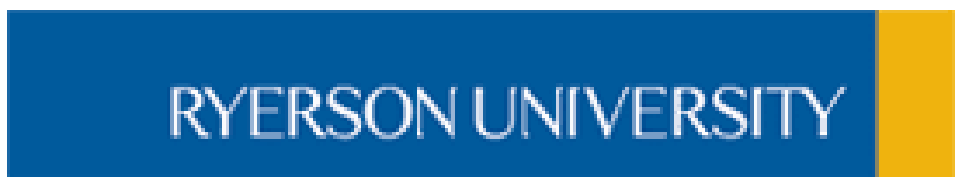

Informed Consent Agreement

\section{Title of Study: Pet Ownership and Stress}

You are being asked to participate in a research study. Before you give your consent to be a volunteer, it is important that you read the following information and ask as many questions as necessary to be sure you understand what you will be asked to do.

\section{Principle Investigator:}

Natalie Ein, B.A., Graduate Student, Department of Psychology, Ryerson University

\section{Supervisors:}

Kristin Vickers, Ph.D., Department of Psychology, Ryerson University Marilyn Hadad, Ph.D., Department of Psychology, Ryerson University

Purpose of the Study: The purpose of this health psychology study is to examine the effects of and the responses to stress through a stress-induction in a laboratory setting. About 120 individuals will take part in this study (all physically healthy who are 18-years of age or older).

Description of the Study: The experiment will involve one visit to the Psychophysiology Lab (room SBB220) at the Psychology Research and Training Centre at Ryerson University, located at 105 Bond Street. The total time commitment will be approximately one hour.

- For 4 hours before your lab visit, it is preferred that you do NOT use any products containing nicotine or caffeine.

- After signing this Consent Form if you choose to participate, there are two parts to this study. The first part you will be hooked up to the BioPAC CNAP blood pressure and heart rate monitoring system. Then you will complete a series of self report questionnaires.

- In the second and final part of the study, which is estimated to take about 15 minutes, you will engage in a stress-induction method used in psychological research. The stress induction method will ask you to perform a mental arithmetic task. During the experiment, you will be shown a picture on a computer screen in front of you throughout the 15-minute session. Please note that, you may or may not see the pictures you brought to the lab. Lastly, at any time, you may stop your participation by signaling to the researcher. Following the stress induction, 
you will complete another set of self-report questionnaires.

- After you complete this portion of the research, you will have the opportunity to learn more about this study in a 10-minute discussion with Natalie Ein. Then your participation in this study will be finished.

What is Experimental in this Study: None of the procedures or questionnaires used in this study is experimental in nature. The only experimental aspect of this study is the gathering of information for the purpose of analysis.

\section{Risks or Discomforts:}

- Temporary psychological discomfort may be caused at those times when you are completing the mental arithmetic task but these effects are entirely harmless and painless. They are expected to disappear once the task is complete.

- If at any point during your participation you begin to feel uncomfortable, you can stop your participation (either temporarily or permanently) immediately by signaling to Natalie Ein, who will be in the room with you at all times.

- Answering questions about your moods and personal history, because of the personal nature of the questions asked, may result in you reflecting on unpleasant memories while responding to the questionnaires or interview. If you begin to feel uncomfortable, you may discontinue participation, either temporarily or permanently. In addition, you may skip any questions that you do not want to answer at any point.

Benefits of the Study: The results of this study will not benefit you directly, but the knowledge gained may help the researcher and others gain a deeper understanding of stress and how it's studied in a laboratory setting. I cannot guarantee, however, that you will receive any benefits from participating in this study.

Confidentiality: Everything you disclose in this study will remain completely confidential and will only be known to the principal investigator of the study, Natalie Ein, and her research supervisors, Dr. Kristin Vickers and Dr. Marilyn Hadad. However, as part of this study, we are obligated to inform everyone that there are five cases in which we might need to break confidentiality:

(1) if you intend to harm yourself;

(2) if you intend on harming someone else;

(3) if there is reasonable suspicion that a child up to the age of 16 years is at risk of neglect or abuse, we are required by law to report this to the Children's Aid Society right away;

(4) if our files are subpoenaed by the courts (records can be opened by a specific court order);

(5) if a regulated health professional has engaged in inappropriate sexual behavior toward you and you provide us with the name of this individual, we are obligated to report them to their regulatory body. 
This informed consent agreement and all data that identify you will be stored in a locked storage space in the Psychophysiology Lab (room SBB220) and access to collected data will be limited to Natalie Ein, Dr. Kristin Vickers, Dr. Marilyn Hadad, any other lab members in the Psychophysiology Lab. All of your data is kept completely confidential, however. An ID number as opposed to your name will be used on all forms you complete (both paper and electronic), and in all computer files that will contain the data you generate during the study. The paper data you generate while participating in this study will be kept in a locked file cabinet, separate from this consent agreement and any other data that identifies you. Your consent form and all data will be kept for seven years after the publication of the results of this research. Your confidentiality will be protected to the full extent allowed by law. Only group findings will be reported in publications and presentations arising from this research.

We do need to tell you that the secure computer program stores its data on a server in the United States. This is mentioned because the Patriot Act means that the U.S. government can monitor all electronic data. If you care to know more about the Patriot Act, please visit the link provided - http://epic.org/privacy/terrorism/hr3162.html. If you would like to see the Patriot Act website now, before going any further, please let the researcher know and she will show you this site on the computer. The online survey is hosted by Qualtrics, a websurvey company located in the USA and as such, is subject to U.S. laws; in particular, the US Patriot Act, which allows authorities access to the records of internet service providers. This survey or questionnaire does not ask for personal identifiers or any information that may be used to identify you. However, if you choose to participate in the survey, you understand that your responses to the survey questions will be stored, and can be accessed, in the USA. The security and privacy policy for the websurvey company can be found at the following link: http://www.qualtrics.com/security-statement/

Incentives to Participate: You will receive a total of $\$ 10$ for participating in this study. You will still receive compensation for your time ( $\$ 10$ / hour) if you choose to stop participation before the end of the lab visit.

Costs and/or Compensation for Participation: There are no costs associated with your participation in this study. You are asked to transport yourself to Ryerson University on one occasion.

Voluntary Nature of Participation: Participation in this study is voluntary. Your choice of whether or not to participate will not influence your future relations with Ryerson University. If you decide to participate, you are free to withdraw your consent and to stop your participation at any time without penalty or loss of benefits to which you are allowed. Your right to withdraw your consent also applies to our use of your data. If you decide that you do not want us to keep or analyze data that you have provided during the course of your participation in this study, please feel free to notify us. At any particular point in the study, you may refuse to answer any particular question or stop participation altogether. 
Questions about the Study: If you have any questions about the research now, please ask. If you have questions later about the research, you may contact the primary investigator at:

\section{Natalie Ein \\ 416-979-5000 ext 4985 \\ nein@psych.ryerson.ca}

Additionally, you may contact the primary investigator's research supervisors:

Dr. Marilyn Hadad

416-979-5000 ext 7109 mhadad@ryerson.ca
Dr. Kristin Vickers

416-979-5000 ext 7727

kvickers@ryerson.ca

If you have questions regarding your rights as a human subject and participant in this study, you may contact Ryerson University Research Ethics Board for information.

Research Ethics Board

Ryerson University, POD 470B

350 Victoria Street

Toronto, Ontario, Canada M5B 2K3

Email: rebchair@ryerson.ca, Web: http://www.ryerson.ca/research

\section{Agreement:}

Your signature below indicates: (1) that you have read the information in this agreement and have had a chance to ask any questions you have about this study; (2) that you agree that information collected from you during the telephone screen for this study can be retained and analyzed and (3) that you agree to be in this study (as described in this consent form) and have been told that you can change your mind and withdraw your consent to participate at any time. You have been given a copy of this agreement. You have been told that by signing this consent agreement you are not giving up any of your legal rights.

Name of Participant (please print)

Signature of Participant

Date

Signature of Investigator

Date 
Informed Consent (for SONA participants)

\section{RYERSONUNIVERSITY}

\section{Informed Consent Agreement}

\section{Title of Study: Pet Ownership and Stress}

You are being asked to participate in a research study. Before you give your consent to be a volunteer, it is important that you read the following information and ask as many questions as necessary to be sure you understand what you will be asked to do.

\section{Principle Investigator:}

Natalie Ein, B.A., Graduate Student, Department of Psychology, Ryerson University

\section{Supervisors:}

Kristin Vickers, Ph.D., Department of Psychology, Ryerson University

Marilyn Hadad, Ph.D., Department of Psychology, Ryerson University

Purpose of the Study: The purpose of this health psychology study is to examine the effects of and the responses to stress through a stress-induction in a laboratory setting. About 120 individuals will take part in this study (all physically healthy who are 18-years of age or older). Participants will be students enrolled in either PSY102 or PSY202 at Ryerson University

Description of the Study: The experiment will involve one visit to the Psychophysiology Lab (room SBB220) at the Psychology Research and Training Centre at Ryerson University, located at 105 Bond Street. The total time commitment will be approximately one hour.

- For 4 hours before your lab visit, it is preferred that you do NOT use any products containing nicotine or caffeine.

- After signing this Consent Form if you choose to participate, there are two parts to this study. The first part you will be hooked up to the BioPAC CNAP blood pressure and heart rate monitoring system. Then you will complete a series of self report questionnaires.

- In the second and final part of the study, which is estimated to take about 15 minutes, you will engage in a stress-induction method used in psychological research. The stress induction method will ask you to perform a mental arithmetic task. During the experiment, you will be shown a picture on a computer screen in front of you throughout the 15-minute session. Please note that, you may or may not see the pictures you brought to the lab. Lastly, at any time, you may stop your participation by signaling to the researcher. Following the stress induction, you will complete another set of self-report questionnaires. 
- After you complete this portion of the research, you will have the opportunity to learn more about this study in a 10-minute discussion with Natalie Ein. Then your participation in this study will be finished.

What is Experimental in this Study: None of the procedures or questionnaires used in this study is experimental in nature. The only experimental aspect of this study is the gathering of information for the purpose of analysis.

\section{Risks or Discomforts:}

- Temporary psychological discomfort may be caused at those times when you are completing the mental arithmetic task but these effects are entirely harmless and painless. They are expected to disappear once the task is complete.

- If at any point during your participation you begin to feel uncomfortable, you can stop your participation (either temporarily or permanently) immediately by signaling to Natalie Ein, who will be in the room with you at all times.

- Answering questions about your moods and personal history, because of the personal nature of the questions asked, may result in you reflecting on unpleasant memories while responding to the questionnaires or interview. If you begin to feel uncomfortable, you may discontinue participation, either temporarily or permanently. In addition, you may skip any questions that you do not want to answer at any point.

Benefits of the Study: The results of this study will not benefit you directly, but the knowledge gained may help the researcher and others gain a deeper understanding of stress and how it's studied in a laboratory setting. I cannot guarantee, however, that you will receive any benefits from participating in this study.

Confidentiality: Everything you disclose in this study will remain completely confidential and will only be known to the principal investigator of the study, Natalie Ein, and her research supervisors, Dr. Kristin Vickers and Dr. Marilyn Hadad. However, as part of this study, we are obligated to inform everyone that there are five cases in which we might need to break confidentiality:

(1) if you intend to harm yourself;

(2) if you intend on harming someone else;

(3) if there is reasonable suspicion that a child up to the age of 16 years is at risk of neglect or abuse, we are required by law to report this to the Children's Aid Society right away;

(4) if our files are subpoenaed by the courts (records can be opened by a specific court order);

(5) if a regulated health professional has engaged in inappropriate sexual behavior toward you and you provide us with the name of this individual, we are obligated to report them to their regulatory body. 
This informed consent agreement and all data that identify you will be stored in a locked storage space in the Psychophysiology Lab (room SBB220) and access to collected data will be limited to Natalie Ein, Dr. Kristin Vickers, Dr. Marilyn Hadad, any other lab members in the Psychophysiology Lab. All of your data is kept completely confidential, however. An ID number as opposed to your name will be used on all forms you complete (both paper and electronic), and in all computer files that will contain the data you generate during the study. The paper data you generate while participating in this study will be kept in a locked file cabinet, separate from this consent agreement and any other data that identifies you. Your consent form and all data will be kept for seven years after the publication of the results of this research. Your confidentiality will be protected to the full extent allowed by law. Only group findings will be reported in publications and presentations arising from this research.

We do need to tell you that the secure computer program stores its data on a server in the United States. This is mentioned because the Patriot Act means that the U.S. government can monitor all electronic data. If you care to know more about the Patriot Act, please visit the link provided - http://epic.org/privacy/terrorism/hr3162.html. If you would like to see the Patriot Act website now, before going any further, please let the researcher know and she will show you this site on the computer. The online survey is hosted by Qualtrics, a websurvey company located in the USA and as such, is subject to U.S. laws; in particular, the US Patriot Act, which allows authorities access to the records of internet service providers. This survey or questionnaire does not ask for personal identifiers or any information that may be used to identify you. However, if you choose to participate in the survey, you understand that your responses to the survey questions will be stored, and can be accessed, in the USA. The security and privacy policy for the websurvey company can be found at the following link: http://www.qualtrics.com/security-statement/

Incentives to Participate: You will receive 1 course credit for participating in this study. As an alternative to completing the questionnaires, you may choose to participate in a 'walk-through' without providing any data. This decision will not affect your relationship with Ryerson University and will not affect your academic standing in any way.

Costs and/or Compensation for Participation: There are no costs associated with your participation in this study. You are asked to transport yourself to Ryerson University on one occasion.

Voluntary Nature of Participation: Participation in this study is voluntary. Your choice of whether or not to participate will not influence your future relations with Ryerson University. If you decide to participate, you are free to withdraw your consent and to stop your participation at any time without penalty or loss of benefits to which you are allowed. At any particular point in the study, you may refuse to answer any particular question or stop participation altogether without losing your course credit.

Questions about the Study: If you have any questions about the research now, please ask. If you have questions later about the research, you may contact the primary investigator at: 


\section{Natalie Ein \\ 416-979-5000 ext 4985 \\ nein@psych.ryerson.ca}

Additionally, you may contact the primary investigator's research supervisors:

Dr. Marilyn Hadad

416-979-5000 ext 7109

mhadad@ryerson.ca
Dr. Kristin Vickers

416-979-5000 ext 7727

kvickers@ryerson.ca

If you have questions regarding your rights as a human subject and participant in this study, you may contact Lynn Lavallee at the Ryerson University Research Ethics Board for information.

Lynn Lavallee

Chair, Research Ethics Board

Ryerson University, POD 470B

350 Victoria Street

Toronto, Ontario, Canada M5B 2K3

Phone: (416) 979-5000 Ext. 4791

Email: rebchair@ryerson.ca, Web: http://www.ryerson.ca/research

If you have questions regarding your participation using SONA, you may contact

Psychology Research Pool at Ryerson University for information

Email: thepool@psych.ryerson.ca

\section{Agreement:}

Your signature below indicates: (1) that you have read the information in this agreement and have had a chance to ask any questions you have about this study and (2) that you agree to be in this study (as described in this consent form) and have been told that you can change your mind and withdraw your consent to participate at any time. You have been given a copy of this agreement. You have been told that by signing this consent agreement you are not giving up any of your legal rights.

Name of Participant (please print)

Signature of Participant

Date

Signature of Investigator

Date 


\section{Appendix D - Demographic Measures}

Demographic and Pet Ownership Questionnaire

1) Age:

2) Gender: $F \quad M$

3) Ethnicity (e.g., Caucasian, Hispanic, etc.):

4) What is your relation to the person in the photo you brought for a supportive important person in your life (i.e. mother, best friend)?

5) Why did you pick this person?

6) How many pets do you have in your household (total number of pets)
○ 1
○ 2
○ 3
○ 4 or more

7) What type of pet(s) do you have?
○ Dog
- Cat
○ Other

8) How many years have you been a pet owner?
$\circ \quad 0-5$ years
○ 6-10 years
○ 11-15 years
○ 16 or more years

9) Is your pet(s) a:

- Personal pet

○ Family Pet

10) Is your pet(s) healthy?

$$
\begin{array}{ll}
\circ & \text { Yes } \\
\circ & \text { No }
\end{array}
$$

11) How old is your pet(s)?

12) How long have you owned your pet(s)?

13) How many people live in your household?

14) Of the people who live in your household, how many of them consider themselves to be pet owners? 


\section{Appendix E - Pet and Social Support Measures}

Pet Attitude Questionnaire (PAQ)

Please answer each of the following questions as honestly as you can, in terms of how you feel right now. This questionnaire is anonymous and no one will ever know which were your answers. So, don't worry about how you think others might answer these questions, There aren't any right or wrong answers. All that matters is that you express your true thoughts on the subject.

Please answer by circling one of the following seven numbers for each question:

$\begin{array}{lllllll}1 & 2 & 3 & 4 & 5 & 6 & 7 \\ \text { strongly } & \text { moderately } & \text { slightly } & \text { unsure } & \text { Slightly } & \text { moderately } & \text { strongl } \\ \text { disagree } & \text { disagree } & \text { disagree } & & \text { agree } & \text { Agree } & \text { agree }\end{array}$

For example, if you slightly disagree with the first item, you would circle 3.

Thank you for your assistance.

1. Ireally like seeing pets enjoy their food.

$\begin{array}{lllllll}1 & 2 & 3 & 4 & 5 & 6 & 7 \\ \text { strongly } & \text { moderately } & \text { slightly } & \text { unsure } & \text { slightly } & \text { moderately } & \text { strongl } \\ \text { disagree } & \text { disagree } & \text { disagree } & & \text { agree } & \text { Agree } & \text { agree }\end{array}$

2. My pet means more to me than any of my friends.

\begin{tabular}{|c|c|c|c|c|c|}
\hline $\begin{array}{l}1 \\
\text { strongly } \\
\text { disagree }\end{array}$ & $\begin{array}{l}2 \\
\text { moderately } \\
\text { disagree }\end{array}$ & $\begin{array}{l}3 \\
\text { slightly } \\
\text { disagree }\end{array}$ & $\begin{array}{l}4 \\
\text { unsure }\end{array}$ & $\begin{array}{l}5 \\
\text { slightly } \\
\text { agree }\end{array}$ & $\begin{array}{l}6 \\
\text { moderately } \\
\text { Agree }\end{array}$ \\
\hline
\end{tabular}

3. I would like a pet in my home.

$\begin{array}{lllllll}1 & 2 & 3 & 4 & 5 & 6 & 7 \\ \text { strongly } & \text { moderately } & \text { slightly } & \text { unsure } & \text { slightly } & \text { moderately } & \text { strongl } \\ \text { disagree } & \text { disagree } & \text { disagree } & & \text { agree } & \text { Agree } & \text { agree }\end{array}$

4. Having pets is a waste of money.

$\begin{array}{lllllll}1 & 2 & 3 & 4 & 5 & 6 & 7 \\ \text { strongly } & \text { moderately } & \text { slightly } & \text { unsure } & \text { slightly } & \text { moderately } & \text { strongl } \\ \text { disagree } & \text { disagree } & \text { disagree } & & \text { agree } & \text { Agree } & \text { Agree }\end{array}$

5. Housepets add happiness to my life (or would if I had one).

$\begin{array}{lllllll}1 & 2 & 3 & 4 & 5 & 6 & 7 \\ \text { strongly } & \text { moderately } & \text { slightly } & \text { unsure } & \text { slightly } & \text { moderately } & \text { strongl } \\ \text { disagree } & \text { disagree } & \text { disagree } & & \text { agree } & \text { Agree } & \text { Agree }\end{array}$


6. I feel that pets should always be kept outside.

\begin{tabular}{|c|c|c|c|c|c|}
\hline $\begin{array}{l}1 \\
\text { strongly } \\
\text { disagree }\end{array}$ & $\begin{array}{l}2 \\
\text { moderately } \\
\text { disagree }\end{array}$ & $\begin{array}{l}3 \\
\text { slightly } \\
\text { disagree }\end{array}$ & $\begin{array}{l}4 \\
\text { unsure }\end{array}$ & $\begin{array}{l}5 \\
\text { slightly } \\
\text { agree }\end{array}$ & $\begin{array}{l}6 \\
\text { moderately } \\
\text { Agree }\end{array}$ \\
\hline
\end{tabular}

7. I spend time every day playing with my pet (or I would if I had one).

$\begin{array}{lllllll}1 & 2 & 3 & 4 & 5 & 6 & 7 \\ \text { strongly } & \text { moderately } & \text { slightly } & \text { unsure } & \text { slightly } & \text { moderately } & \text { strongl } \\ \text { disagree } & \text { disagree } & \text { disagree } & & \text { agree } & \text { Agree } & \text { Agree }\end{array}$

8. I have occasionally communicated with my pet and understood what it was trying to express.

$\begin{array}{lllllll}1 & 2 & 3 & 4 & 5 & 6 & 7 \\ \text { strongly } & \text { moderately } & \text { slightly } & \text { unsure } & \text { slightly } & \text { moderately } & \text { strongl } \\ \text { disagree } & \text { disagree } & \text { disagree } & & \text { agree } & \text { Agree } & \text { Agree }\end{array}$

9. The world would be a better place if people would stop spending so much time caring for their pet and started caring more for other human beings instead.

$\begin{array}{lllllll}1 & 2 & 3 & 4 & 5 & 6 & 7 \\ \text { strongly } & \text { moderately } & \text { slightly } & \text { unsure } & \text { slightly } & \text { moderately } & \text { strongl } \\ \text { disagree } & \text { disagree } & \text { disagree } & & \text { agree } & \text { Agree } & \text { Agree }\end{array}$

10. I like to feed animals out of my hand.

$\begin{array}{lllllll}1 & 2 & 3 & 4 & 5 & 6 & 7 \\ \text { strongly } & \text { moderately } & \text { slightly } & \text { unsure } & \text { slightly } & \text { moderately } & \text { strongl } \\ \text { disagree } & \text { disagree } & \text { disagree } & & \text { agree } & \text { Agree } & \text { Agree }\end{array}$

11. I love pets.

$\begin{array}{lllllll}1 & 2 & 3 & 4 & 5 & 6 & 7 \\ \text { strongly } & \text { moderately } & \text { slightly } & \text { unsure } & \text { slightly } & \text { moderately } & \text { strongl } \\ \text { disagree } & \text { disagree } & \text { disagree } & & \text { agree } & \text { Agree } & \text { Agree }\end{array}$

12. Animals belong in the wild or in zoos, but not in the home.

$\begin{array}{lllllll}1 & 2 & 3 & 4 & 5 & 6 & 7 \\ \text { strongly } & \text { moderately } & \text { slightly } & \text { unsure } & \text { slightly } & \text { moderately } & \text { strongl } \\ \text { disagree } & \text { disagree } & \text { disagree } & & \text { agree } & \text { Agree } & \text { Agree }\end{array}$

13. If you keep pets in the house you can expect a lot of damage to the furniture.

$\begin{array}{lllllll}1 & 2 & 3 & 4 & 5 & 6 & 7 \\ \text { strongly } & \text { moderately } & \text { slightly } & \text { unsure } & \text { slightly } & \text { moderately } & \text { strongl } \\ \text { disagree } & \text { disagree } & \text { disagree } & & \text { agree } & \text { Agree } & \text { Agree }\end{array}$


14. I like housepets.

$\begin{array}{lllllll}1 & 2 & 3 & 4 & 5 & 6 & 7 \\ \text { strongly } & \text { moderately } & \text { slightly } & \text { unsure } & \text { slightly } & \text { moderately } & \text { strongl } \\ \text { disagree } & \text { disagree } & \text { disagree } & & \text { agree } & \text { Agree } & \text { Agree }\end{array}$

15. Pets are fun but it's not worth the trouble of owning one.

$\begin{array}{lllllll}1 & 2 & 3 & 4 & 5 & 6 & 7 \\ \text { strongly } & \text { moderately } & \text { slightly } & \text { unsure } & \text { slightly } & \text { moderately } & \text { strongl } \\ \text { disagree } & \text { disagree } & \text { disagree } & & \text { agree } & \text { Agree } & \text { Agree }\end{array}$

16. I frequently talk to my pet.

$\begin{array}{lllllll}1 & 2 & 3 & 4 & 5 & 6 & 7 \\ \text { strongly } & \text { moderately } & \text { slightly } & \text { unsure } & \text { slightly } & \text { moderately } & \text { strongl } \\ \text { disagree } & \text { disagree } & \text { disagree } & & \text { agree } & \text { Agree } & \text { Agree }\end{array}$

17. I hate animals.

$\begin{array}{lllllll}1 & 2 & 3 & 4 & 5 & 6 & 7 \\ \text { strongly } & \text { moderately } & \text { slightly } & \text { unsure } & \text { slightly } & \text { moderately } & \text { strongl } \\ \text { disagree } & \text { disagree } & \text { disagree } & & \text { agree } & \text { Agree } & \text { Agree }\end{array}$

18. You should treat your housepets with as much respect as you would a human of your family.

$\begin{array}{lllllll}1 & 2 & 3 & 4 & 5 & 6 & 7 \\ \text { strongly } & \text { moderately } & \text { slightly } & \text { unsure } & \text { slightly } & \text { moderately } & \text { strongl } \\ \text { disagree } & \text { disagree } & \text { disagree } & & \text { agree } & \text { Agree } & \text { Agree }\end{array}$




\section{$\underline{\text { Pet Anthropomorphism }}$}

For the next task, please think about your closest pet. With respect to this pet, please consider each of the attributes listed below and report the extent to which each is true of your closest pet based on the 9-point scale provided.

$\begin{array}{cccccccc}1 & 2 & 3 & 4 & 5 & 6 & 7 & 8 \\ \text { Not at all true } & & & & & & \\ \text { Completely true }\end{array}$

1) Your closest pet is thoughtful.

2) Your closest pet is sympathetic.

3) Your closest pet is considerate. 


\section{Interpersonal Supportive Evaluation List (ISEL)}

Instructions:

This scale is made up of a list of statements each of which may or may not be true about you. For each statement we would like you to circle probably TRUE (PT) if the statement is true about you or probably false (PF) if the statement if not true about you.

You may find that many of the statements are neither clearly true nor clearly false. In these cases, try to decide quickly whether probably true or probably false is most descriptive of you. Although some questions will be difficult to answer, it is important that you pick one alternative or the other. Remember to circle only one for each statement.

Please read each item quickly but carefully before responding. Remember that this is not a test and there are no right or wrong answers.

\begin{tabular}{|c|c|c|}
\hline 1. I know someone who would loan me $\$ 50$ so I could go away for the weekend. & PT & $\mathrm{PF}$ \\
\hline $\begin{array}{l}\text { 2. I know someone who would give me some old dishes if I moved into my own } \\
\text { apartment. }\end{array}$ & $\mathrm{PT}$ & $\mathrm{PF}$ \\
\hline 3. I know someone who would loan me $\$ 100$ to help pay my tuition. & PT & $\mathrm{PF}$ \\
\hline $\begin{array}{l}\text { 4. If I needed it, my family would provide me with an allowance and spending } \\
\text { money. }\end{array}$ & PT & $\mathrm{PF}$ \\
\hline $\begin{array}{l}\text { 5. If I wanted a date for a party next weekend, I know someone at school or in town } \\
\text { who would fix me up. }\end{array}$ & PT & $\mathrm{PF}$ \\
\hline $\begin{array}{l}\text { 6. I know someone at school or in town who would bring my meals to my room or } \\
\text { apartment if I were sick. }\end{array}$ & PT & $\mathrm{PF}$ \\
\hline $\begin{array}{l}\text { 7. I don't know anyone who would loan me several hundred dollars to pay a doctor } \\
\text { bill or dental bill. }\end{array}$ & PT & $\mathrm{PF}$ \\
\hline $\begin{array}{l}\text { 8. I don't know anyone who would give me some old furniture if I moved into my } \\
\text { own apartment. }\end{array}$ & PT & $\mathrm{PF}$ \\
\hline $\begin{array}{l}\text { 9. Even if I needed it } m \text { family would (or could) not give me money for tuition and } \\
\text { books. }\end{array}$ & PT & $\mathrm{PF}$ \\
\hline $\begin{array}{l}\text { 10. I don't know anyone at school or in town who would help me study for an exam } \\
\text { by spending several hours reading me questions. }\end{array}$ & PT & $\mathrm{PF}$ \\
\hline $\begin{array}{l}\text { 11. I don't know anyone at school or in town who would loan me their car for a } \\
\text { couple of hours. }\end{array}$ & PT & $\mathrm{PF}$ \\
\hline $\begin{array}{l}\text { 12. I don't know anyone at school or in town who would get assignments for me } \\
\text { from my teachers if I was sick. }\end{array}$ & PT & $\mathrm{PF}$ \\
\hline $\begin{array}{l}\text { 13. There are people at school or in town who I regularly run with, exercise with, or } \\
\text { play sports with. }\end{array}$ & PT & $\mathrm{PF}$ \\
\hline 14. I hang out in a friend's room or apartment quite a lot. & $\mathrm{PT}$ & $\mathrm{PF}$ \\
\hline
\end{tabular}




\begin{tabular}{|c|c|c|}
\hline 15. I can get a date who I enjoy spending time with whenever I want. & PT & $\mathrm{PF}$ \\
\hline $\begin{array}{l}\text { 16. If I decided at dinner time to take a study break this evening and go to a movie, I } \\
\text { could easily find someone to go with me. }\end{array}$ & PT & $\mathrm{PF}$ \\
\hline 17. People hang out in my room or apartment during the day or in the evening. & PT & $\mathrm{PF}$ \\
\hline $\begin{array}{l}\text { 18. I belong to a group at school or in town that meets regularly or does things } \\
\text { together regularly. }\end{array}$ & PT & $\mathrm{PF}$ \\
\hline $\begin{array}{l}\text { 19. I am not a member of any social groups (such as church groups, clubs, teams, } \\
\text { etc.) }\end{array}$ & PT & $\mathrm{PF}$ \\
\hline 20. Lately, I often feel lonely, like I don't have anyone to reach out to. & PT & $\mathrm{PF}$ \\
\hline $\begin{array}{l}\text { 21. I don't have friends at school or in town who would comfort me by showing } \\
\text { some physical affection. }\end{array}$ & PT & $\mathrm{PF}$ \\
\hline 22. I don't often get invited to do things with other people. & PT & $\mathrm{PF}$ \\
\hline 23. I don't talk to a member of my family at least once a week. & PT & $\mathrm{PF}$ \\
\hline 24. I don't usually spend two evenings on the weekend doing something with others. & PT & $\mathrm{PF}$ \\
\hline $\begin{array}{l}\text { 25. I know someone who I see or talk to often with whom I would feel perfectly } \\
\text { comfortable talking about problems I might have budgeting my time between school } \\
\text { and my social life. }\end{array}$ & PT & $\mathrm{PF}$ \\
\hline $\begin{array}{l}\text { 26. I know someone who I see or talk to often with whom I would feel perfectly } \\
\text { comfortable talking about any problems I might have adjusting to college life. }\end{array}$ & PT & $\mathrm{PF}$ \\
\hline $\begin{array}{l}\text { 27. I know someone who I see or talk to often with whom I would feel perfectly } \\
\text { comfortable talking about sexually transmitted diseases. }\end{array}$ & PT & $\mathrm{PF}$ \\
\hline $\begin{array}{l}\text { 28. I know someone who I see or talk to often with whom I would feel perfectly } \\
\text { comfortable talking about any problems I might have meeting people. }\end{array}$ & PT & $\mathrm{PF}$ \\
\hline $\begin{array}{l}\text { 29. I know someone who I see or talk to often with whom I would feel perfectly } \\
\text { comfortable discussing any sexual problems I might have. }\end{array}$ & PT & $\mathrm{PF}$ \\
\hline $\begin{array}{l}\text { 30. I know someone who I see or talk to often with whom I would feel perfectly } \\
\text { comfortable talking about any problems I might have with drugs. }\end{array}$ & PT & $\mathrm{PF}$ \\
\hline $\begin{array}{l}\text { 31. There isn't anyone at school or in town with whom I would feel perfectly } \\
\text { comfortable talking about any problems I might have with making friends. }\end{array}$ & PT & $\mathrm{PF}$ \\
\hline $\begin{array}{l}\text { 32. There isn't anyone at school or in town with whom I would feel perfectly } \\
\text { comfortable talking about any problems I might have getting along with my parents. }\end{array}$ & PT & $\mathrm{PF}$ \\
\hline $\begin{array}{l}\text { 33. There isn't anyone at school or in town with whom I would feel perfectly } \\
\text { comfortable talking about difficulties with my social life. }\end{array}$ & PT & $\mathrm{PF}$ \\
\hline $\begin{array}{l}\text { 34. There isn't anyone at school or in town with whom I would feel perfectly } \\
\text { comfortable talking about my feelings of loneliness and depression. }\end{array}$ & PT & $\mathrm{PF}$ \\
\hline $\begin{array}{l}\text { 35. I don't know anyone at school or in town who makes my problems clearer and } \\
\text { easier to understand. }\end{array}$ & PT & $\mathrm{PF}$ \\
\hline 36. Lately, when I've been troubled, I keep things to myself. & PT & $\mathrm{PF}$ \\
\hline
\end{tabular}




\begin{tabular}{|l|l|l|}
\hline 37. Most people who know me well think highly of me. & PT & PF \\
\hline 38. Most of my friends think that I'm smart. & PT & PF \\
\hline 39. Most of my friends don't do as well as I do in school. & PT & PF \\
\hline 40. I will have a better future than most other people will. & PT & PF \\
\hline 41. Most of my friends have not adjusted to college as easily as I have. & PT PF \\
\hline $\begin{array}{l}\text { 42. Most people think I have a good sense of humor. } \\
\text { 43. I don't feel friendly with any teaching assistants, professors, campus or student } \\
\text { officials. }\end{array}$ & PT & PF \\
\hline 44. Most of my friends are more satisfied or happier with themselves than I am. & PT & PF \\
\hline 45. Most of my friends are more popular than I am. & PT & PF \\
\hline 46. Most of my friends are more interesting than I am. & PT & PF \\
\hline 47. Most of my friends have more control over what happens to them than I. & PT & PF \\
\hline 48. Most people are more attractive than I am. & PT & PF \\
\hline
\end{tabular}




\section{$\underline{\text { Animal-Human Continuity Scale (AHCS) }}$}

Directions: Please answer each of the following questions as honestly as you can. Use the scale provided below. Choose only one answer and put the number on the line next to the question.

$\begin{array}{ccccccc}1 & 2 & 3 & 4 & 5 & 6 & 7 \\ \text { Strongly } & \text { Moderately } & \text { Slightly } & \text { Unsure } & \text { Slightly } & \text { Moderately } & \text { Strongly } \\ \text { Disagree } & \text { Disagree } & \text { Disagree } & & \text { Agree } & \text { Agree } & \text { Agree }\end{array}$

1. Humans have a soul but animals do not.

2. Humans can think but animals cannot.

3. People have a life after death but animals do not.

4. People are animals

5. Animals are afraid of death.

6. People evolved from lower animals.

7. People are superior to animals.

8. Animals can fall in love.

9. People have a spiritual nature but animals do not.

10. The needs of people should always come before the needs of animals.

11. It's okay to use animals to carry out tasks for humans.

12. It's crazy to think of an animal as a member of your family. 
Appendix F - Social Phobia and Stress Measures

\section{$\underline{\text { Social Phobia Inventory (SPIN) }}$}

Please indicate how much the following problems have bothered you during the past week. Mark only one box for each problem, and be sure to answer all items.

$0=$ Not at all $\quad 1=$ A little bit $\quad 2=$ Somewhat $\quad 3=$ Very much $\quad 4=$ Extremely

1. I am afraid of people in authority

2. I am bother by blushing in front of people

3. Parties and social events scare me

4. I avoid talking to people I don't know

5. Being criticized scares me a lot

6. Fear of embarrassment causes me to avoid doing things or speaking to people

7. Sweating in front of people causes me distress

8. I avoid going to parties

9. I avoid activities in which I am the centre of attention

10. Talking to strangers scares me

11. I avoid having to give speeches

12. I would do anything to avoid being criticized

13. Heart palpitations bother me when I am around people

14. I am afraid of doing things when people might be watching

15. Being embarrassed or looking stupid is among my worst fears

16. I avoid speaking to anyone in authority

17. Trembling or shaking in front of others is distressing to me 


\section{$\underline{\text { Perceived Stress Scale (PSS) }}$}

The questions in this scale ask you about your feelings and thoughts during the last month. In each case, you will be asked to indicate by circling how often you felt or thought a certain way.

\begin{tabular}{|c|c|c|c|c|}
\hline 0 - Never & $\begin{array}{c}1-\text { Almost } \\
\text { Never }\end{array}$ & 2 - Sometimes & $\begin{array}{c}\text { 3- Fairly } \\
\text { Often }\end{array}$ & 4 - Very Often \\
\hline
\end{tabular}

\begin{tabular}{|c|c|c|c|c|c|}
\hline $\begin{array}{l}\text { I. In the last month, how often have you been upset because of } \\
\text { something that happened unexpectedly }\end{array}$ & 0 & 1 & 2 & 3 & 4 \\
\hline $\begin{array}{l}\text { 2. In the last month, how often have you felt that you were unable to } \\
\text { control the important things in your life }\end{array}$ & 0 & 1 & 2 & 3 & 4 \\
\hline nd "stressed" & 0 & 1 & 2 & 3 & 4 \\
\hline $\begin{array}{l}\text { 4. In the last month, how often have you felt confident about your ability } \\
\text { to handle your personal problems }\end{array}$ & 0 & 1 & 2 & 3 & 4 \\
\hline $\begin{array}{l}\text { 5. In the last month, how often have you felt that things were going your } \\
\text { way }\end{array}$ & 0 & 1 & 2 & 3 & 4 \\
\hline $\begin{array}{l}\text { 6. In the last month, how often have you found that you could not cope } \\
\text { with all the things that you had to do }\end{array}$ & 0 & 1 & 2 & 3 & 4 \\
\hline $\begin{array}{l}\text { 7. In the last month, how often have you been able to control irritations } \\
\text { in your life }\end{array}$ & 0 & 1 & 2 & 3 & 4 \\
\hline $\begin{array}{l}\text { 8. In the last month, how often have you felt that you were on top of } \\
\text { things }\end{array}$ & 0 & 1 & 2 & 3 & 4 \\
\hline $\begin{array}{l}\text { 9. In the last month, how often have you been angered because of things } \\
\text { that were outside of your control }\end{array}$ & 0 & 1 & 2 & 3 & 4 \\
\hline $\begin{array}{l}\text { 10. In the last month, how often have you felt difficulties were piling up } \\
\text { so high that you could not overcome them }\end{array}$ & 0 & 1 & 2 & 3 & 4 \\
\hline
\end{tabular}




\section{Appendix G - Pre- and Post-Challenge Symptom Measures}

$\underline{\text { Visual Analogue Scale (VAS) }}$

On this scale, 0 means no anxiety, not at all, and 100 means extreme anxiety, the worst ever. Please rate your current level of anxiety by making a mark on the line below:

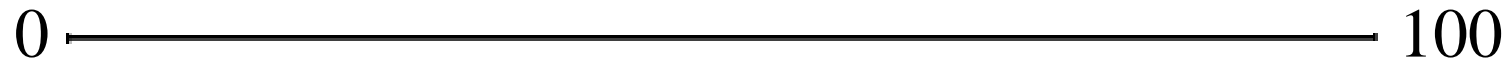


On this scale, 0 means no stress, not at all, and 100 means extreme stress, the worst ever. Please rate your current level of stress by making a mark on the line below:

0

0 
On this scale, 0 means no happiness, not at all, and 100 means extreme happiness, the best ever. Please rate your current level of happiness by making a mark on the line below:

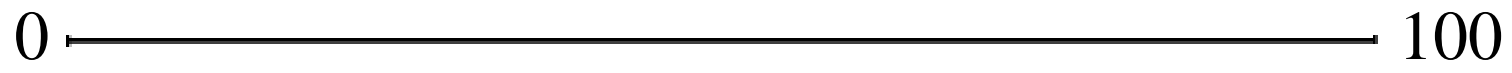


On this scale, 0 means no relaxation, not at all, and 100 means extreme relaxation, the best ever. Please rate your current level of relaxation by making a mark on the line below:

$0 \longrightarrow 100$ 


\section{$\underline{\text { Acute Panic Inventory (API) }}$}

Please use the following rating scale to complete each item as you feel now:

not at all (0), slight (1), moderate (2), or severe (3).

1. Do you feel faint?

2. Are you afraid of dying?

3. Are you generally fearful?

4. Do you have heart palpitations?

5. Do you have any difficulty in breathing, or are you breathing rapidly?

6. Do you have the urge to urinate?

7. Do you have the urge to defecate?

8. Do you feel dizzy or light-headed?

9. Do you feel confused?

10. Do you have a sense of unreality?

11. Do you feel detached from part or all of your body?

12. Is it difficult for you to concentrate?

13. Are you sweating?

14. Is it difficult for you to speak?

15. Would it be difficult for you to do a job?

16. Do you feel any shakiness, trembling, or twitching?

17. Do you feel nauseous? 
$\underline{\text { Panic Symptom Inventory (PSI) }}$

INSTRUCTIONS: Please put a tick in the column that best describes the feelings that you have at this moment. If you are unclear about the meaning of any of the terms, please just ask.

\begin{tabular}{|c|c|c|c|c|c|c|}
\hline QU. & & Not AT ALL & SLIGHT & MODERATE & SEVERE & VERY SEVERE \\
\hline 1 & Muscle pain & & & & & \\
\hline 2 & Weakness & & & & & \\
\hline 3 & Sweating & & & & & \\
\hline 4 & Going mad & & & & & \\
\hline 5 & Tremor & & & & & \\
\hline 6 & Drowsiness & & & & & \\
\hline 7 & $\begin{array}{l}\text { Numbness of fingers } \\
\text { or toes }\end{array}$ & & & & & \\
\hline 8 & Dry mouth & & & & & \\
\hline 9 & Feelings of unreality & & & & & \\
\hline 10 & $\begin{array}{l}\text { Churning of stomach / } \\
\text { butterflies }\end{array}$ & & & & & \\
\hline 11 & Heart racing & & & & & \\
\hline 12 & Nausea & & & & & \\
\hline 13 & Unhappiness & & & & & \\
\hline 14 & Shakiness & & & & & \\
\hline 15 & Fear of loss of control & & & & & \\
\hline 16 & Anxiety & & & & & \\
\hline 17 & Choking & & & & & \\
\hline 18 & Headache & & & & & \\
\hline 19 & Fear of dying & & & & & \\
\hline 20 & Heart pounding & & & & & \\
\hline 21 & Faintness & & & & & \\
\hline 22 & Tension & & & & & \\
\hline 23 & Tingling & & & & & \\
\hline 24 & Pins and needles & & & & & \\
\hline 25 & $\begin{array}{l}\text { Coldness of hands or } \\
\text { feet }\end{array}$ & & & & & \\
\hline 26 & Dizziness & & & & & \\
\hline 27 & Tight muscles & & & & & \\
\hline 28 & Tearful / sad & & & & & \\
\hline 29 & Breathlessness & & & & & \\
\hline 30 & Heavy headed & & & & & \\
\hline 31 & Legs wobbly & & & & & \\
\hline 32 & Apprehension / fear & & & & & \\
\hline 33 & Discomfort in chest & & & & & \\
\hline 34 & Hot or cold all over & & & & & \\
\hline 35 & Other (please specify) & & & & & \\
\hline
\end{tabular}




\section{Appendix H - Visual Representation Measure}

Visual Representation Perceptive

1. What picture was displayed on the computer screen?

2. How did the picture make you feel?

$\begin{array}{lllllll}1 & 2 & 3 & 4 & 5 & 6 & 7 \\ \text { completely } & \text { moderately } & \text { slightly } & \text { neutral } & \begin{array}{l}\text { slightly } \\ \text { relaxed }\end{array} & \begin{array}{l}\text { moderately } \\ \text { relaxed }\end{array} & \begin{array}{l}\text { completely } \\ \text { Relaxed }\end{array}\end{array}$


Appendix I - Debriefing Forms

Debriefing form (for Community participants)

\section{RYERSON UNIVERSITY}

\section{Debrief Form}

\section{Title of Study: Pet Ownership and Stress}

Thank you very much for participating in our study. Your contributions to this research are extremely valuable.

In this study, we are investigating the topic of stress and how thinking about one's pet can alleviate stress. Stress is a normal part of life and at times can be advantageous; however, stress can pose a serious threat to our physical and emotional health. Research that delineates ways to help alleviate stress is thus important for the wellbeing of society. This study can help provide a biological assessment of stress which can enhance the ability to handle stress.

You first completed questionnaires regarding your attitudes towards your relationship with your pet(s), followed by measures regarding your emotions surrounding stress. You then completed a method in which the researcher induced stress in a laboratory setting (mental arithmetic task). The stress induction method was a mental arithmetic task in which you completed a calculation task. In the stress method, a picture was displayed on the computer screen. Following the stress-induction method, you completed sets of questionnaires regarding your emotions after each stress test.

In this study, the independent variable of interest was the visual representation (picture) groups. There are various visual representation groups such as: a picture of a personal pet, an unfamiliar animal (i.e., picture of an unknown dog), a supportive important person (i.e., a picture of a family member, significant other or friend), an unfamiliar person (i.e., picture of a stranger), a pleasant image (i.e., sunset) or no image. The outcome or dependent variable was the response to the mental arithmetic task, the physiological and psychological responses to the stressor. It is hypothesized that the picture of a personal pet would be the most effective at reducing stress, followed by the picture of supportive important person. Your participation in this study will help us to better understand the relationship between the different types of social support as a buffer for stress.

Approximately 120 participants will complete this study. This study is available to individuals from the Greater Toronto Area community. If you would like your data to be withdrawn from the study, please be aware that you have the option to do so now without any consequences or penalties. Please note that this is a research study only, and any findings will contribute to a better understanding of stress. This area of 
research is relatively novel, and the data you have provided will begin to point us in the right direction for investigation.

Once again, we would like to thank you very much for your participation. If you are interested in further information, you are encouraged to take a look at the references provided on the next page. Finally, if you have any further questions or concerns pertaining to this research, feel free to contact the primary investigator at:

\section{Natalie Ein \\ 416-979-5000 ext 4985 \\ nein@psych.ryerson.ca}

Additionally, you may contact the primary investigator's research supervisors:

Dr. Marilyn Hadad

416-979-5000 ext 7109 mhadad@ryerson.ca
Dr. Kristin Vickers

or 416-979-5000 ext 7727 kvickers@ryerson.ca

\section{References}

Allen, K., Blascovich, J., \& Mendes, W. B. (2002). Cardiovascular reactivity in the presence of pets, friends, and spouses: The truth about cats and dogs.

Psychosomatic Medicine, 64(5), 727-739.

doi:10.1097/01.PSY.0000024236.11538.4

Allen, K., Shykoff, B. E., \& Izzo, J. L., Jr. (2001). Pet ownership, but not ACE inhibitor therapy, blunts home blood pressure response to mental stress. Hypertension, 38, 815-820. Retrieved from http://hyper. ahajournals.org/content/38/4/815.full

Wells, D. L. (2005). The effect of videotapes of animals on cardiovascular response to stress. Stress and Health: Journal of the International Society for the Investigation of Stress, 21(3), 209-213. doi:10.1002/smi.1057

If you would like to know more about this line of research, the following journal articles are available for free via the Ryerson library, or please email Natalie Ein to have the journal articles sent to you. 


\section{CRISIS LINE SERVICES}

In a crisis, call 911. Other emergency numbers are listed at the front of the phone book.

\begin{tabular}{|c|c|}
\hline $\begin{array}{l}\text { Distress Centres of Toronto - Immediate } \\
\text { emotional support, crisis intervention, and suicide } \\
\text { prevention over the phone. Open } 24 \text { hours, } 7 \text { days } \\
\text { a week. www.torontodistresscentre.com } \\
\text { (416) } 408-4357\end{array}$ & $\begin{array}{l}\text { Emergencies CAMH (Centre for Addiction and } \\
\text { Mental Health) } \\
416535-8501 \text { ext. } 6885 \text { ( } 24 \text { hour service) }\end{array}$ \\
\hline $\begin{array}{l}\text { The Gerstein Crisis Centre } \\
416-929-5200\end{array}$ & $\begin{array}{l}\text { Victim Support Line - Ontario referral service that } \\
\text { connects victims of crimes to community services. } \\
1-888-579-2888\end{array}$ \\
\hline $\begin{array}{l}\text { Aboriginal Crisis Centre } \\
416-531-0330\end{array}$ & $\begin{array}{l}\text { Addiction Research Foundation Info Line } \\
416-595-6111\end{array}$ \\
\hline $\begin{array}{l}310 \text { Cope (York Region, Richmond Hill and } \\
\text { Newmarket) - Community Crisis Response } \\
\text { Centre, Distress Centre } \\
905-310-2673\end{array}$ & $\begin{array}{l}\text { Telehealth Ontario } \\
1-866-797-0007\end{array}$ \\
\hline $\begin{array}{l}\text { Durham Region } \\
1-800-742-1890\end{array}$ & $\begin{array}{l}\text { MARS (Metro Addiction Referral Service) } \\
416-599-1448\end{array}$ \\
\hline \multirow{2}{*}{$\begin{array}{l}\text { Assaulted Women's Helpline - An anonymous and } \\
\text { confidential crisis line for abused and assaulted } \\
\text { women in Ontario. They provide crisis counseling, } \\
\text { emotional support, safety plans and referrals (e.g. for } \\
\text { shelters, rape crisis centers, housing, legal services), } \\
\text { and interpretation services. } \\
\text { 1-866-863-051 }\end{array}$} & $\begin{array}{l}\text { Lesbian, Gay, Bi Youth Hotline - A provincial } \\
\text { hotline for gay, lesbian, bisexual, transexual, } \\
\text { transgendered, two-spirited and unsure youth. } \\
1-800-268-9688\end{array}$ \\
\hline & $\begin{array}{l}\text { National Eating Disorders Information } \\
\text { Centre (NEDIC) help hotline for eating } \\
\text { disorders } \\
\text { toll free: } 1-866-633-4220 \\
\text { Toronto: } 416-340-4156 \\
\end{array}$ \\
\hline $\begin{array}{l}\text { Toronto Area of Narcotics Anonymous } \\
\text { toll free: } 1-888-811-3887\end{array}$ & $\begin{array}{l}\text { St. Michael's Hospital Toronto Downtown } \\
416-864-5346\end{array}$ \\
\hline
\end{tabular}

Useful web pages:

Canadian Mental Health Association

- Finding mental health services in Toronto: http://www.toronto.cmha.ca/ct $\mathrm{mh}$ services in TO/mh services in TO.asp

- Also see Information, Intake, and Referral Service for the CMHA clinic: http://www.toronto.cmha.ca/ct services we offer/intake $n$ referral.asp

Ontario Psychological Association

- Referral service, allows you to search registered psychologists in Ontario by specialty, theoretical orientation, location, etc.: http://www.psych.on.ca/split.asp?location=referral.asp

Psychlinks Directory of Health and Mental Health Resources

- http://directory.psychlinks.ca/ 
Debriefing form (for SONA participants)

\section{RYERSONUNIVERSITY}

\section{Debrief Form}

\section{Title of Study: Pet Ownership and Stress}

Thank you very much for participating in our study. Your contributions to this research are extremely valuable.

In this study, we are investigating the topic of stress and how thinking about one's pet can alleviate stress. Stress is a normal part of life and at times can be advantageous; however, stress can pose a serious threat to our physical and emotional health. Research that delineates ways to help alleviate stress is thus important for the wellbeing of society. This study can help provide a biological assessment of stress which can enhance the ability to handle stress.

You first completed questionnaires regarding your attitudes towards your relationship with your pet(s), followed by measures regarding your emotions surrounding stress. You then completed a method in which the researcher induced stress in a laboratory setting (mental arithmetic task). The stress induction method was a mental arithmetic task in which you completed a calculation task. In the stress method, a picture was displayed on the computer screen. Following the stress-induction method, you completed sets of questionnaires regarding your emotions after each stress test.

In this study, the independent variable of interest was the visual representation (picture) groups. There are various visual representation groups such as: a picture of a personal pet, an unfamiliar animal (i.e., picture of an unknown dog), a supportive important person (i.e., a picture of a family member, significant other or friend), an unfamiliar person (i.e., picture of a stranger), a pleasant image (i.e., sunset) or no image. The outcome or dependent variable was the response to the mental arithmetic task, the physiological and psychological responses to the stressor. It is hypothesized that the picture of a personal pet would be the most effective at reducing stress, followed by the picture of supportive important person. Your participation in this study will help us to better understand the relationship between the different types of social support as a buffer for stress.

Approximately 120 participants will complete this study. This study is available to undergraduates in Introductory Psychology at Ryerson University. Please note that this is a research study only, and any findings will contribute to a better understanding of stress. This area of research is relatively novel, and the data you have provided will begin to point us in the right direction for investigation. 
If you are an introductory Psychology student at Ryerson and are currently experiencing psychological distress and would like to discuss your concerns in a safe and confidential environment, the Ryerson Centre for Student Development and Counselling (CSDC) is a free resource located on campus. Staff provides support and guidance for a range of concerns including anxiety, low mood, and academic difficulties. The contact information for the CSDC is as follows:

Centre for Student Development and Counselling

Website: http://www.ryerson.ca/counselling/index.html

Email: csdc@ryerson.ca

Phone: 416-979-5195

Location: JOR-07C (Lower level of Jorgensen Hall, 380 Victoria Street)

The city of Toronto also offers a free telephone hotline available 24 hours a day. If you are extremely distressed, please call the Toronto Distress Centre:

416-408-HELP (4357)

Website: http://torontodistresscentre.com/

Once again, we would like to thank you very much for your participation. If you are interested in further information, you are encouraged to take a look at the references provided on the next page. Finally, if you have any further questions or concerns pertaining to this research, feel free to contact the primary investigator at:

Natalie Ein

416-979-5000 ext 4985

nein@psych.ryerson.ca

Additionally, you may contact the primary investigator's research supervisors:

Dr. Marilyn Hadad

416-979-5000 ext 7109

mhadad@ryerson.ca
Dr. Kristin Vickers

or 416-979-5000 ext 7727 kvickers@ryerson.ca

If you have questions regarding your participation using SONA, you may contact Psychology Research Pool at Ryerson University for information

Email: thepool@psych.ryerson.ca 
If you would like to know more about this line of research, the following journal articles are available for free via the Ryerson library, or please email Natalie Ein to have the journal articles sent to you.

Allen, K., Blascovich, J., \& Mendes, W. B. (2002). Cardiovascular reactivity in the presence of pets, friends, and spouses: The truth about cats and dogs.

Psychosomatic Medicine, 64(5), 727-739. doi:10.1097/01.PSY.0000024236.11538.4

Allen, K., Blascovich, J., Tomaka, J., \& Kelsey, R. M. (1991). Presence of human friends and pet dogs as moderators of autonomic responses to stress in women. Journal of Personality and Social Psychology, 61(4), 582-589. doi:10.1037/00223514.61.4.582

Allen, K., Shykoff, B. E., \& Izzo, J. L., Jr. (2001). Pet ownership, but not ACE inhibitor therapy, blunts home blood pressure response to mental stress. Hypertension, 38, 815-820. Retrieved from http://hyper.ahajournals.org/content/38/4/815.full

McConnell, A. R., Brown, C. M., Shoda, T. M., Stayton, L. E., \& Martin, C. E. (2011). Friends with benefits: On the positive consequences of pet ownership. Journal of Personality and Social Psychology, 101(6), 1239-1252. doi:10.1037/a0024506

Wells, D. L. (2005). The effect of videotapes of animals on cardiovascular response to stress. Stress and Health: Journal of the International Society for the Investigation of Stress, 21(3), 209-213. doi:10.1002/smi.1057 
Pleasant Image Condition

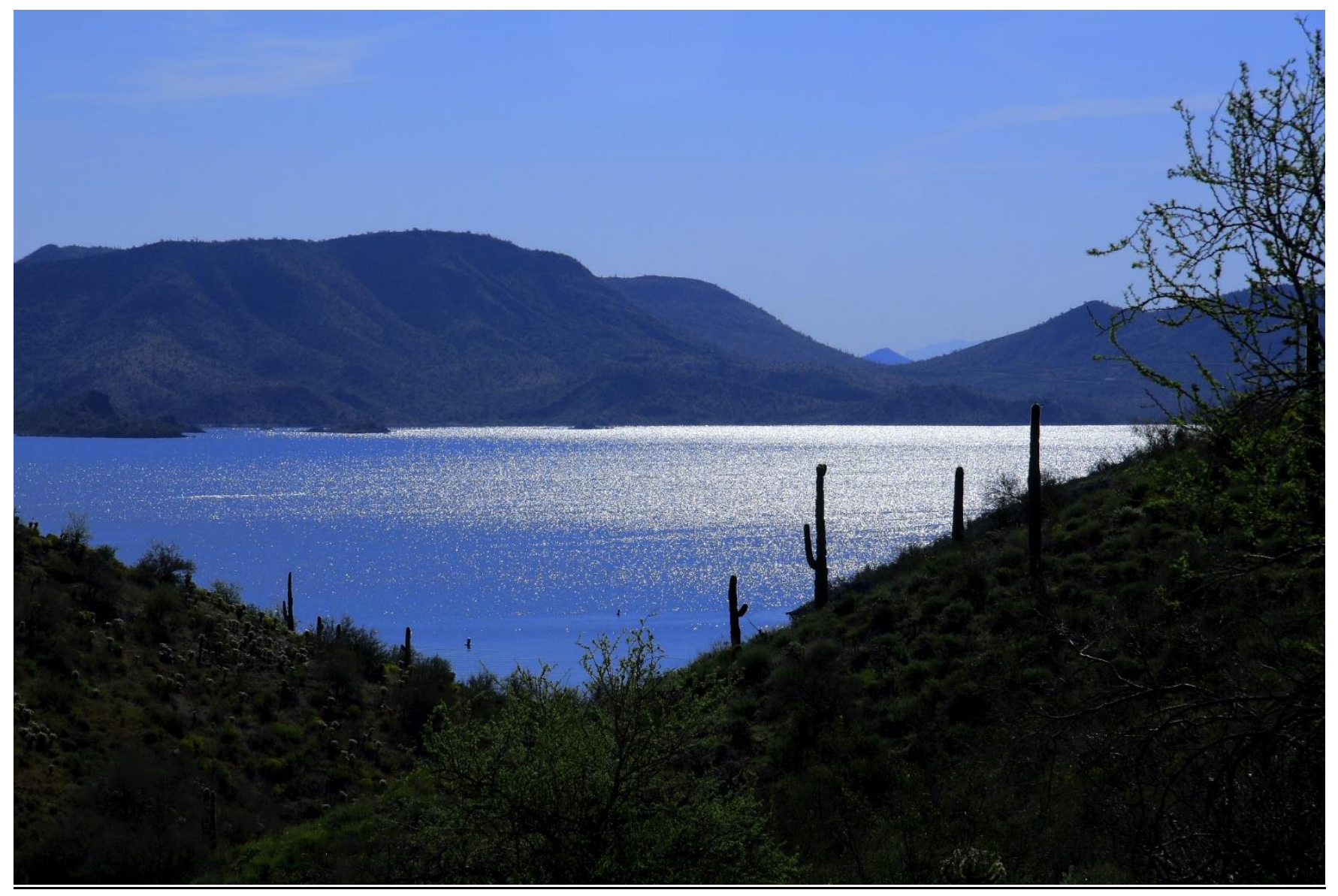


Unfamiliar Person Condition (for Male Participants)

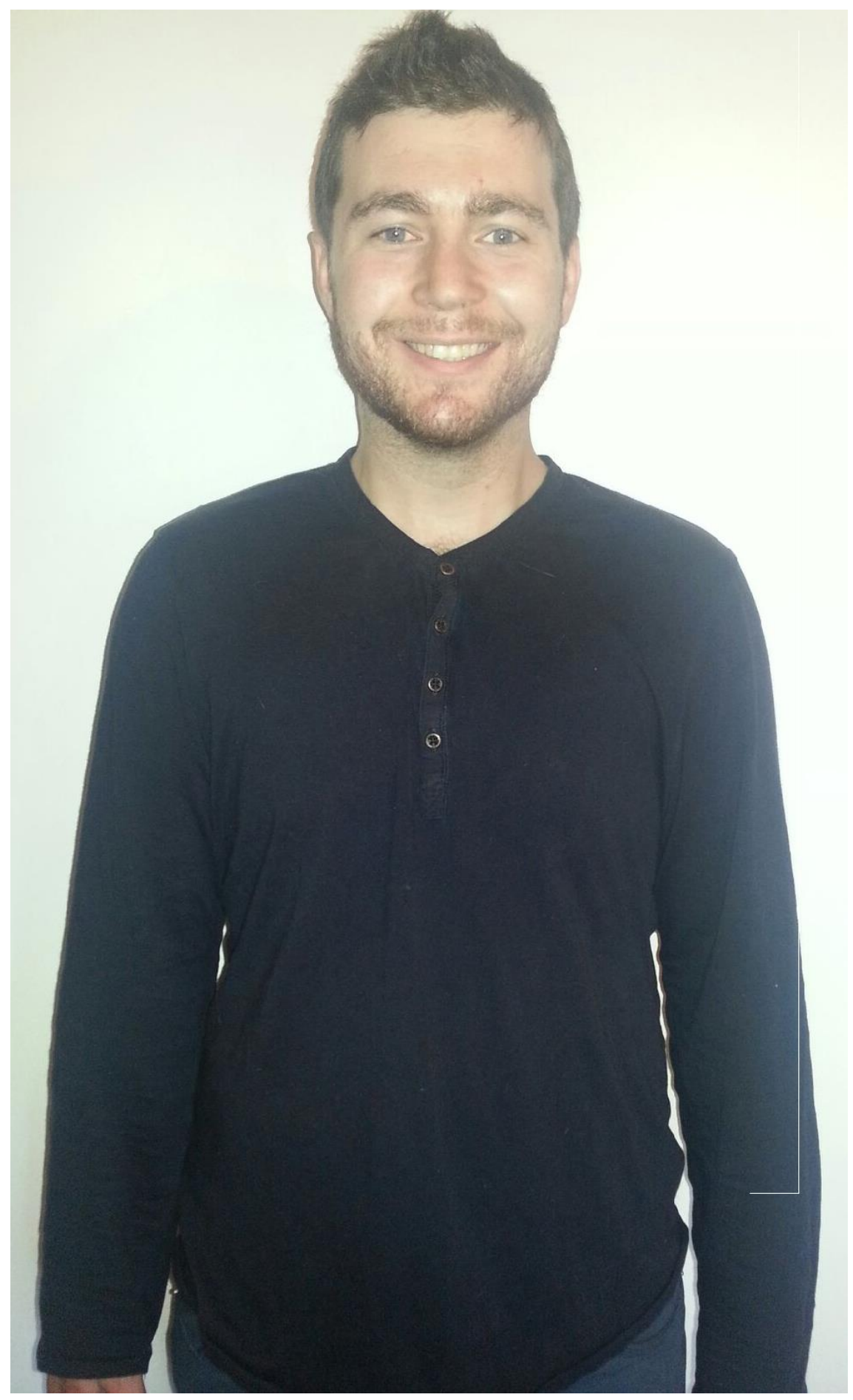


Unfamiliar Person Condition (for Female Participants)

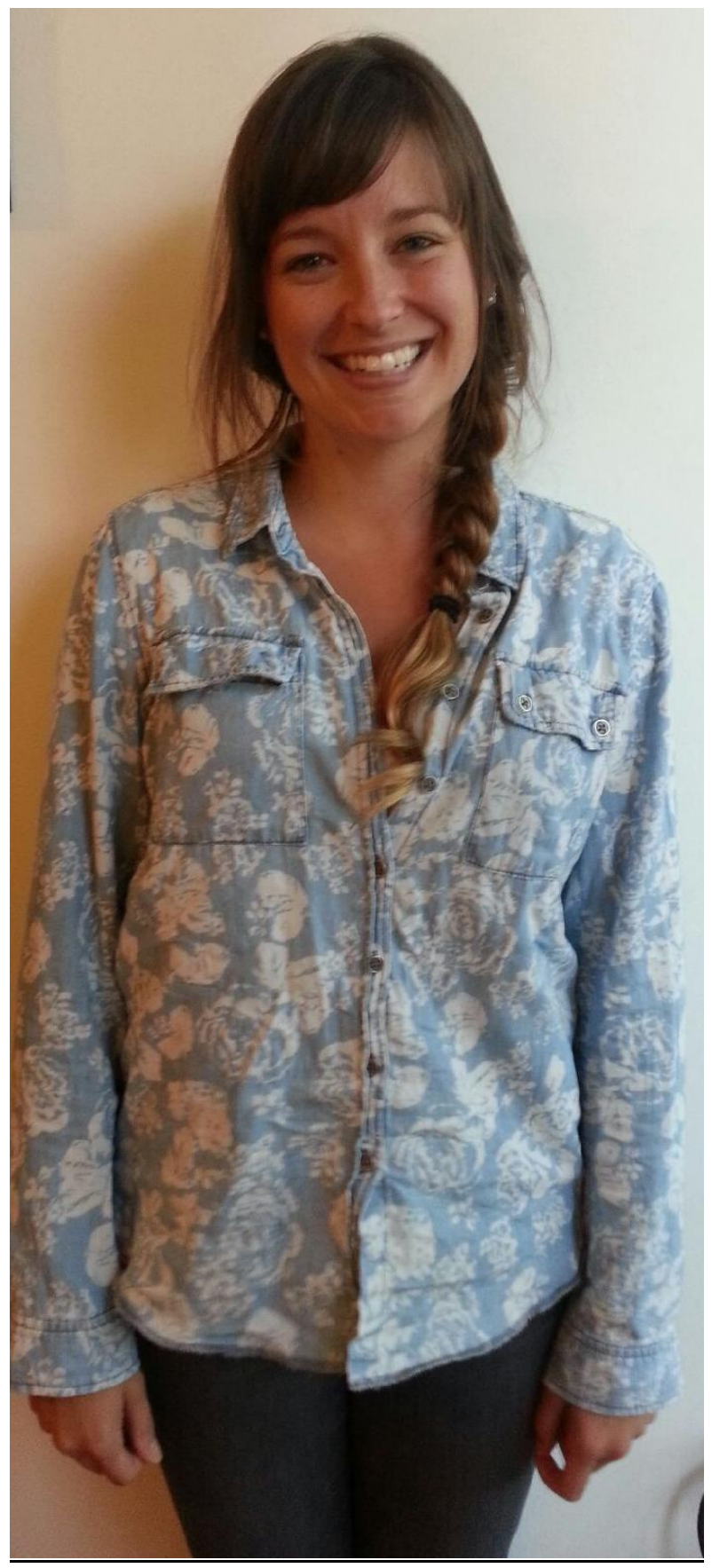


Unfamiliar Animal Condition (for Dog Owner Participants)

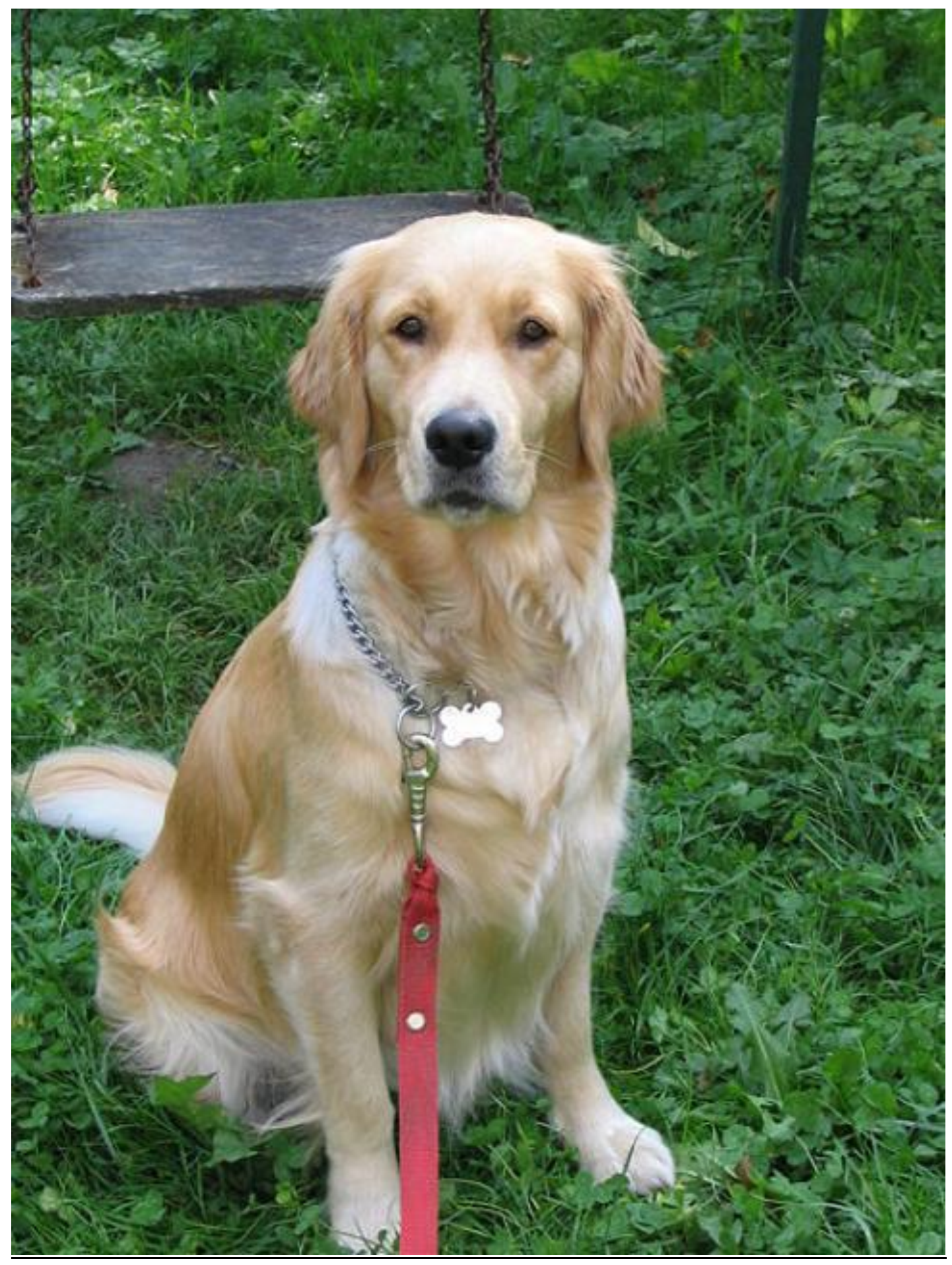


$\underline{\text { Unfamiliar Animal Condition (for Cat Owner Participants) }}$

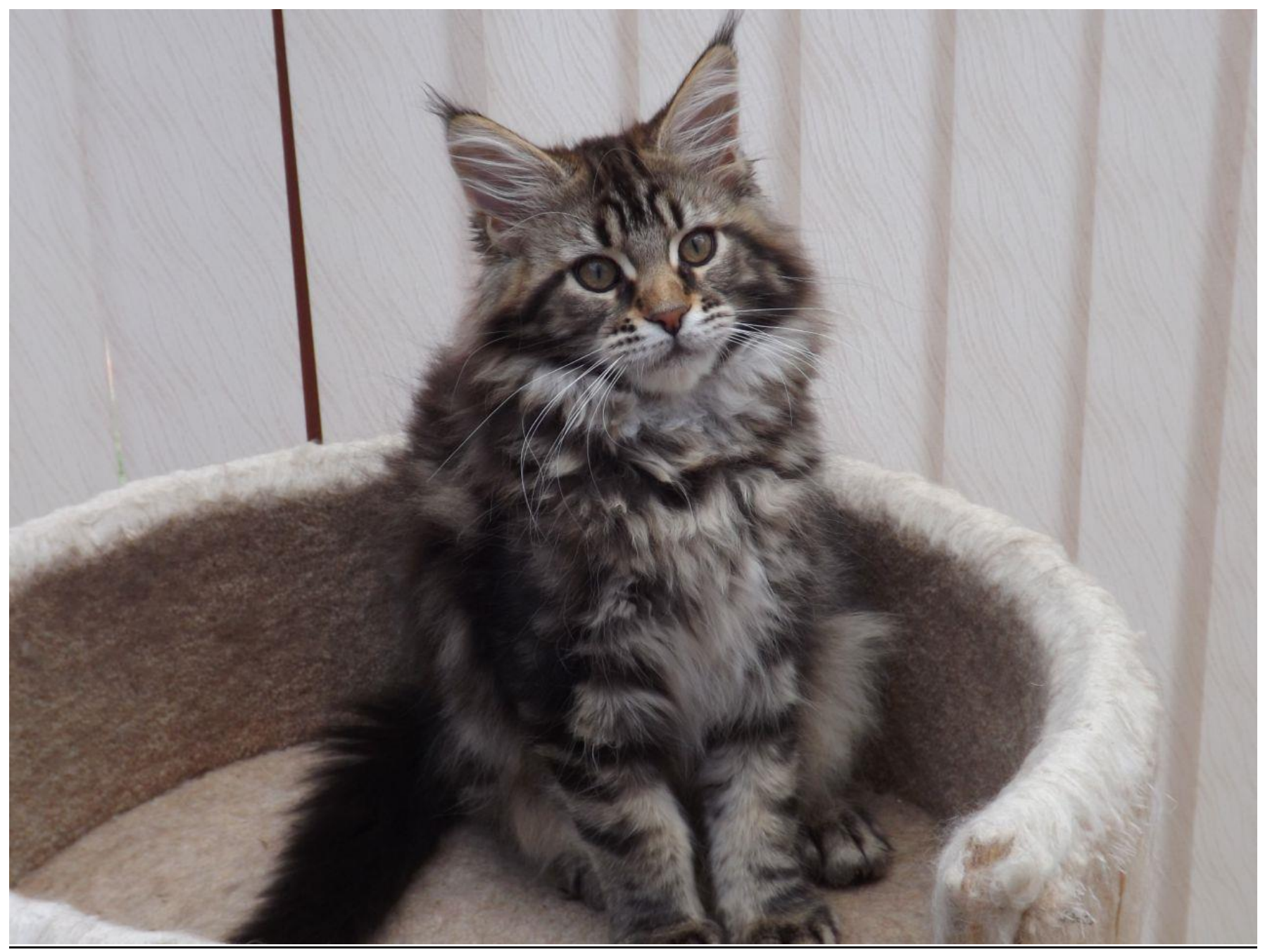




\section{References}

Adamle, K. N., Riley, T. A., \& Carlson, T. (2009). Evaluating college student interest in pet therapy. Journal of American College Health, 57(5), 545-548. doi:10.3200/JACH.57.5.545-548

Allen, K., Blascovich, J., \& Mendes, W. B. (2002). Cardiovascular reactivity in the presence of pets, friends, and spouses: The truth about cats and dogs. Psychosomatic Medicine, 64(5), 727-739. doi:10.1097/01.PSY.0000024236.11538.4

Allen, K., Blascovich, J., Tomaka, J., \& Kelsey, R. M. (1991). Presence of human friends and pet dogs as moderators of autonomic responses to stress in women. Journal of Personality and Social Psychology, 61(4), 582-589. doi:10.1037/0022-3514.61.4.582

Allen, K., Shykoff, B. E., \& Izzo, J. L., Jr. (2001). Pet ownership, but not ACE inhibitor therapy, blunts home blood pressure response to mental stress. Hypertension, 38, 815-820. Retrieved from http://hyper.ahajournals.org/content/38/4/815.full

Anderson, W. P., Reid, C. M., \& Jennings, G. L. (1992). Pet ownership and risk factors for cardiovascular disease. Medical Journal of Australia, 157(5), 298 -301. Retrieved from http://europepmc.org/abstract/MED/1435469/reload=0;jsessionid=sqgmnba170TkCh2BYJ gv.12

Barker, S. B., Knisely, J. S., McCain, N. L., Schubert, C. M., \& Pandurangi, A. K. (2010). Exploratory study of stress-buffering response patterns from interaction with a therapy dog. Anthrozoos, 23(1), 79-91. Retrieved from 
http://ezproxy.lib.ryerson.ca/login?url=http://search.proquest.com.ezproxy.lib.ryerson.ca/d ocview/622148710?accountid=13631

Batson, K., McCabe, B., Baun, M. M., \& Wilson, C. (1998). The effect of a therapy dog on socialization and physiological indicators of stress in persons diagnosed with Alzheimer's disease. In C. Wilson \& D. Turner (Eds.), Companion animals in human health (pp. 203215). Thousand Oaks, CA: Sage Publication Inc.

Baum, A. (1990). Stress, intrusive imagery, and chronic distress. Health Psychology, 9(6), 653675. doi:10.1037/0278-6133.9.6.653

Beukeboom, C. J., Langeveld, D., \& Tangja-Dijkstra, K. (2012). Stress-reducing effects of real and artificial nature in a hospital waiting room. The Journal of Alternative and Complementary Medicine, 18(4), 329-333. doi:10.1089/acm.2011.0488

Blonna, R. (2007). Coping with stress in a changing world (4 $4^{\text {th }}$ ed.). Boston, MA: McGraw-Hill.

Brown, J. L., Sheffield, D., Leary, M. R., \& Robinson, M. E. (2003). Social support and experimental pain. Psychosomatic Medicine, 65(2), 276-283.

doi:10.1097/01.PSY.0000030388.62434.46

Campbell, J. \& Ehlert, U. (2012). Acute psychosocial stress: Does the emotional stress response correspond with physiological responses? Psychoneuroendocrinology, 37(8), 1111-1134. doi:10.1016/j.psyneuen.2011.12.010 
Carter, M. M., Hollon, S. D., Carson, R., \& Shelton, R. C. (1995). Effects of a safe person on induced distress following a biological challenge in panic disorder with agoraphobia. Journal of Abnormal Psychology, 104(1), 156-163. doi:10.1037/0021-843X.104.1.156

Clark, D. M., \& Hemsley, D. R. (1982). The effects of hyperventilation; individual variability and its relation to personality. Journal of Behavior Therapy and Experimental Psychiatry, 13(1), 41-47. doi:10.1016/0005-7916(82)90034-9

Cochran, W. G. (1954). Some methods for strengthening the common $\mathrm{X}^{2}$ tests. Biometrics, 10 , 417-451. doi: 10.2307/3001616

Cohen, S., \& Hoberman, H. M. (1983). Positive events and social supports as buffers of life change to stress. Journal of Applied Social Psychology, 13(2), 99 -125. doi:10.1111/j.1559-1816.1983.tb02325.x

Cohen, S., Kamarck, T., \& Mermelstein, R. (1983). A global measure of perceived stress. Journal of Health and Social Behavior, 24(4), 385-396. doi:10.2307/2136404

Connor, K. M., Davidson, J. R. T., Churchill, E., Sherwood, A., Weisler, R. H., \& Foa, E. (2000). Psychometric properties of the social phobia inventory (SPIN): New self-rating scale. The British Journal of Psychiatry, 176, 379-386. doi:10.1192/bjp.176.4.379

Coren, S. (2010). Foreword. In A. H. Fine (Ed.), Handbook on animal-assisted therapy: Theoretical foundation and guidance for practice (pp. xv-xviii). San Diego, CA: Academic Press. 
DeMello, L. R. (1999). The effect of the presence of a companion-animal on physiological changes following the termination of cognitive stressors. Psychology \& Health, 14(5), 859-868. doi:10.1080/08870449908407352

DeSchriver, M. M., \& Riddick, C. C. (1990). Effects of watching aquariums on elders' stress. Anthrozoos, 4(1), 44-48. doi:10.2752/089279391787057396

Dillion, D. J., Gorman, J. M., Liebowitz, M. R., Fyer, A. J., \& Klein, D. F. (1987). Measure of lactate-induced panic and anxiety. Psychiatry Research, 20(2), 97-105. doi:10.1016/01651781(87)90002-3

Dimsdale, J. E. (1984). Generalizing from laboratory studies to field studies of human stress physiology. Psychosomatic Medicine, 46(5), 463-469. Retrieved from http://ezproxy.lib.ryerson.ca/login?url=http://search.proquest.com.ezproxy.lib.ryerson.ca/d ocview/617043335?accountid=13631

Duchesne, A., Tessera, E., Dedovic, K., Engert, V., \& Pruessner, J. C. (2012). Effects of panel sex composition on the physiological stress responses to psychosocial stress in healthy young men and women. Biological Psychology, 89(1), 99-106. Retrieved from http://ezproxy.lib.ryerson.ca/login?url=http://search.proquest.com.ezproxy.lib.ryerson.ca/d ocview/901319467?accountid=13631

Ein, N., \& Vickers, K. (2015). The effect of pets on stress reactivity. In Columbus, A.M. (Ed.) Advances in psychology research (pp.111-124). Hauppauge, NY: Nova Publishers.

Eisenberger, N. I., Master, S. L., Inagaki, T. K., Taylor, S. E., Shirinyan, D., Lieberman, M. D., Naliboff, B. D. (2011). Attachment figures activate a safety signal-related neural region 
and reduce pain experience. Proceedings of the National Academy of Sciences of the United States of America (PNAS), 108(28), 11721-11726. doi:10.1073/pnas.1108239108

Epley, N., Waytz, A., Akalis, S., \& Cacioppo, J. T. (2008). When we need a human: Motivational determinants of anthropomorphism. Social Cognition, 26(2), 143-155. doi: $10.1521 /$ soco.2008.26.2.143

Epley, N., Waytz, A., \& Cacioppo, J. T. (2007). On seeing human: A three-factor theory of anthropomorphism. Psychological Review, 114(4), 864-886. doi: 10.1037/0033295X.114.4.864

France, C., \& Ditto, B. (1992). Cardiovascular responses to the combination of caffeine and mental arithmetic, cold pressor and static exercise stressors. Psychophysiology, 29(3), 272282. doi: 10.1111/j.1469-8986.1992.tb01698.x

Friedmann, E., \& Thomas, S. A. (1998). Pet ownership, social support, and one-year survival after acute myocardial infarction in the cardiac arrhythmia suppression trial (CAST). In C. Wilson \& D. Turner (Eds.), Companion animals in human health (pp. 187-201). Thousand Oaks, CA: Sage Publication Inc.

Glaser, R. \& Kiecolt-Glaser, J. K. (2005). Stress damages immune system and health. Discovery Medicine, 5(26), 165-169.

Goetz, R. R., Klein, D. F., Papp, L. A., Martinez, J. M., \& Gorman, J. M. (2001). Acute panic inventory symptoms during $\mathrm{CO} 2$ inhalation and room-air hyperventilation among panic disorder patients and normal controls. Depression and Anxiety, 14(2), 123-136. doi:10.1002/da.1054 
Hagger, M. S. (2009). Personality, individual differences, stress and health. Stress and Health: Journal of the International Society for the Investigation of Stress, 25(5), 381-386. doi:10.1002/smi.1294

Harrington, R. (2013). Stress, health \& well-being. Belmont, CA: Wadsworth Cengage Learning.

Heinrichs, M., Baumgartner, T., Kirschbaum, C., \& Ehlert, U. (2003). Social support and oxytocin interact to suppress cortisol and subjective responses to psychosocial stress. Biological Psychiatry, 54(12), 1389-1398. doi:10.1016/S0006-3223(03)00465-7

Johnson, R. A., Meadows, R. L., Haubner, J. S., \& Sevedge, K. (2003). Human-animal interaction: A complementary/alternative medical (CAM) intervention for cancer patients. American Behavioral Scientist, 47(1), 55-69. doi:10.1177/0002764203255213

Kaye, J., Buchanan, F., Kendrick, A., Johnson, P., \& Lowry, C. (2004). Acute carbon dioxide exposure in healthy adults: Evaluation of a novel means of investigating the stress response. Journal of Neuroendocrinology, 16(3), 256-264. doi:10.1111/j.09538194.2004.01158.x

Kirschbaum, C., Pirke, K. M., \& Hellhammer, D. H. (1993). The 'trier social stress test' - a tool for investigating psychobiological stress responses in a laboratory setting. Neuropsychobiology, 28, 76-81. doi:10.1159/000119004

Kors, D. J., Linden, W., \& Gerin, W. (1997). Evaluation interferes with social support: Effects on cardiovascular stress reactivity in women. Journal of Social and Clinical Psychology, 16(1), 1-23. doi:10.1521/jscp.1997.16.1.1 
Lepore, S.J. (1998). Problems and prospects for the social support reactivity hypothesis. Annals of Behavioral Medicine, 20(4), 257-269. doi:10.1007/BF02886375

Lewis, R. S., Weekes, N. Y., \& Wang, T. H. (2007). The effect of a naturalistic stressor on frontal EEG asymmetry, stress, and health. Biological Psychology, 75(3), 239-247. doi:10.1016/j.biopsycho.2007.03.004

Liebowitz, M. R., Gorman, J. M., Fyer, A. J., Dillon, D. J., \& Klein, D. F. (1984). Effects of naloxone on patients with panic attacks. American Journal of Psychiatry, 141, 995-997. Retrieved from http://ezproxy.lib.ryerson.ca/login?url=http://search.proquest.com.ezproxy.lib.ryerson.ca/d ocview/617015609? accountid=13631

Lindsay, S. D., Paulhus, D. L. \& Nairne, J. S. (2008). Psychology: The adaptive mind ( $3^{\text {rd }}$ ed.). Toronto, ON: Thomson Nelson.

Lockwood, R. (1983). The influence of animals on social perception. In A. H. Katcher \& A. M. Beck (Eds.), New perspectives on our lives with animal companions (pp. 64-71). Philadelphia, PA: University of Pennsylvania Press.

Marin, M. F., Lord, C., Andrews, J., Juster, R. P., Sindi, S., Arsenault-Lapierre, G.,...Lupien, S. J. (2011). Chronic stress, cognitive functioning and mental health. Neurobiology of Learning and Memory, 96(4), 583-595. doi:10.1016/j.nlm.2011.02.016

McClelland, L. E., \& McCubbin, J. A. (2008). Social influence and pain response in women and men. Journal of Behavioral Medicine, 31(5), 413-420. doi:10.1007/s10865-008-9163-6 
McConnell, A. R., Brown, C. M., Shoda, T. M., Stayton, L. E., \& Martin, C. E. (2011). Friends with benefits: On the positive consequences of pet ownership. Journal of Personality and Social Psychology, 101(6), 1239-1252. doi:10.1037/a0024506

McEwen, B. S. (2007). Physiology and neurobiology of stress and adaptation: Central role of the brain. Psychological Reviews, 87(3), 873-904. doi:10.1152/physrev.00041.2006

Nestler, E. J., \& Carlezon, W. A. (2006). The mesolimbic dopamine reward circuit in depression. Biological Psychiatry, 59, 1151-1159. doi:10.1016/j.biopsych.2005.09.018

Odendaal, J. S. J., \& Meintjes, R. A. (2003). Neurophysiological correlates of affiliative behaviour between humans and dogs. The Veterinary Journal, 165(3), 296-301. doi:10.1016/S1090-0233(02)00237-X

Osbourne, J.W. (2002). Notes on the use of data transformations. Practical Assessment, Research, and Evaluation, 8(6). Retrieved from http://PAREonline.net/getvn.asp? $\mathrm{v}=8 \& \mathrm{n}=6$

Perrin, T. (2009). The business of urban animals survey: The facts and statistics on companion animals in Canada. The Canadian Veterinary Journal, 50(1), 48-52. Retrieved from http://www.ncbi.nlm.nih.gov/pmc/articles/PMC2603652/

Peter, R., \& Siegrist, J. (1999). Chronic psychosocial stress at work and cardiovascular disease: The role of effort-reward imbalance. International Journal of Law and Psychiatry, 22(56), 441-449. doi:10.1016/S0160-2527(99)00020-5 
Polheber, J. P., \& Matchock, R. L. (2014). The presence of a dog attenuates cortisol and heart rate in the trier social stress test compared to human friends. Journal of Behavioral Medicine, 37(5), 860-867. doi:10.1007/s10865-013-9546-1

Rook, K., Sorkin, D., Zettel, L. (2004). Stress in social relationships: Coping and adaptation across the life span. In L. R. Frieder \& K. L. Fingerman (Eds.), In growing together: Personal relationships across the lifespan (pp. 210-239). New York, NY: Cambridge University Press.

Rosch, P. J. (Ed.). (2001, March). The quandary of job stress compensation. Health and Stress, $3,1-4$.

Rosch, P. J. (1996). Stress and sleep: Some startling and sobering statistics. Stress Medicine, 12(4), 207-210. doi:10.1002/(SICI)1099-1700(199610)12:4

Shufflebotham, J., Wetherell, M. A., Hince, D., Hood, S., Lightman, S., Nutt, D.,...Potokar, J. (2009). Women with diarrhoea-predominant irritable bowel syndrome show an increased pressure response to $35 \%$ carbon dioxide stress challenge. Stress: The International Journal on the Biology of Stress, 12(1), 30-36. doi:10.1080/10253890801976926

Siegel, J. M. (1990). Stressful life events and use of physician services among the elderly: The moderating role of pet ownership. Journal of Personality and Social Psychology, 58(6), 1081-1086. doi:10.1037/0022-3514.58.6.1081

Siegel, J. M., Angulo, F. J., Detels, R., Wesch, J., \& Mullen, A. (1999). AIDS diagnosis and depression in the multicenter AIDS cohort study: The ameliorating impact of pet ownership. AIDS Care, 11(2), 157-169. doi:10.1080/09540129948054 
Somervill, J. W., Kruglikova, Y. A., Robertson, R. L., Hanson, L. M., \& MacLin, O. H. (2008). Physiological responses by college students to a dog and a cat: Implications for pet therapy. North American Journal of Psychology, 10(3), 519-528. Retrieved from http://ezproxy.lib.ryerson.ca/login?url=http://search.proquest.com.ezproxy.lib.ryerson.ca/d ocview/621672615?accountid=13631

Stewart, L. A., Dispensa, F., Parker, L., Chang, C. Y., Cunnien, T. (2014). A pilot study assessing the effectiveness of an animal-assisted outreach program. Journal of Creativity in Mental Health, 9(3), 332-345. doi:10.1080/15401383.2014.892862

Stixrud, W. R. (2012). Why stress is such a big deal. Journal of Management Education, 36(2), 135-142. doi:10.1177/1052562911430317

Statistics Canada. (2013). Perceived life stress, 2013. (Catalogue \# 82-625-X). Retrieved from: http://www.statcan.gc.ca/pub/82-625-x/2014001/article/14023-eng.htm

Steketee, G. \& Chambless, D. L. (1992). Methodological issue in prediction of treatment outcome. Clinical Psychology Review, 12(4), 387-400. doi:10.1016/0272-7358(92)90123-P

Tedeschi, R. G., \& Kilmer, R. P. (2005). Assessing strengths, resilience, and growth to guide clinical interventions. Professional Psychology: Research and Practice, 36(3), 230-237. doi:10.1037.0735-7028.36.3.230

Templer, D. I., Connelly, H. J., Bassman, L., \& Hart, J. (2006). Construction and validation of an animal-human continuity scale. Social Behavior and Personality, 34(7), 769-776. doi:10.2224/sbp.2006.34.7.769 
Templer, D. I., Salter, C. A., Dickey, S., Baldwin, R., \& Veleber, D. M. (1981). The construction of a pet attitude scale. Psychological Record, 31(3), 343-348. Retrieved from http://ezproxy.lib.ryerson.ca/login?url=http://search.proquest.com.ezproxy.lib.ryerson.ca/d ocview/616595797?accountid=13631

Virués-Ortega, J., \& Buela-Casal, G. (2006). Psychophysiological effects of human-animal interaction: Theoretical issues and long-term interaction effects. Journal of Nervous and Mental Disease, 194(1), 52-57. doi:10.1097/01.nmd.0000195354.03653.63

Vollrath, M. (2001). Personality and stress. Scandinavian Journal of Psychology, 42, 335-347. doi:10.1111/1467-9450.00245

Vormbrock, J. K., \& Grossberg, J. M. (1988). Cardiovascular effects of human-pet dog interactions. Journal of Behavioral Medicine, 11(5), 509-517. doi:10.1007/BF00844843

Wells, D. L. (2005). The effect of videotapes of animals on cardiovascular response to stress. Stress and Health: Journal of the International Society for the Investigation of Stress, 21(3), 209-213. doi:10.1002/smi.1057

Wetherell, M. A., Crown, A. L., Lightman, S. L., Miles, J. N. V., Kaye, J., \& Vedhara, K. (2006). The four-dimensional stress test: Psychological, sympathetic-adrenal-medullary, parasympathetic and hypothalamic-pituitary-adrenal responses following inhalation of $35 \%$ $\mathrm{CO}_{2}$. Psychoneuroendocrinology, 31, 736-747. doi:10.1016/j.psyneuen.2006.02.005

Wilkinson, L. (1999). Statistical methods in psychology journals: Guidelines and explanations. American Psychologist, 54(8), 594-604. doi:10.1037/0003-066X.54.8.594 
Wilson, C. C. (1991). The pet as an anxiolytic intervention. Journal of Nervous and Mental Disease, 179(8), 482-489. doi:10.1097/00005053-199108000-00006

Zilcha-Mano, S., Mikulincer, M., \& Shaver, P. R. (2012). Pets as safe havens and secure bases: The moderating role of pet attachment orientations. Journal of Research in Personality, 46(5), 571-580. doi:10.1016/j.jrp.2012.06.005 